\title{
SEISMIC STUDIES IN THE SOUTHERN PUNA PLATEU AND THE PERUVIAN ANDES
}

A Dissertation Presented to

The Faculty of Graduate School

University of Missouri-Columbia

In Partial Fulfillment

Of the Requirements for the Degree of

Doctor of Philosophy

by

FRANK JIMMY CALIXTO MORY

Dr. Eric Sandvol, Dissertation Supervisor

May, 2014 
Then undersigned, appointed by the Dean of the Graduate School, have examined the dissertation entitled

\section{SEISMIC STUDIES IN THE SOUTHERN PUNA PLATEU}

AND THE PERUVIAN ANDES

Presented by Frank Jimmy Calixto Mory, a candidate for the degree of Doctor of Philosophy of Geological Sciences, and hereby certify that, in their opinion, it is worthy of acceptance.

Professor Eric Sandvol

Professor Robert Bauer

Professor Mian Liu

Professor Brent Rosenblad 


\section{ACKNOWLEDGEMENTS}

I am especially indebted to my wife, Susana Alvarez, for her love and continue support during my Ph.D. studies.

I would like to express my sincere thanks to my advisor, Dr. Eric Sandvol, for his guidance and help during the realization of this dissertation. He helped me both in the field and the laboratory to deal with multiple challenges, and taught me to think critically. I sincerely admire his passion for science which he transmitted to me during all our discussions. I firmly believe that without his support and guidance this work would not have been possible.

I would also like to thank Dr. Robert Bauer, Dr. Mian Liu and Dr. Brent Rosenblad for being part of my dissertation committee and for providing critical and helpful comments that led to major improvements in the realization of this dissertation.

Thanks to Hernando Tavera, head of the seismology section at Instituto Geofísico del Perú, and Susan Beck, professor at the University of Arizona, for collaborating with me in the Peruvian attenuation project that is presented in chapter 4 of this dissertation. Without their help, this study would not have been possible.

Additionally, I would like to thank my fellow colleagues Savas Ceylan, Gleb Skobeltsyn, Xiaofeng Liang, Bao Xueyang and Ku Wenfei, for many discussions that helped me during my Ph.D. studies.

Financial support for the studies of velocity structure beneath the southern Puna plateau and the shear wave splitting and shear wave splitting tomography beneath the southern Puna plateau was providing by the National Science Foundation through the 
grant EAR-05 382 45. Funding for the Lg attenuation measurements in Peru came from the Research Board of the University of Missouri. 


\section{TABLE OF CONTENTS}

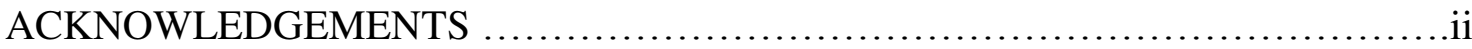

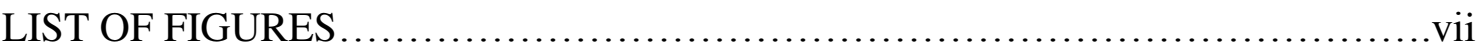

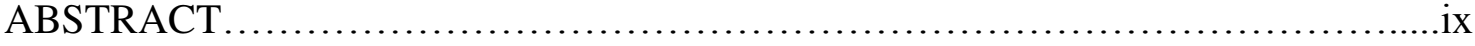

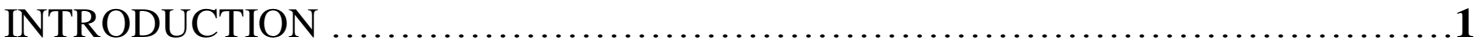

1.1 OVERVIEW OF THE CENTRAL ANDES ..................................1

1.1.1 STAGES OF SUBDUCTION DURING THE MESOZOIC-

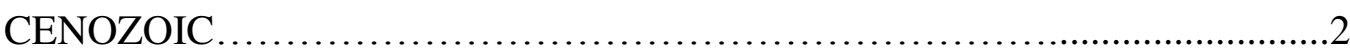

1.1.2 OROGENIC CYCLE FOLLOWED BY AND ANDEAN-TYPE MARGIN ......................................................................

1.2 RESEARCH OBJECTIVES ...............................................

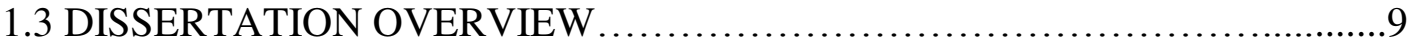

1.4 REFERENCES ......................................................... 10

VELOCITY STRUCTURE BENEATH THE SOUTHERN PUNA PLATEAU: EVIDENCE FOR DELAMINATION .......................................12

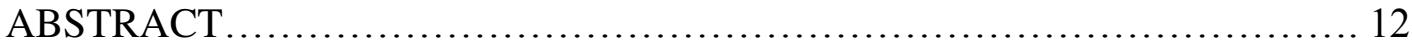

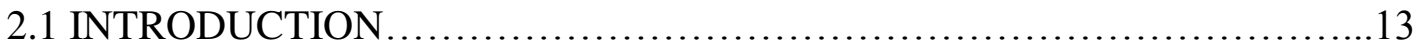

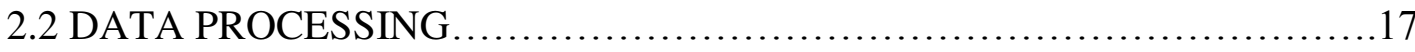

2.3 SURFACE WAVE TOMOGRAPHY METHOD............................19

2.4 DISPERSION CURVE AND PHASE VELOCITIES.......................20

2.4.1 DISPERSION CURVE AND 1D SHEAR WAVE VELOCITY

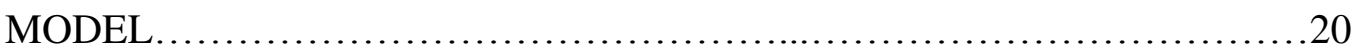

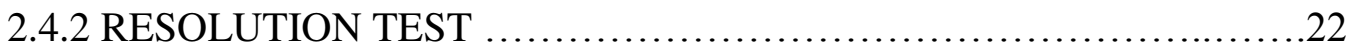




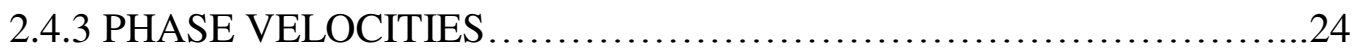

2.5 SHEAR WAVE VELOCITY STRUCTURE ..............................26

2.6 DISCUSSION .................................................................

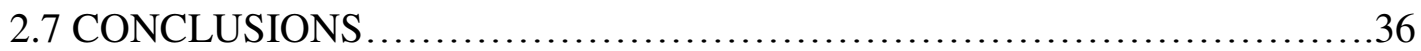

2.8 ACKNOWLEDGMENT_.................................................

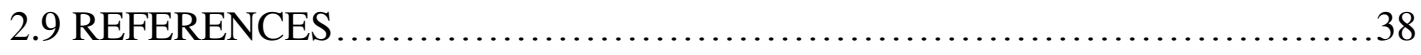

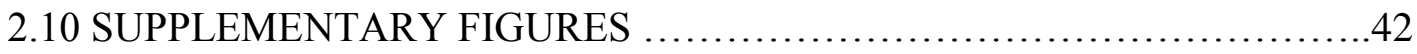

SHEAR WAVE SPLITTING AND SHEAR WAVE SPLITTING TOMOGRAPHY BENEATH THE SOUTHERN PUNA PLATEU $\ldots \ldots \ldots \ldots \ldots \ldots \ldots \ldots \ldots \ldots \ldots \ldots . \ldots \ldots$

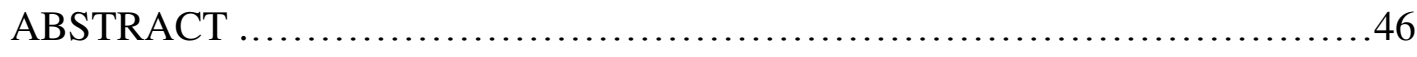

3.1. INTRODUCTION ................................................... 47

3.2. SHEAR WAVE SPLITTING ANALYSIS...............................51

3.2.1 METHODOLOGY ...............................................

3.2.2 DATA AND OBSERVATIONS ....................................53

3.3. SHEAR WAVE SPLITTING TOMOGRAPHY ............................55

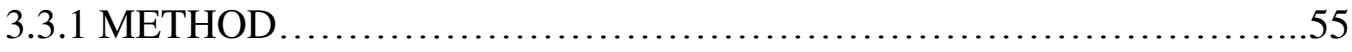

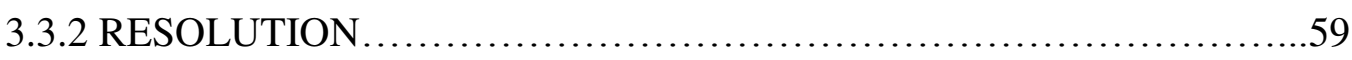

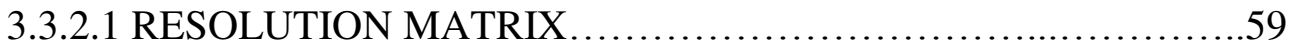

3.3.2.2 CHECKERBOARD TEST ....................................60

3.3.3 SHEAR WAVE SPLITTING TOMOGRAPHY RESULTS .............64

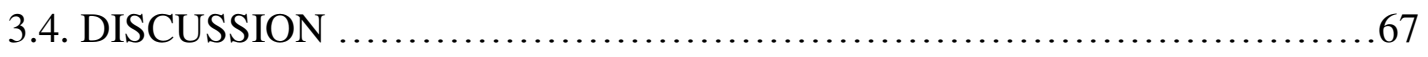

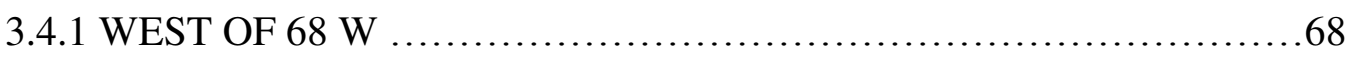

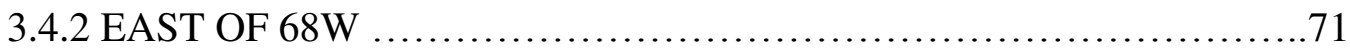




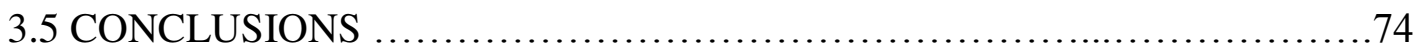

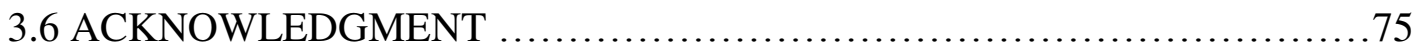

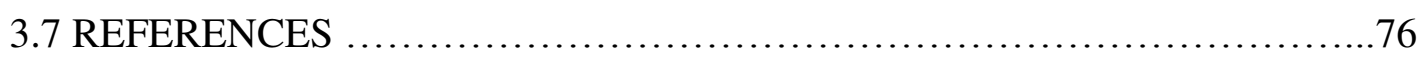

3.8 SUPPLEMENTARY FIGURES ........................................ 81

REGIONAL SEISMIC ATTENUATION IN PERU.............................83

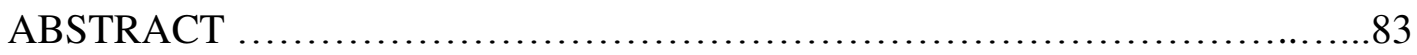

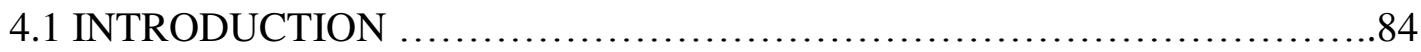

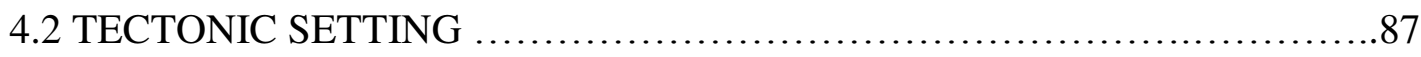

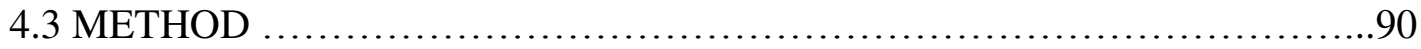

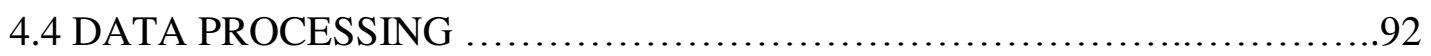

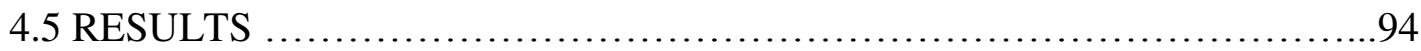

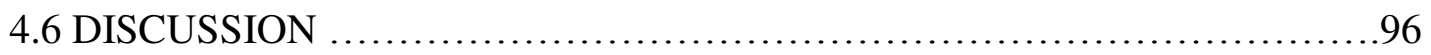

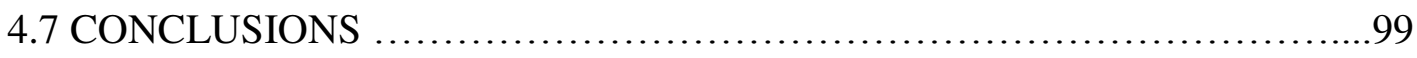

4.8 ACKNOWLEDGEMENTS ...........................................

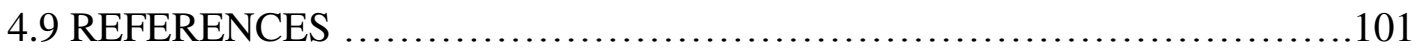

4.10 SUPPLEMENTARY FIGURES ...................................... 104

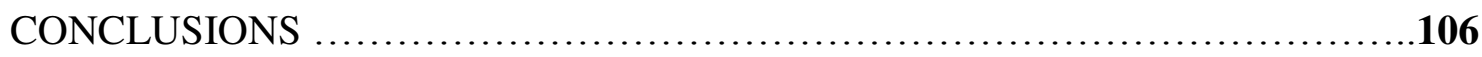

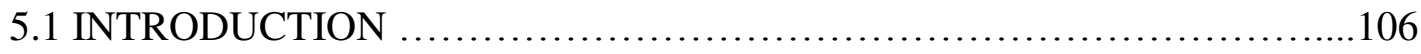

5.2 CONCLUSIONS .........................................................

5.2.1 CONCLUSIONS ON THE SOUTHERN PUNA PLATEAU .............107

5.2.2 CONCLUSIONS ON THE PERUVIAN ANDES .....................108

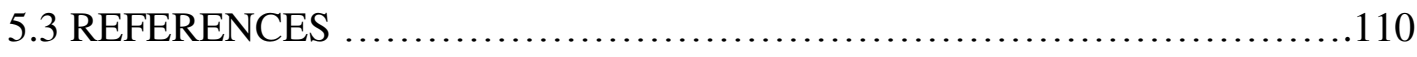

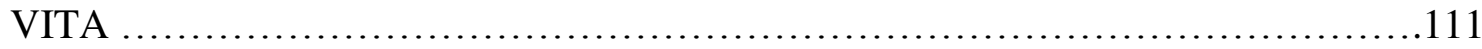




\section{LIST OF FIGURES}

Figure $\quad$ Page

Figure 2.1 Andean orogeny and region of study.............................. 14

Figure 2.2 Station distribution along the southern Puna plateau ......................18

Figure 2.3 Dispersion curve for the southern Puna plateau........................21

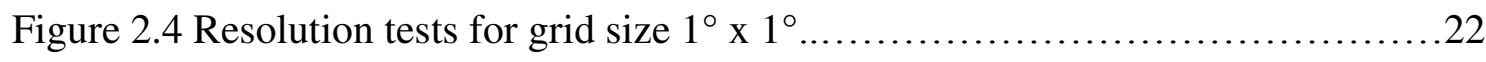

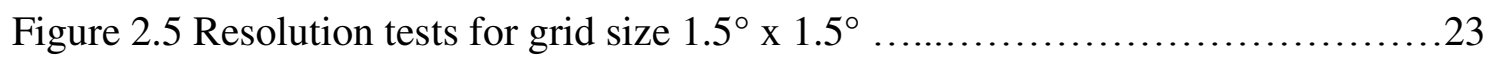

Figure 2.6 Map view of Rayleigh wave phase velocities..........................25

Figure 2.7 Cross-sections of shear wave velocities and dispersion curves ...........27

Figure 2.8 Shear wave velocity anomalies greater than $1.0 \%$ and $2.0 \% \ldots \ldots \ldots \ldots \ldots . .28$

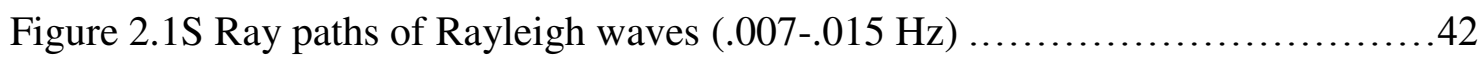

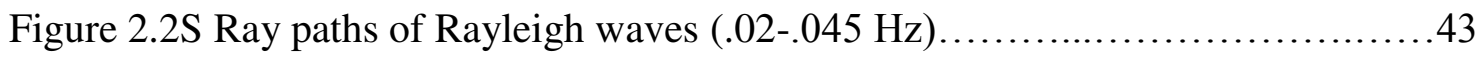

Figure 2.3S Rayleigh wave phase velocities and standard deviations (.007-.015 Hz).. 44

Figure 2.4S Rayleigh wave phase velocities and standard deviations (.02-.045 Hz)....45

Figure 3.1 Andean orogeny and region of study ............................49

Figure 3.2 Seismic station distribution along the southern Puna plateau..............50

Figure 3.3 Local and teleseismic shear wave splitting results.....................54

Figure 3.4 Checkerboard test for 0-100, 100-200, 200-300 and 300-400 km depth ... 61

Figure 3.5 Difference between checkerboard fast direction azimuths and inverted

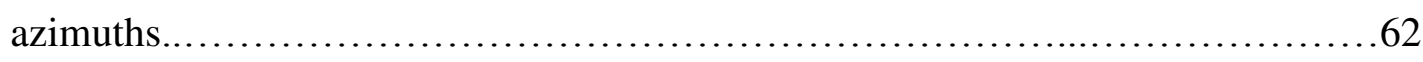

Figure 3.6 Difference between checkerboard strength of anisotropy values and inverted

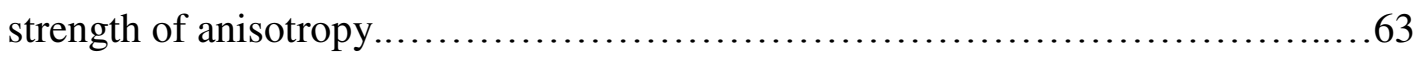


Figure 3.7 Map view of shear wave splitting tomography with 556 (teleseismic and local earthquake) rays for various depth ranges. .65

Figure 3.8 (a) Across longitude and (b) across latitude view of the shear wave splitting results with 556 (teleseismic and local earthquake) rays .66

Figure 3.1S Resolution of the strength of azimuthal anisotropy for depth intervals of 50 $\mathrm{km}$ from 0 to $400 \mathrm{~km}$ .81

Figure 3.2S Resolution of the azimuth of the $\left[\begin{array}{lll}1 & 0 & 0\end{array}\right]$ axis for depth intervals of $50 \mathrm{~km}$ from 0 to $400 \mathrm{~km}$. .82

Figure 3.3S Resolution of the dip of the $\left[\begin{array}{lll}1 & 0 & 0\end{array}\right]$ axis for depth intervals of $50 \mathrm{~km}$ from 0 to $400 \mathrm{~km}$. .82

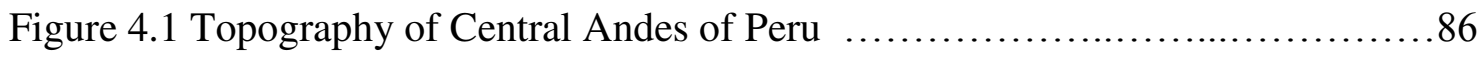

Figure 4.2 Reverse two station method schematic drawing ......................92

Figure 4.3 Examples of $\operatorname{Lg}$ phase in Peru.................................. 93

Figure 4.4 $\mathrm{Q}_{\mathrm{Lg}}$ values for $1 \mathrm{~Hz}$ using TSM across the Peruvian Andes ...............95

Figure 4.5 Qs and Qp measurements across the Bolivian Andes....................97

Figure 4.1S $\mathrm{Q}_{\mathrm{Lg}}$ values for $1 \mathrm{~Hz}$ using RTS across the Peruvian Andes................104

Figure 4.2S Q $\mathrm{Q}_{\mathrm{Lg}}$ values for $2 \mathrm{~Hz}$ using RTS across the Peruvian Andes...............105 


\title{
SEISMIC STUDIES IN THE SOUTHERN PUNA PLATEAU AND PERU
}

\author{
Frank Jimmy Calixto Mory \\ Dr. Eric Sandvol, Dissertation Supervisor
}

\begin{abstract}
I present three studies in two regions, both within the Central Andes. In both regions it is clear that there are significant variations in the subduction geometry. I have used surface wave tomography to investigate the shear wave velocity structure beneath the southern Puna plateau and found evidence of widespread melting of the crust beneath the high elevations which correlates with a gap in intermediate depth seismicity and the recent eruptions of ignimbrite complexes. All of these observations can be explained by the delamination of the lithospheric mantle beneath it. I measured Rayleigh wave phase velocities as a function of frequency and inverted then to obtain shear wave velocities as a function of depth. The results show a high velocity body sitting above the subducting Nazca plate beneath the northern edge of the Cerro Galan ignimbrite. This high velocity body is interpreted to be the delaminated piece of lithosphere that detached and sank leading to a localized upwelling of asthenosphere that, in turn, caused widespread crustal melting leading to the eruption of the most recent ignimbrite complexes. Furthermore it is possible that this upwelling also thermally eroded the slab in this region. It is apparent that there is a significant slab gap or hole where there are very few intermediate depth earthquakes.
\end{abstract}


In addition, I have used shear wave splitting analysis and shear wave splitting tomography in the southern Puna plateau to investigate the patterns of seismic anisotropy and mantle flow. The results show very complex shear wave splitting and seismic anisotropy patterns throughout the southern Puna plateau. The observations suggest that different mechanisms are driving the mantle flow from region to region. The subslab mantle outside the region where delamination took place is mostly driven by slab roll back and small degree of coupling between the subducting slab and the mantle below it. In the region apparently dominated by delamination, the subslab mantle outlines a rotation pattern of a-axis and small strength of anisotropy, suggesting that a slab gap or heated slab is regionally driving the mantle flow. In the mantle wedge, there is evidence for vertical a-axis suggesting vertical flow. This is observed beneath the main ignimbrite complexes and above the delaminated block imaged in the first study. Anisotropy in the western edge of the region above the slab is driven by compression of the South American lithosphere, which leads to trench parallel a-axis orientation.

Finally, I have studied the attenuation of high frequency seismic waves in Southern Peru using the two-station and reverse two station methods. I have focused on the largest regional phase Lg which is a wave that is entirely guided in the crust and travels mostly as an S-wave. This study allowed me to investigate the correlation of attenuation measurements with topography and regions of high heat flow. Furthermore, this study is important as it can be used to distinguish regions with higher seismic hazard from distance earthquakes. Low attenuation, or high quality factor $(\mathrm{Q})$, usually leads to high stronger ground shaking even at larger distances from the epicenter. Our 
attenuation model should determine whether the attenuation is intrinsic or cause by scattering. The western cordillera in northern Peru is characterized by high attenuation. I have also found that most regions with high attenuation (low $\operatorname{LgQ}$ ) in southern Peru correlated very well with location of volcanoes. However, we have also found regions with high attenuation where there is very little active volcanism. We believe the high level of attenuation is associated with scattering attenuation caused by a thick crustal root. The Altiplano plateau, where Lake Titicaca is located, shows intermediate values of attenuation. The city of Pisco shows the highest values of Q in Peru ( 1500) associated with a high degree of site effect which makes this region potentially more susceptible to strong ground motion from regional earthquakes. Most of southern Peru tends to exhibit high intrinsic attenuation but scattering attenuation is also observed to dominate in regions where the topography changes drastically over small distances such as the northern edge of the Altiplano plateau. 


\section{CHAPTER 1}

\section{INTRODUCTION}

\subsection{OVERVIEW OF THE CENTRAL ANDES}

The most common kind of convergent plate boundaries in plate tectonics are subduction zones. Subduction zones can occur when one oceanic subducts beneath another or beneath continental lithosphere and is termed an active continental margin. In these regions an oceanic lithosphere subducts beneath a less dense continental lithosphere. This dissertation focuses on two particular zones within the Central Andean active continental margin that exhibit spatial varying subduction geometry: the southern Puna Plateau and southern Peru. The Andes produced the largest active orogenic system on earth related to subduction and is more than $8000 \mathrm{~km}$ long starting at the Caribean Sea in Central America and going as far south as northern Scotia Ridge, south of Chile. The Andes have a long history of collision, accretion as well as subduction of different kinds of oceanic crust.

The Andes subduction zone was developed soon after the break up of the supercontinent Rodinia in the Late Proterozoic ( $600 \mathrm{Ma})$ and the development of the Pacific Ocean between Laurentia and South America (Cawood, 2005). The Central Andes are categorized as a typical Andean-type orogeny due to their lack of Mesozoic and Cenozoic metamorphic-ophiolitic rocks (Ramos 1999). The Central Andes has produced little accretion and regional metamorphism as opposed to the northern Andes.

The protomargin of Peru shows not significant igneous and metamorphic rocks of Mesoproterozoic age exposures (Dalmayrac et. al 1980) and Grenville-age rocks in the 
western Pampia terrane located in north and central Argentina show that Pampia may have detached soon after Rodinia break up. The central Andean segment that extends from Peru to Central Argentina has two belts (eastern and western, or oriental and occidental). The eastern belt was developed on the western boundary of Amazonia and Pampia cratonic terranes (Ramos and Aleman, 2000). The Peruvian eastern belt (also know as the Marañon arc) shows evidence for plutonic, methamorphic and metasedimentary rocks that evidence an Early to Middle Ordovician magmatic arc (490-475 Ma) that existed prior to the accretion of the Paracas terrane (Cardona 2005, Chew 2007, Ramos 2009). This arc is presently located on the Marañon Massif basement and end at the Abancay deflection (See Figure 7 of Ramos 2009) where the subduction angle starts to change from flat to normal. After that point, the current volcanic arc resumes closer to the present trench, to the west of the Arequipa Massif, in southern Peru. The Central Andes are characterized by two current large zones of flat subduction; both zone have very little late Cenozoic arc magmatism (Baranzangi and Isacks, 1976, 1979). The northern flab slab region is known as the Peruvian (extending between $2 \mathrm{~S}$ and $15 \mathrm{~S}$ ) and the southern is termed the Pampean flat slab (extending between $27 \mathrm{~S}$ and $33 \mathrm{~S})$.

\subsubsection{STAGES OF SUBDUCTION DURING THE MESOZOIC-CENOZOIC}

During the Mesozoic and Cenozoic times the Andes were subjected to a transition from extension to compression that can be summarized in a three-stage model (See Figure 15 of Ramos, 2009). 
- The first stage, intra-arc extension, occurred around the Jurassic and Early Cretaceous ( $>115 \mathrm{Ma}$ ) and is characterized by negative trench rollback velocity and steep angle subductions that are greater than 45 in a predominantly extensional regime that leads to an intra-arc basin surrounded by an inner and outer arc. Marine retro-arc basins are also developed by backarc volcanism. This stage is characterized by extension and little to no accretionary prism as well as normal faulting at the edges of the intra-arc basin.

- The second, transitional stage consists of an almost null rollback velocity and shallowing of the subduction angle to less than 45 and greater than 30 . This happened during the middle cretaceous when the Andes were subjected to a change from extensional to compressive regime (Vicente, 1970; Auboin et al., 1973), which is interpreted to be related to closure of an ensialic marginal basin. The absence of the intra-arc basin is due a fusion of the inner and outer arc into a single main arc and resulted in higher elevations as compare to the first stage. During this stage the compression caused a well developed accretionary prism. Characteristic of this stage are retro-arc volcanism and continental deposits.

- The third stage is characterized by positive trench rollback velocity and shallowing of the subduction angle to less than 30 in a mostly compressive regime that also caused a thin-skinned fold and thrust belt due to tectonic inversion of previously developed normal faults. Slab dehydration stopped and arcs with volcanism started to die out. During this stage, an arc and frontal 
cordillera as well as a foreland retroarc basin were formed. The dominant compresional stress regime was related to a westward acceleration of the South American plate overriding the trench during the Late cretaceous (Somoza and Zaffarana 2008) in what may have been a time of major plate reorganization 95 Ma after the final breakup of Africa and South America forming the Atlantic Ocean.

\subsubsection{OROGENIC CYCLE FOLLOWED BY AND ANDEAN-TYPE MARGIN}

The following is an overview of the conceptual Andean orogenic cycle proposed by Ramos (2009) to explain the various periodic mountain building episodes that the Central Andes have undergone. The episodes include extensive deformation and magmatism in a unique cycle with seven characteristic stages. Episodes of flat slab subduction appear to be a key part for mountain building. Processes of shallowing and steepening of subduction are inferred for various segments along the central Andean Altiplano-Puna plateau (Kay and Coira, 2009; Coira et al., 1993, Kay et al., 1999). Ramos and Folguera (2009) found that flat slab subduction is not unique to the Central Andes but it is a common process along the entire Andean margin.

- The first stage involves a quiescence period with a subduction regime that causes little or null extension or compression. There is presence of modest mafic volcanic activity and absence of deformation. 
- The second stage consists of increased magmatism and deformation toward the foreland. This stage is characterized by increased heat flux that cause the development of brittle-ductile transitions in the crust, slab dehydration that cause more evolved andesitic melts, slight thickening of the continental crust below the arc due to shortening caused by thermal heating. To accommodate the shortening thrust faults develop between the arc and the sediments formed in the foreland basin.

- In the third stage there is shallowing of the subduction zone and a subsequent arc expansion and migration towards the foreland basin associated with a significant increase in slab dehydration into the mantle wedge above the slab. The melts involve a more significant crustal andesitic signature (Kay et al., 1991; Kay and Mpodozis, 2002). Crustal deformation now involves a broadening of the thrusting faulting to include the arc which accommodates a significant crustal thickening cause by thermal weakening. Magmas accumulate at the base of the thicker crust and over time start to develop into an eclogitic root at the boundary between the crust and the mantle (Kay et al., 1991). Thick and thin-skinned deformations are common within the orogenic front. At this stage, increase of sedimentation is also observed in the foreland basin.

- The fourth stage is characterized by flat-slab subduction causing a significant coupling between the subducting plate and overriding plate that derives in significant broadening of crustal deformation. The enhanced intra-crustal 
deformation develops into deep seated basement crustal shortening that generates shallow crustal earthquakes as seen in in the present day Peruvian and Sierras Pampeanas flat slab sections. The foreland basin starts to break due to basement uplifts caused by an extensive compressive regime. The eclogite at the base of the thickened crust becomes denser and fully developed. A shut down of magmatism and disappearance of the volcanic arc correlate with significant decrease of slab dehydration. It is important to mention that sometimes this stage can be skipped and shallowing of the subduction zone may follow direct steepening the slab (Kay and Coira, 2009).

- In the fifth stage the once flat slab starts to steepen or rollback, which may produce trench retreat and local resumption of arc volcanism in the foreland. The crustal stress regime transitions from compressional to a more chaotic regime with cases of extensional collapse. There is also formation of high plateaus (e.g. the Altiplano-Puna plateau) with localized extensional collapse. The slab rollback leads to a rapid upwelling of asthenosphere that starts to erode the lithospheric mantle beneath the eclogitic crustal root.

- The sixth stage involves a subsequent steepening of the subduction that resumes a well defined volcanic arc that shifts toward the trench. The slab roll back together with mantle lithospheric erosion by the injection of hot asthenosphere leads to a density instability and delamination of lower eclogitic crust as well as a part of lithospheric mantle. This is evidenced by the development of silicic- 
dacitic calderas or ignimbrite complexes at the surface (e.g. the Cerro Galan ignimbrite complex in the southern Puna plateau). At this stage there exist a high heat flux associated with partial crustal melting and lithospheric thinning.

- In the seventh stage, a thermal uplift of the arc associated with a thinned or absent lithospheric mantle or lower crust. The final foreland deformation develops into a foreland fold and thrust belt due to significant crustal shortening (e.g. $130 \mathrm{~km}$ over 6-7 m.y.). Increased heat flow allows extensive lower crustal flow. Towards the end of this stage of thickening of the crust is where delamination occurs.

\subsection{RESEARCH OBJECTIVES}

The southern Puna plateau used to be flat around 18 to $12 \mathrm{Ma}$ and currently has transitioned from normal subduction in the north to shallow subduction in the south along with recent (6-2 Ma) episodes of delamination followed by the uplifting without a significant amount of crustal shortening. This suggests that this region maybe in the seventh stage of the Andean orogenic cycle. On the other hand the Altiplano of southern Peru used to experience flat slab subduction between 40-32 Ma to 27-18 Ma and is currently experiencing steep subduction with arc volcanism. It also experienced delamination but prior to that of the southern Puna plateau. This suggests that Altiplano of southern Peru is also in the seventh stage but it entered this stage earlier than the Puna. Since both of these regions have experienced similar orogenic histories including episodes of delamination and flat slab subduction, they provide a rare and unique 
opportunity to study the delamination effects on the velocity structure, seismic anisotropy and crustal attenuation within different times in the same stage of the Andean orogenic cycle. This is of great importance as it may provide parallels and implications for orogenic processes in other parts of the world like the Laramide orogeny in western North America.

My specific dissertation objectives for the two regions of study summarized below:

For the southern Puna plateau:

- Investigate the presence and nature of delamination by resolving the shear wave velocity structure. The delaminated eclogitic crustal root should have an abnormally high velocity signature and the crust should show evidence for partial melting that could be identified as zones of abnormally low velocities.

- Investigate the effects of post-delamination upwelling and reflux on the underlying slab by looking at differences in the velocity structure of the slab.

- Elucidate seismic anisotropy structure in a steepening subduction zone with the added complexity of delamination. Provide a three-dimensional model of anisotropy.

- Provide evidence for close to vertical flow beneath the zones where delamination was proposed. 
For Peru:

- Measure the seismic attenuation in the crust beneath the Peruvian Andes and investigate its possible correlation with topography, seismic velocity, crustal thickness and zones of high heat flow.

- Analyze implications for seismic hazard evaluation.

\subsection{DISSERTATION OVERVIEW}

Chapter 2 provides surface Rayleigh waves phase velocity measurements for the southern Puna plateau that were inverted using the two plane wave approach (Forsyth and Li, 2005). The phase velocities were further inverted using Saito’s (1988) approach to obtain shear wave velocities as a function of depth. Chapter 3 presents a comprehensive study of the three dimensional anisotropic structure of the southern Puna plateau using shear wave splitting analysis and shear wave splitting tomography. Shear wave splitting analysis was performed using the method of Silver and Chan (1991) and the tomographic shear wave splitting inversion was obtained using the method developed by Abt and Fisher (2008). In chapter 4, measurements of Lg seismic attenuation and quality factor (Q) are obtained for the Peruvian Andes using the twostation method and the reverse two-station method. The study investigates whether there are possible correlations with the present topography, volcanic zones, and/or regions of geothermal potential. Chapter 4 also discusses possible implications for seismic hazard assessment as attenuation is an important input for such calculations. Lastly, chapter 5 covers a summary of the main findings and the conclusions drawn from this dissertation work. 


\subsection{REFERENCES}

Abt, D. L., \& Fischer, K. M. (2008). Resolving three - dimensional anisotropic structure with shear wave splitting tomography. Geophysical Journal International, 173(3), 859-886.

Aubouin, J., Borrello, A. V., Cecioni, G., Charrier, R., Chotin, P., Frutos, J., Thiele, R., and Vicente, J. C. (1973). Esquisse paléogéographique et structurale des Andes Méridionales. Revue de Géographique Physique et Géologie Dynamique, 15(1-2), 11-72.

Barazangi, M., \& Isacks, B. L. (1976). Spatial distribution of earthquakes and subduction of the Nazca plate beneath South America. Geology, 4(11), 686-692.

Barazangi, M., \& Isacks, B. L. (1979). Subduction of the Nazca plate beneath Peru: evidence from spatial distribution of earthquakes. geophysical Journal of the Royal Astronomical society, 57(3), 537-555.

Cardona, A., Cordani, U. G., Ruiz, J., Valencia, V., Nutman, A. P., \& Sánchez, A. (2005). U/Pb Detrital zircon geochronology and $\mathrm{Nd}$ isotopes from Paleozoic metasedimentary rocks of the Marañon Complex: insights on the proto-Andean tectonic evolution of the eastern Peruvian Andes. In 5 South American Symposium on Isotope Geology, Proceedings, Punta del Este (pp. 208-211).

Cawood, P. A. (2005). Terra Australis Orogen: Rodinia breakup and development of the Pacific and Iapetus margins of Gondwana during the Neoproterozoic and Paleozoic. Earth-Science Reviews, 69(3), 249-279.

Chew, D. M., Schaltegger, U., Košler, J., Whitehouse, M. J., Gutjahr, M., Spikings, R. A., \& Miškovíc, A. (2007). U-Pb geochronologic evidence for the evolution of the Gondwanan margin of the north-central Andes. Geological Society of America Bulletin, 119(5-6), 697-711.

Coira, B., Kay, S. M., \& Viramonte, J. (1993). Upper Cenozoic magmatic evolution of the Argentine Puna - a model for changing subduction geometry. International Geology Review, 35(8), 677-720.

Dalmayrac, B., Laubacher, G., Marocco, R., Martinez, C., \& Tomasi, P. (1980). La chaine hercynienne d'amerique du sud structure et evolution d'un orogene intracratonique. Geologische Rundschau, 69(1), 1-21.

Forsyth, D. W., \& Li, A. (2005). Array analysis of two-dimensional variations in surface wave phase velocity and azimuthal anisotropy in the presence of multipathing interference. Geophysical Monograph Series, 157, 81-97.

Kay, S. M., Mpodozis, C., Ramos, V. A., \& Munizaga, F. (1991). Magma source variations for mid-late Tertiary magmatic rocks associated with a shallowing subduction zone and a thickening crust in the central Andes (28 to $33 \mathrm{~S}$ ). Geological Society of America Special Paper, 265, 113-137. 
Kay, S. M., Mpodozis, C., \& Coira, B. (1999). Neogene magmatism, tectonism, and mineral deposits of the Central Andes (22 to $33 \mathrm{~S}$ latitude). Geology and Ore Deposits of the Central Andes (Skinner, BJ; editor). Society of Economic Geologists, Special Publication, 7, 27-59.

Kay, S. M., \& Mpodozis, C. (2002). Magmatism as a probe to the Neogene shallowing of the Nazca plate beneath the modern Chilean flat-slab. Journal of South American Earth Sciences, 15(1), 39-57.

Kay, S. M., \& Coira, B. L. (2009). Shallowing and steepening subduction zones, continental lithospheric loss, magmatism, and crustalflow under the Central Andean Altiplano-Puna Plateau. Backbone of the Americas: shallow subduction, plateau uplift, and ridge and terrane collision, 204, 229.

Ramos, V. (1999). Plate tectonic setting of the Andean Cordillera. Episodes, 22, 183190.

Ramos, V. A., \& Aleman, A. (2000). Tectonic evolution of the Andes. Tectonic Evolution of South America, 31, 635-685.

Ramos, V. A., \& Folguera, A. (2009). Andean flat-slab subduction through time. Geological Society, London, Special Publications, 327(1), 31-54.

Ramos, V. A. (2009). Anatomy and global context of the Andes: Main geologic features and the Andean orogenic cycle. Backbone of the Americas: Shallow Subduction, Plateau Uplift, and Ridge and Terrane Collision (Kay, SM, 31-65.

Saito, M. (1988). DISPER80: A subroutine package for the calculation of seismic normal-mode solutions. Seismological algorithms, 293-319.

Silver, P. G., \& Chan, W. W. (1991). Shear wave splitting and subcontinental mantle deformation. Journal of Geophysical Research: Solid Earth (1978-2012), 96(B10), 16429-16454.

Somoza, R., \& Zaffarana, C. B. (2008). Mid-Cretaceous polar standstill of South America, motion of the Atlantic hotspots and the birth of the Andean cordillera. Earth and Planetary Science Letters, 271(1), 267-277.

Vicente, J. C. (1970). Reflexiones sobre la porción meridional del sistema peripacífico oriental. In Symposium on the results of upper mantle investigations with special emphasis on Latin America (Vol. 37). 


\title{
CHAPTER 2
}

\section{VELOCITY STRUCTURE BENEATH THE SOUTHERN PUNA PLATEU: EVIDENCE FOR DELAMINATION}

\author{
Reproduced by written permission from John Wiley and Sons Publishing \\ American Geophysical Union. All Rights Reserved.
}

\begin{abstract}
The high elevation of the Southern Puna Plateau, the widespread melting of its crust, the gap in intermediate depth seismicity and the recent eruptions of ignimbrite complexes can be explained by delamination of the lithospheric mantle beneath it. To test this hypothesis, an array consisting of 73 broad band and short period seismic stations was deployed in the region for a period of two years starting in 2007 . We inverted the data using the two plane wave approach and obtained 1D and 3D Rayleigh wave phase velocities. Our dispersion curve shows that at short periods $(<70 \mathrm{~s})$ the phase velocities are slightly higher than those of the Tibetan plateau and lower than those of the Anatolian plateau. At periods of 100-140 s we observe a low velocity zone that might be remnant hot asthenosphere below a flat slab (7-10 Ma). We estimate the average continental lithosphere thickness for the region to be between 100 and $130 \mathrm{~km}$. Our three dimensional Rayleigh wave phase velocities show a high velocity anomaly at low frequencies $(0.007,0.008$ and $0.009 \mathrm{~Hz})$ slightly to the north of Cerro Galan. This would be consistent with the hypothesis of delamination in which a piece of lithosphere has detached and caused upwelling of hot asthenosphere which in turn caused
\end{abstract}


widespread alkaline-collision related volcanism. This interpretation is also corroborated by our shear wave velocity model where a high velocity anomaly beneath the northern edge of Cerro Galan at $130 \mathrm{~km}$ depth is interpreted as the delaminated block on top of the subducting Nazca slab.

\subsection{INTRODUCTION}

The southern Puna plateau (25S-28S) offers an excellent natural laboratory to study the formation and evolution of a continental plateau along an active continental margin. The Puna -Altiplano plateau numerous important features that set it apart from much of the rest of the Andean mountain belt. Such features include a distinctive spatial and geochemical pattern of mafic lavas and giant ignimbrites, a high topography with a large deficit of crustal shortening, and a slab with a gap in intermediate depth seismicity. The slab has a steeper segment to the north and a flat to the south. This region is also believed to have hosted a series of delamination events starting 6-7 Ma with the most recent occurring around 2 Ma (Kay and Kay, 1993; Kay and Coira, 2009). We believe that we have imaged the delaminated block as a region of abnormally high shear wave velocities on top of the subducting slab at a depth of around $150 \mathrm{~km}$ slightly to the north of Cerro Galan ignimbrite.

The Andean Mountain Range (Figure 2.1) is the typical example of an active continental margin and the associated mountain building processes. The Andes are characterized by the high active volcanoes $(>6000 \mathrm{~m}$, with Ojos del Salado being the highest at $6890 \mathrm{~m}$ ), high peaks (Aconcagua is the highest peak with $6959 \mathrm{~m}$ ), and some of thickest crust on earth $(>70 \mathrm{~km})$, (Heit et al., in prep.), the second greatest plateau 


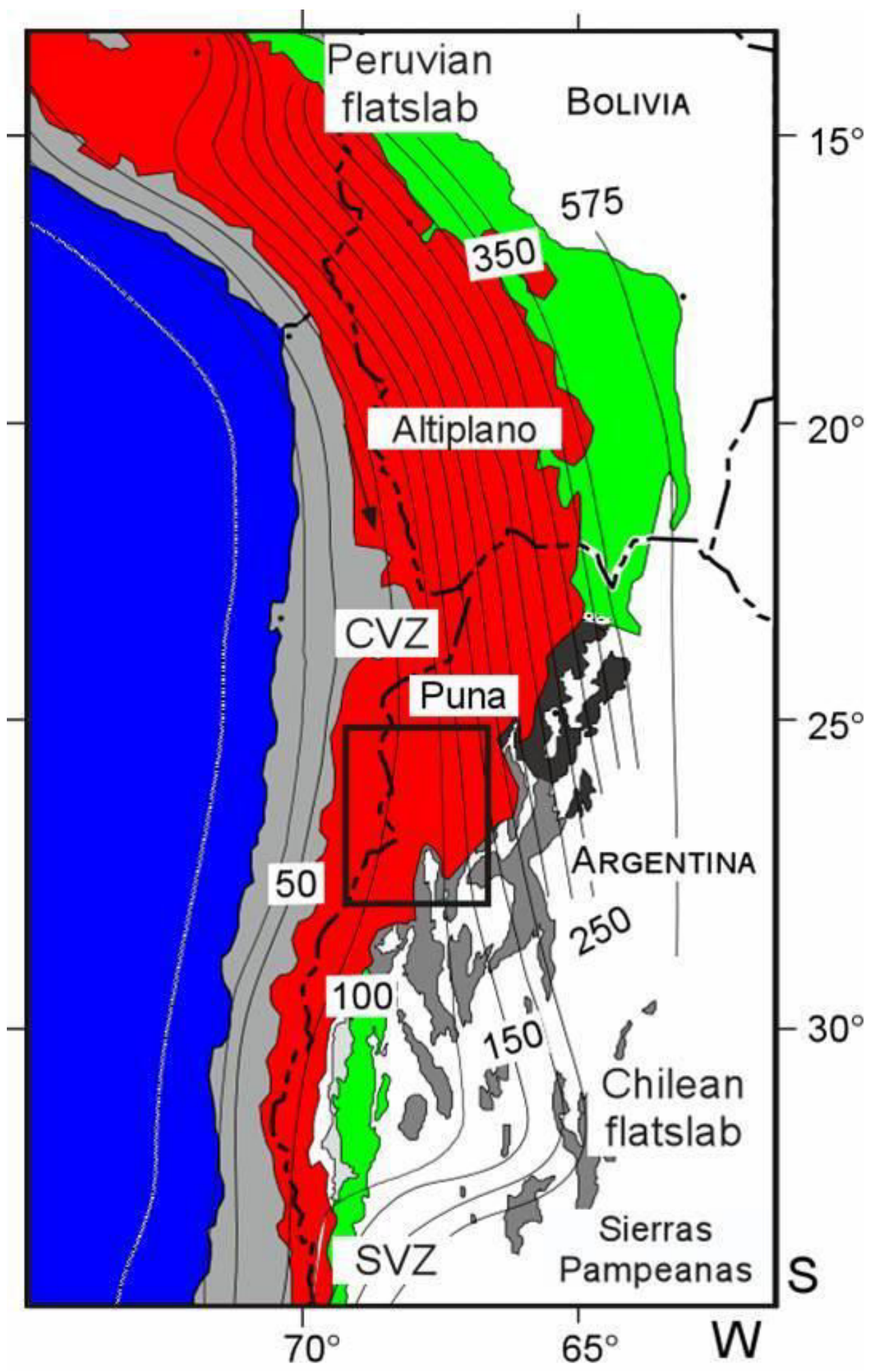

Figure 2.1. Andean Orogeny and region of study (Southern Puna Plateau) shown in the black rectangle. Slab contours show the southward transition from shallow subduction to normal subduction towards the north (Cahill and Isacks, 1992). 
with the largest Tertiary ignimbrite calderas, and among the most shortened continental crust. By comparison the crustal thickness of the Tibetan Plateau ranges from 63-72 km (Holt and Wallace, 1990), the northern Tibet has a crustal thickness of 55-75 km (Herquel et al., 1995) with felsic composition, probably generated from partially melted sedimentary rocks (Wang et al., 2012); and the crustal thickness of Eastern Turkey ranges from 40-50 km (Zor et al., 2003) with intermediate composition composed mainly by andesite and dacite (Karsli et al., 2010). The Andes are a perfect place for investigating the effects of shallowly subducting oceanic plates (Isacks et al 1988, Cahill and Isacks 1992), continental lithosphere removal by forearc subduction erosion (Von Huene and Scholl, 1991; Kay et al 2005), and delamination of continental and mantle lithosphere (Kay and Kay 1993; Beck et al 2002; Sobolev and Babeyko 2005).

Kay and Kay (1993) proposed a model with an episode or perhaps episodes of crustal and lithospheric delamination to explain a number of geodynamic features of the Central Andean Plateau and particularly in the Southern Puna Plateau, such as the distinctive spatial and geochemical pattern of the mafic lavas and giant ignimbrite fields, the high topography with a large deficit in crustal shortening and a slab with a gap in intermediate depth seismicity. However, the mechanism and extent of delamination remains controversial. The first delamination models (proposed for the western US and Tibet, not the Andes) used delamination of mantle lithosphere to explain rapid uplift, extension and rapid variation of regional stress, lithospheric thinning and increased magmatism (Bird, 1979; England and Houseman 1988). Kay and Kay (1993) and Kay et. al. (1994) used the delamination model to explain similar features in the southern 
Puna plateau of the central Andes. Nonetheless, their model has a fundamental difference from previous models because they include the removal and sinking of dense eclogitic crust along with lithospheric mantle. This could lead to larger density contrast that accounts for the gravitational potential energy needed for delamination to occur (Kay and Kay, 1993). However, the scale and mechanism of this type of delamination are still not well understood.

The current models suggest that delamination occurs either as lithospheric pieces and drips falling in the asthenosphere (Jull and Keleman 2002; Babeyko et. al. 2002; and Sobelev and Babeyko 2005), or as large crustal and lithospheric blocks being removed like those proposed for Sierra Nevada (e.g. Ducea et al. 2003). An important reason to consider crustal delamination in the Andes is that it helps to explain the apparent paradox of mantle-derived magmas entering the crust that are basaltic in composition, yet the bulk composition of the crust is andesitic. One way to explain crustal composition is to preferentially remove dense mafic eclogitic roots of thickened continental crust (Kay and Kay, 1993; Rudnick, 1995). Such a model would include crustal delamination which removes lower crust, sediment subduction which removes upper crust, forearc subduction erosion which removes both lower and upper crust, and slab break-off which primarily removes lower crust. However, only the removal of mafic crust helps to resolve the andesitic crustal paradox. In this context, the southern Puna plateau is an excellent place to test models for crustal delamination and ultimately crustal destruction and recycling. This study aims to provide geophysical evidence to test the delamination hypothesis in the southern Puna plateau. If delamination indeed occurred, then it is important to explore whether it occurred as a single block or 
multiply delaminated bodies. We also want to examine the relationship between delamination, seismic gap, abnormal upwelling of the region and the eruption of the recent ignimbrite complexes.

\subsection{DATA PROCESSING}

We use fundamental mode Rayleigh waves recorded at the Puna array within the boundaries: $24^{\circ} \mathrm{S}$ to $29^{\circ} \mathrm{S}$ and $64^{\circ} \mathrm{W}$ to $71^{\circ} \mathrm{W}$. About 50 teleseismic events with Ms>5.9 and epicentral distances of $30^{\circ}-120^{\circ}$ from the center of the array were used. These events together with the 73 seismic stations (see Figure 2.2) generate a very dense ray coverage which allows us to resolve high-resolution phase velocity maps.

I use only the vertical component and Rayleigh waves firstly removing all of the instrument responses, means and trends. Next, we filtered the seismograms in 13 narrow frequency bands ranging from $0.007 \mathrm{~Hz}$ up to $0.05 \mathrm{~Hz}$. Then we visually inspected that waveforms and discarded the ones with low signal to noise ratio. After that, we isolated the fundamental mode Rayleigh waves by windowing the filtered seismogram. The width of each cut is determined according to the width of the fundamental mode Rayleigh wave packet. Finally, the filtered and windowed seismograms are converted into the frequency domain in order to get amplitude and phase measurements. We normalized the amplitudes in order to prevent a bias resulting from variations in earthquake magnitude. We use high damping for Rayleigh wave velocities and anisotropy in order to minimize the trade off between lateral 
heterogeneity of Rayleigh wave velocities and anisotropy. We use a constant smoothing length of $65 \mathrm{~km}$ for all periods and a grid size of $0.25^{\circ}$ by $0.25^{\circ}$. Details of the data processing procedure are given in Yang and Forsyth, 2006a, 2006b. However, a brief summary of their method is presented in the next section.

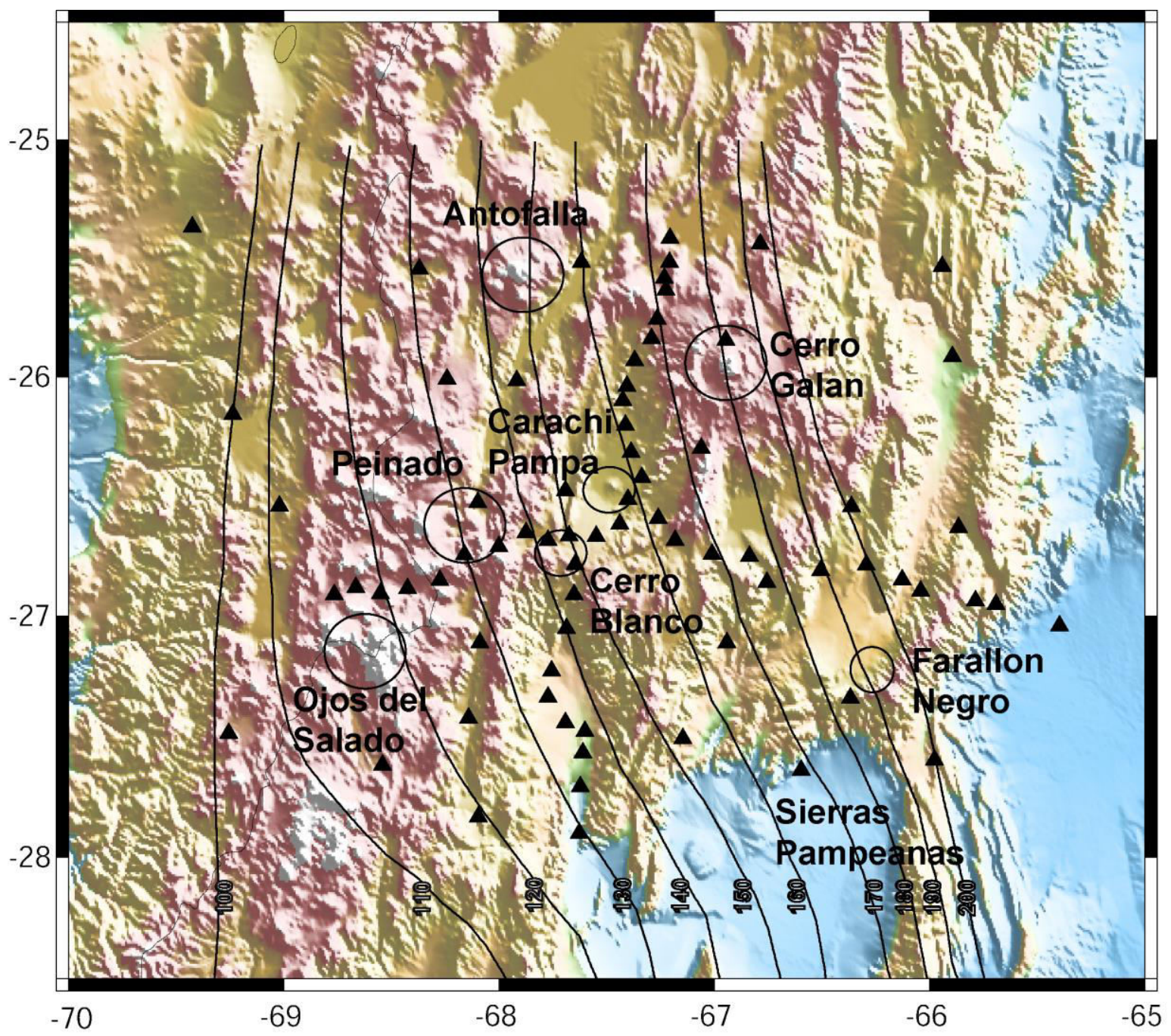

Figure 2.2. Station distribution (black triangles) along the Southern Puna Plateau. Antofalla, Cerro Galan, Ojos del Salado, Cerro Blanco, Carachi Pampa, Peinado and Farallon Negro volcanic centers are shown, as well as the Sierras Pampeanas flat subduction region. The slab contours from 100 to $200 \mathrm{~km}$ depth are also shown (Mulcahy et. al. 2010) 


\subsection{SURFACE WAVE TOMOGRAPHY METHOD}

Also known as the two plane wave approach, this method uses variations in amplitude and phase of the distorted wave front due to lateral velocity variations. This method also has the advantage of solving for distribution of anisotropy with frequency. This approach models the azimuthal variations of Rayleigh wave phase velocities $\left(\mathrm{V}_{\mathrm{ij}}\right)$ (Forsyth and $\mathrm{Li}, 2005$ ) which can be expressed as

$$
V_{i j}\left(w, \theta_{i j}\right)=\left(B_{0}\right)_{j}+\left(B_{0}\right)_{j} \cos \left(2 \theta_{i j}\right)+\left(B_{2}\right)_{j} \sin \left(2 \theta_{i j}\right)
$$

where $\mathrm{w}$ is the frequency, $\mathrm{V}_{\mathrm{ij}}$ is the phase velocity at the $\mathrm{jth}$ grid point due to event $\mathrm{i}, \theta_{\mathrm{ij}}$ is the backazimuth from the $\mathrm{jth}$ grid point to the ith event in the geographic coordinate system, $\mathrm{B}_{0}$ is the azimuthally averaged phase velocity, and $\mathrm{B}_{1}$ and $\mathrm{B}_{2}$ are azimuthal anisotropic coefficients. Thus, the phase velocity corresponding with an event $i$ at the grid point $\mathrm{j}$ is described using 3 parameters. The above expression assumes that the higher order azimuthal terms can be neglected, which is an acceptable assumption for Rayleigh waves (Smith and Dahlen, 1973).

The method also models the teleseismic wavefield using the sum of two plane waves at a given frequency (w) for an event i. Each plane wave has initial unknown amplitude, phase and propagation direction. The vertical displacement is expressed as:

$$
U_{z}(w)=A_{1}(w) \exp \left[-i\left(\vec{k}_{1} \cdot \vec{x}-w t\right)\right]+A_{2}(w) \exp \left[-i\left(\vec{k}_{2} \cdot \vec{x}-w t\right)\right]
$$


where $A$ is the amplitude, $k$ is the horizontal wavenumber and $x$ is the position vector. In practice, these waves need to be expressed in the reference frame of the jth grid point where they can undergo either constructive or destructive interference, causing an interference pattern. Thus, at each frequency and grid point $\mathrm{j}$, the incoming wavefield is described using six parameters: the amplitude, reference phase and direction of the two plane waves.

The method also uses 2-D sensitivity kernels based on the first Born approximation, which takes into account finite frequency effects, together with the two plane wave method. This combination yields results with higher resolution at regional scales as compared to the results obtained by representing the sensitivity kernels with a Gaussian-shaped zone (Forsyth and $\mathrm{Li}, 2005 ; \mathrm{Li}, 2011$ ). The use of finite frequency sensitivity kernels provides improved lateral resolution at deeper depths (generally below $50 \mathrm{~km}$ ) as compared to previous methods without sensitivity kernels.

\subsection{DISPERSION CURVE AND PHASE VELOCITIES}

\subsubsection{DISPERSION CURVE AND 1D SHEAR WAVE VELOCITY MODEL}

Figure 2.3a shows that the crustal phase velocities in the southern Puna plateau (PP), below $40 \mathrm{~s}$, are about 5\% slower than those of Eastern Turkey (ET) (Skobeltsyn et. al., in prep) and 2\% faster than those of Northern Tibet (NT) (Ceylan et. al. 2013). Phase velocities at periods of 60-80 s are consistent with NT but are 3\% faster than ET. At periods of $80-125 \mathrm{~s}$, the phase velocities are slower than NT by an average of $1.5 \%$ and faster than ET by $1 \%$. Figure 2.3a also shows a parallel shift of the AK135 curve 
respect to the other three curves. The 1D Rayleigh velocities were inverted to obtain average $\mathrm{S}$ wave velocities for the region (Figure 2.3b). The average $\mathrm{S}$ wave model suggests a continental lithosphere thickness between 100 to $130 \mathrm{~km}$. The $\mathrm{S}$ wave model confirms the existence of a low velocity zone at depths below $130 \mathrm{~km}$. A synthetic dispersion curve was obtained from the Vs model and it fits the measured dispersion curved (Figure 2.3a).
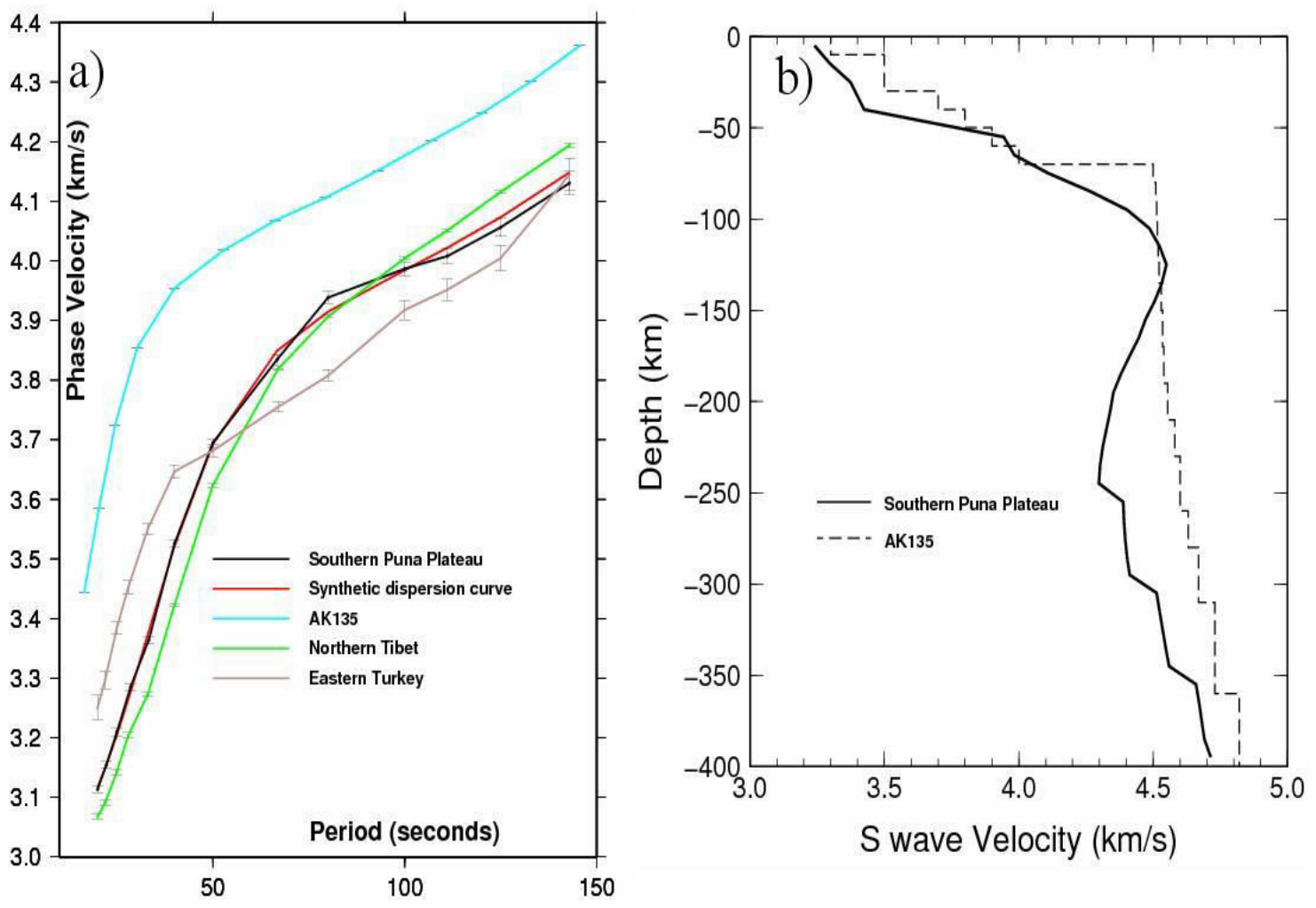

Figure 2.3. a) Dispersion curve for the Southern Puna Plateau with standard deviation errors and a synthetic dispersion curve obtained from the 1D shear wave model. The AK135, Northern Tibet (Ceylan et. al., 2013) and Eastern Turkey (Skobeltsyn et. al., in prep) dispersion curves are also shown for comparison. The Southern Puna Plateau exhibits a low velocity zone at periods greater than $100 \mathrm{~s}$. b) (solid line) Inferred shear wave velocities showing the low velocity zone below $100 \mathrm{~km}$ and (dashed line) initial guess for 1D shear wave velocity model (AK135). 


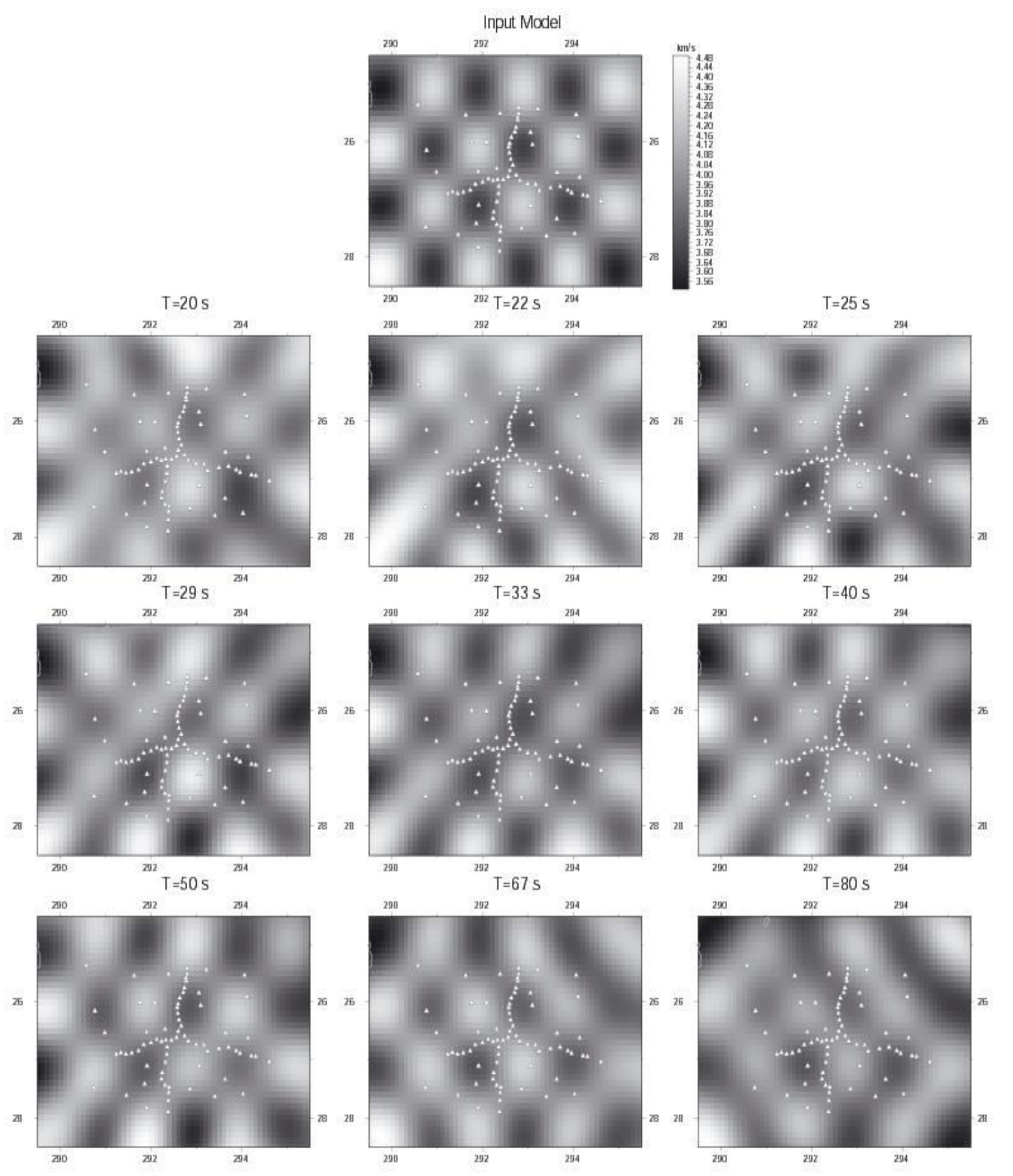

Figure 2.4. Resolution tests for a grid size $1^{\circ} \times 1^{\circ}$. The test yields acceptable results for periods of 20-80 s.

\subsubsection{RESOLUTION TEST}

We also performed a resolution test to estimate the extent to which the method and the station array will be able to resolve velocity anomalies in our area. The same 
smoothing length and geometry used in the real inversion was applied here. We used a checkerboard with anomalies of size $1^{\circ} \times 1^{\circ}$ for short periods (20-80 seconds) and anomalies of size $1.5^{\circ} \times 1.5^{\circ}$ for longer periods (80-143 seconds). A series of synthetic amplitudes and phases were calculated and used to invert for the phase velocity structure. Figures 2.4 and 2.5 show the corresponding results. The resolution test shows that we should be able to resolve anomalies of $1^{\circ} \times 1^{\circ}$ or greater for short periods and $1.5^{\circ} \times 1.5^{\circ}$ or greater for long periods. Therefore, our inversions should be fairly reliable.

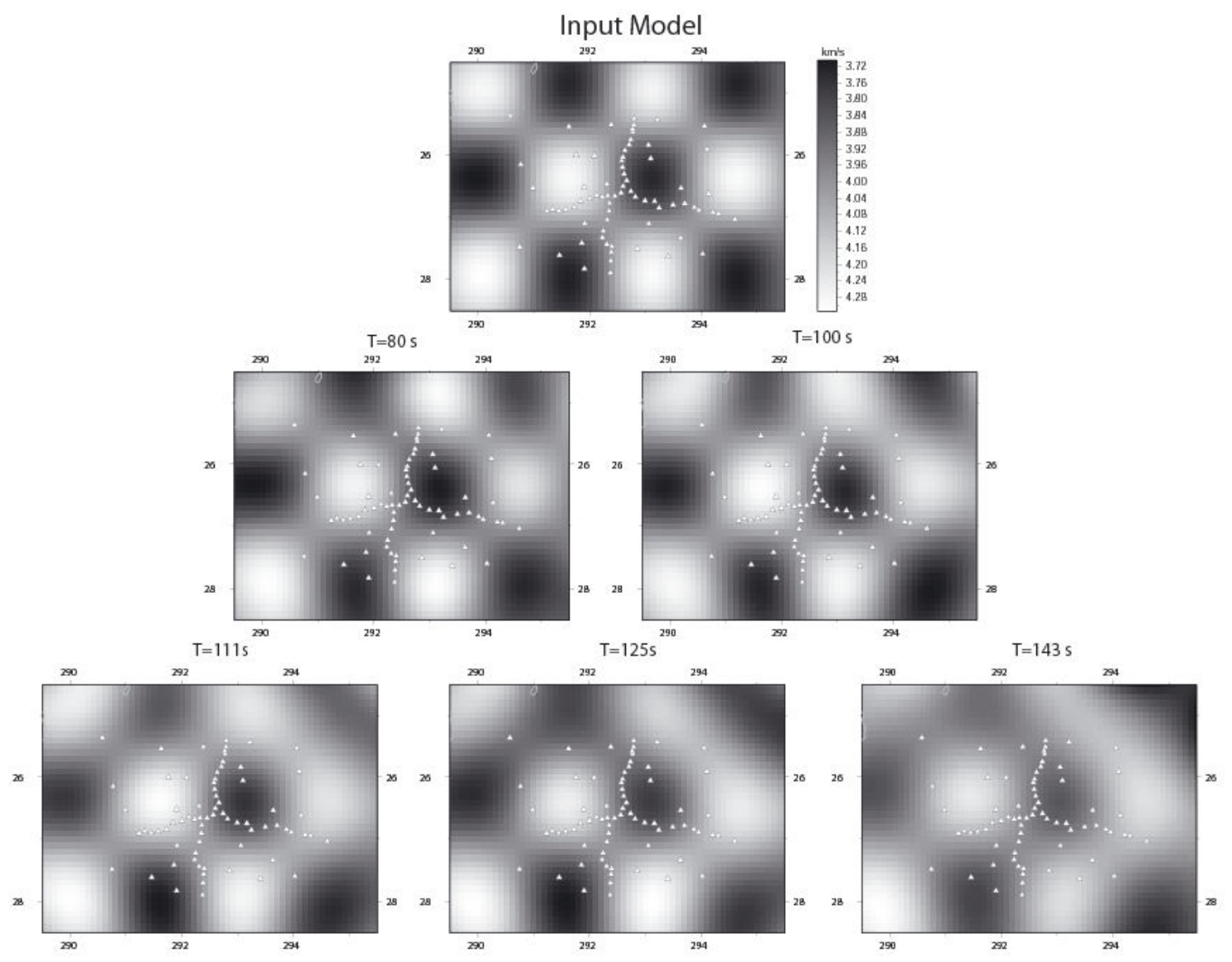

Figure 2.5. Resolution tests for a grid size $1.5^{\circ} \times 1.5^{\circ}$. This test yields acceptable results for all periods. However, here we only show the results for long periods. 


\subsubsection{PHASE VELOCITIES}

The surface wave phase velocity measurements (Figure 2.6) indicate the presence of a high phase velocity block beneath and slightly to the north of Cerro Galan, a very large ignimbrite volcanic center, at frequencies between 0.007 and $0.009 \mathrm{~Hz}$ (roughly between the peak sensitivity depths of 190 and $150 \mathrm{~km}$ ). Figure 2.6 only shows phase velocities with standard deviation equal or less than $0.1 \mathrm{~km} /$. The standard deviations are low near the center of the station array and increases towards the edges (not shown here but available as a supplementary material). The standard deviations suggest that it is possible to obtain reliable results outside the station array $\left(71^{\circ} \mathrm{W}\right.$ to $65^{\circ} \mathrm{W}$ and $25^{\circ} \mathrm{S}$ to $\left.29^{\circ} \mathrm{S}\right)$. At $0.0125 \mathrm{~Hz}(105 \mathrm{~km})$ we start to see the slab which undergoes a transition from a normal angle of subduction in the north to a shallower regime in the south. At higher frequencies, $0.02 \mathrm{~Hz}(66 \mathrm{~km})$, a low velocity zone appears beneath and south-east of Cerro Galan, approaching Ojos del Salado. The low velocity zone gets wider for higher frequencies $(0.025-0.04 \mathrm{~Hz})$ or shallower depths, covering Peinado, Carachi Pampa, Cerro Blanco, Ojos del Salado and part of Cerro Galan. The low velocity zone gets narrower again for $0.045 \mathrm{~Hz}$, covering only Peinado, Carachi Pampa and western Cerro Galan. Figure 2.6 also shows an estimation of seismic anisotropy. The black lines are parallel to the fast direction and their size is proportional to the degree of seismic anisotropy. Overall the mantle beneath this region seems to be weakly anisotropic for low frequencies (depths of $190 \mathrm{~km}$ ) and anisotropy increases towards higher frequencies (shallower depths). Anisotropy also increases from west to east, which is expected in a west-east subduction setting. At crustal depths, the seismic anisotropy fast directions appear to have south-west north-east orientation. 

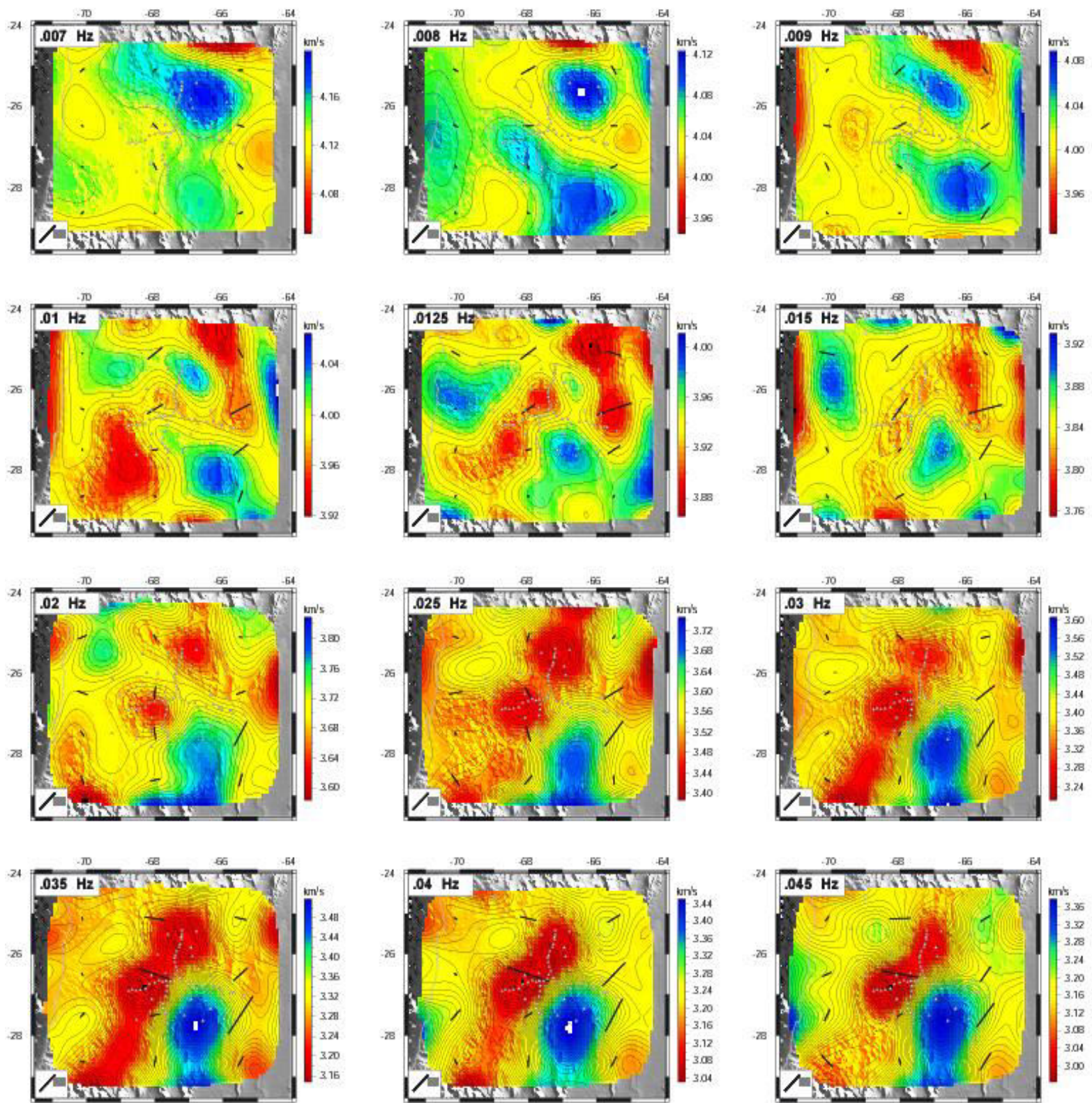

Figure 2.6. Map view of Rayleigh wave phase velocities for different frequency bands. Phase velocities values are plotted only for regions where the standard deviation does not exceed $0.1 \mathrm{~km} / \mathrm{s}$. High frequencies are sensitive to shallow structure as oppose to low frequencies, which are sensitive to deeper structures. The black lines are parallel to the fast direction and their size is proportional to the degree of anisotropy. 


\subsection{SHEAR WAVE VELOCITY STRUCTURE}

Although the phase velocity measurements give us an idea of the velocity structure, it only provides depth averages of phase velocities as a function of frequency. Here we used the method developed by Saito (1988) and inverted our Rayleigh wave phase velocity measurements to obtain shear wave velocities as a function of depth. For the 1-D inversion (Figure 2.3, right), the model AK135 is used as the starting model with a crustal thickness of $55 \mathrm{~km}$. For the 3-D inversion we simply performed the 1-D inversion at each map point using the 1-D result (Figure 2.3, right) as the starting model. Figure 2.7 shows the results as various relative shear wave velocity east-west crosssections. We also plot the seismicity obtained from the PDE catalog and the slab contours from Mulcahy et al (2010). One striking feature is a seismic gap in intermediate depth slab earthquakes observed beneath Cerro Galan $\left(25.5^{\circ} \mathrm{S}\right.$ and $\left.26.0^{\circ} \mathrm{S}\right)$.

The relative shear wave velocity cross-sections beneath Cerro Galan $\left(25.5^{\circ} \mathrm{S}\right.$ and $26.0^{\circ} \mathrm{S}$, Figures $2.7 \mathrm{a}-2.7 \mathrm{~b}$ ) show the slab as a high velocity body but surprisingly they also contain a much faster block at around $140 \mathrm{~km}$ depth that seems to extend down to $190 \mathrm{~km}$ beneath northern Cerro Galan. At first it may seem that this block could merely be part of the slab, but when comparing it to the slab contours, it appears that this high velocity body may be sitting on top of the slab. Figures $2.7 \mathrm{c}-2.7 \mathrm{~d}$ show the slab as a high velocity body that correlates nicely with the slab contours from Mulcahy et a. (2010). Figures $2.7 \mathrm{c}-2.7 \mathrm{~d}$ also show that to the east of the unusual high velocity body we see a low velocity zone that appears to spread well into the crust. 

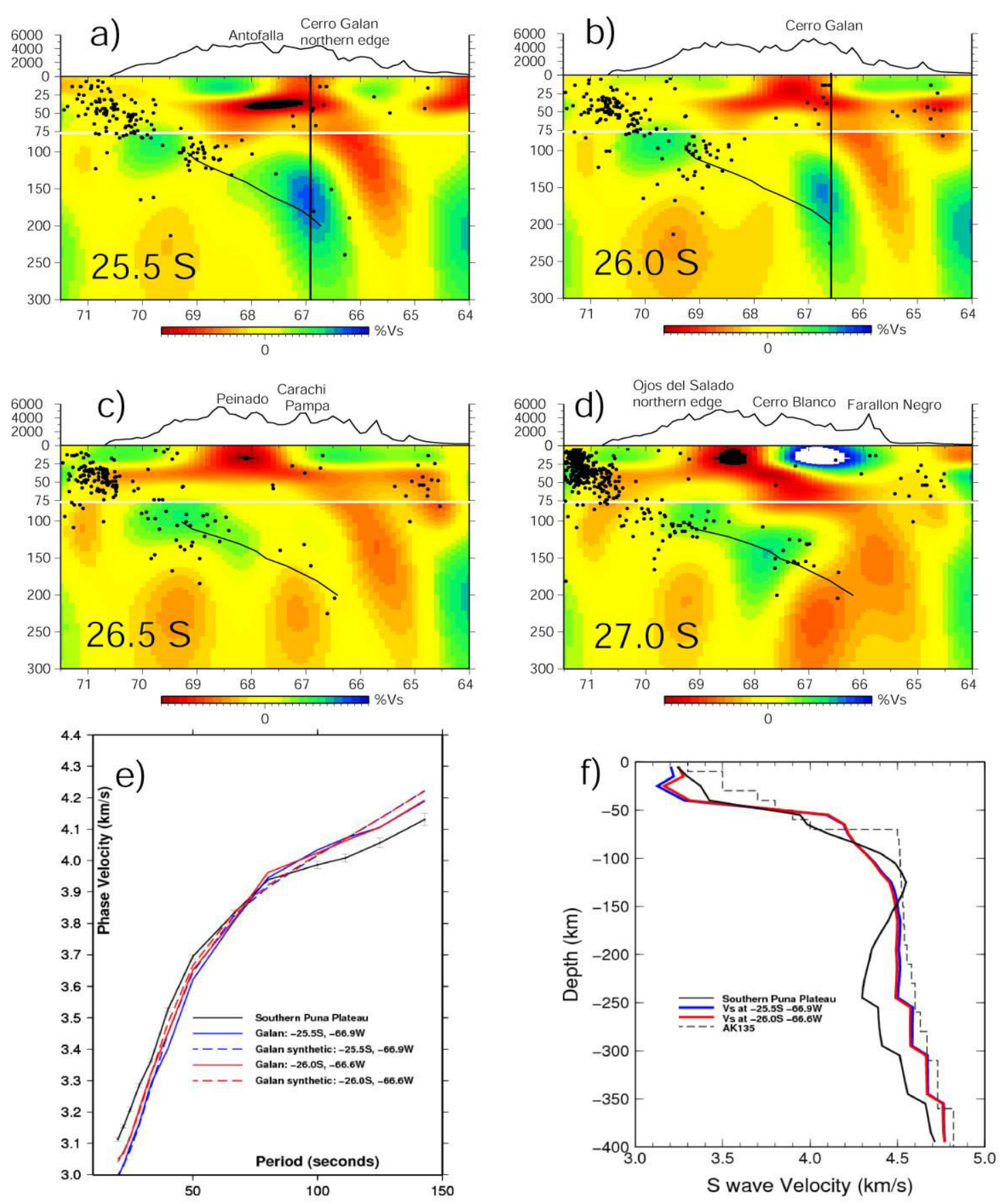

Figure 2.7. (a), (b), (c) and (d): East-west shear wave velocity anomaly cross-sections at $25.5^{\circ} \mathrm{S}, 26.0^{\circ} \mathrm{S}, 26.5^{\circ} \mathrm{S}$ and $27.0^{\circ} \mathrm{S}$. The color scale minimum and maximum values correspond to $\pm 5 \%$ anomalies between $0-75 \mathrm{~km}$ depth, and $\pm 3 \%$ anomalies between 76-300 km depth. The black dots show the epicenters of regional earthquakes obtained from the PDE catalog. Slab contours from Mulcahy et. al (2010) are shown as thin black lines. Thick vertical black lines are the locations where the dispersion curves and inferred shear wave velocity model are shown in (e) and (f). (e) Dispersion curves beneath Cerro Galan at [25.5 S, 69.9 W] and [26.0 S, 66.6 W]. Their respective synthetic dispersion curves and average dispersion curve for the southern Puna plateau 
are also shown for comparison. (f) Calculated shear wave velocity models beneath Cerro Galan at [25.5 S, 69.9 W] and [26.0 S, 66.6 W], average shear wave velocity model for the southern Puna plateau and initial shear wave velocity model (AK135).
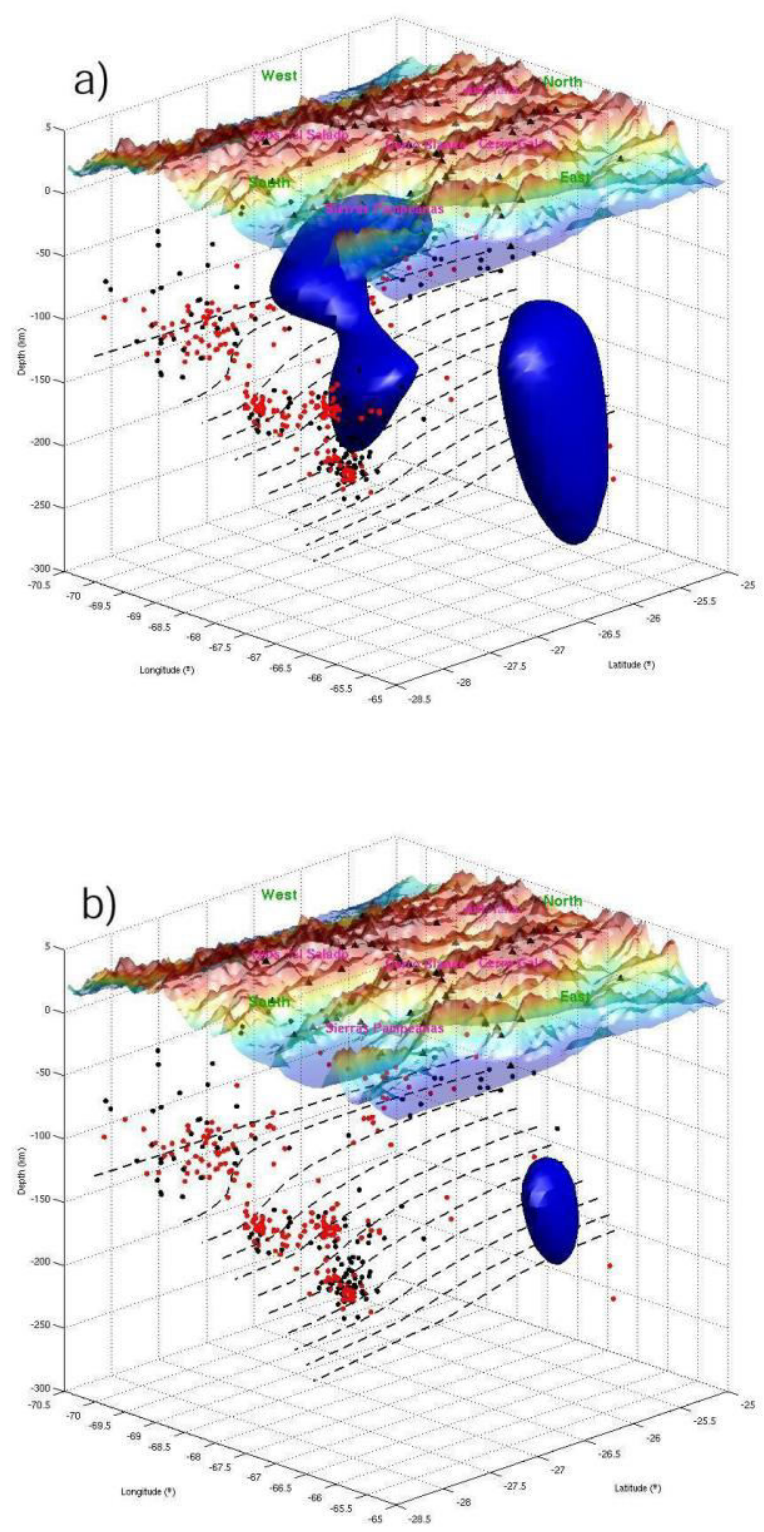

Figure 2.8. (a) Shear wave velocity anomalies of $1.0 \%$ and higher are shown in blue. The black dots are local earthquake locations obtained from the PDE catalog. The red dots earthquake locations and the slab contours shown in black dashed lines were obtained by Mulcahy et. al. (2010). The blue region is interpreted as the slab and the delaminated block combined. (b): Same as Figure (2.8a) but showing shear wave velocity anomalies $2.0 \%$ and higher. The blue region only shows the delaminated block on top of the slab. Three-dimensional animations of these figures are available in the online version of this article. 
The low velocity zone gets wider in the lower crust $(50 \mathrm{~km})$ and narrows as it reaches the surface beneath Cerro Galan and west Cerro Galan This low velocity zone extends to depths of about $50 \mathrm{~km}$ beneath Carachi Pampa and reaches the surface beneath Peinado (Figure 2.7c). The same low velocity is seen further south beneath Cerro Blanco and near the surface beneath the northern edge of Ojos del Salado (Figure 2.7d). The dispersion curves crossing the high velocity body at $\left[25.5^{\circ} \mathrm{S}, 66.9^{\circ} \mathrm{W}\right]$ and $\left[26.0^{\circ} \mathrm{S}, 66.6^{\circ} \mathrm{W}\right]$ suggest that Rayleigh wave velocities beneath northern Cerro Galan are slower than average for periods below $68 \mathrm{~s}$ (crustal depths) and faster than average for periods greater than $80 \mathrm{~s}$ (Figure 2.7e). Faster shear wave velocities than average are also observed beneath northern Cerro Galan for depths greater than $110 \mathrm{~km}$, and lower shear wave velocities than average for depths shallower than $100 \mathrm{~km}$ (Figure 2.7f). The synthetic dispersion curves calculated from 1D shear wave velocities beneath Cerro Galan at $\left[25.5^{\circ} \mathrm{S}, 66.9^{\circ} \mathrm{W}\right]$ and $\left[26.0^{\circ} \mathrm{S}, 66.6^{\circ} \mathrm{W}\right]$ (vertical black lines in Figures $2.7 \mathrm{a}-$ 2.7b) show a very good fit with their corresponding measured phase velocities (Figure 2.7e).

Figure 2.8 shows three dimensional views of the shear wave velocity anomalies greater than $1.0 \%$ and $2.0 \%$, respectively (Three dimensional animations of Figure 2.8 are available online as supplementary material). Figure 2.8 also shows the slab contours (Mulcahy et. al. 2010) to illustrate where the slab is located respect to these high velocity anomalies. When looking at high velocity anomalies greater than $1.0 \%$ (Figure 2.8a) we clearly see the slab and the unusually high velocity body combined. We also observed a gap in the slab between Cerro Galan and Cerro Blanco, and it seems to 
spread towards the north-west. If, instead, the high velocity anomalies greater than $2.0 \%$ are plotted (Figure 2.8b), then the slab is not observed and only the abnormal high velocity block is seen in northern Cerro Galan, between $25.5^{\circ} \mathrm{S}$ and $26.0^{\circ} \mathrm{S}$. The unusual high velocity block is located above the slab contours, which suggest that it is not part of the slab.

\subsection{DISCUSSION}

Delamination is commonly referred to as the detachment and sinking of the lower portion of the continental lithosphere into the asthenosphere. Delamination is believed to be linked to shortening which results in the formation of a denser crustal root. Delamination can also be linked to magmatic addition at the base of the crust. One of the effects of delamination is a thermal anomaly that leads to delamination magmatism, which is non-arc related and has a distinct chemical signature. Delamination also causes a regional change in stress orientation.

In the Southern Puna plateau not only do we observe the effects listed above, but we also see surface manifestations of delamination magmatism. One of them is the Cerro Galan ignimbrite complex (2.2 Ma), which is one of the largest in the Andes.

Delamination in Cerro Galan was postulated in 1993 by Kay and Kay to explain the rapid localized uplift and extension, and the increased magmatic production. This region exposes late Miocene and Pliocene volcanic rocks that are mostly silicic andesites and dacites, which are linked to crustal melting due to crustal thickening and plateau uplift. The southern Puna plateau also experienced a regional change in stress 
(Allmendinger et al, 1986, 1989; and Marrett et al. 1994) from a very uniform NW-SE compressive regime in the Miocene to a more complex regime in the early Pliocene.

Kay and Kay 1993 interpreted these observations as a detachment and sinking of a large portion of the continental lithosphere, which in turn caused asthenospheric uplift and changes in stress. The outbreak of the Cerro Galan ignimbrite complex was the result of mantle-derived magmas that ascended through strike-slip and normal faults that were created by the delamination event. The crustal chemical signature is due to the mixing of the mafic lavas with crustal melt on their way up to the surface. Recently, receiver function analysis using the same data set has shown that the crust beneath Cerro Galan is thicker than the rest of the southern Puna plateau (Heit et al. in prep.). The crustal thickness in the southern Puna plateau $(40-70 \mathrm{~km})$ is thicker and weaker than that of eastern Turkey $(40-50 \mathrm{~km})$, and thinner and stronger than that of northern Tibet (55-75), which explains the fact that our average phase velocities for periods below $40 \mathrm{~s}$ (Figure $2.3 \mathrm{a}$ ) are slower than those of eastern Turkey and faster than those of northern Tibet.

The region of anomalous high velocity (greater than $2.0 \%$ ) at 140-190 km depth slightly to the north of Cerro Galan (Figures 2.7a, 2.7b and 2.8b) is interpreted as delaminated crust. A comparison with the slab contours inferred from local seismicity (Mulcahy et al., 2010) suggests that this high velocity block is on top of the slab. Crustal phase velocities are slower than average and mantle phase velocities are higher than average beneath northern Cerro Galan (Figure 2.7e). The synthetic dispersion curves calculated from the 1D shear wave velocities beneath Cerro Galan (Figure 2.7e) 
fit very well with their respective dispersion curves. This demonstrates that our shear wave velocity model is robust and the data require the presence of a high velocity anomaly beneath northern Cerro Galan. Moreover, there is no apparent reason why part of a slab should have much higher seismic velocities than the rest of it. Other pieces of evidence that supports this idea were obtained from independent studies of attenuation tomography and teleseismic tomography that show a block of high Q on top of the slab (Liang et al, 2011) and a block of high P-wave velocity anomalies (Bianchi et. al 2013) imaged right where we see the high velocity block but with a depth of around $100 \mathrm{~km}$. This difference in depth could be just a matter of resolution since surface wave tomography offers significantly better resolution than attenuation tomography or teleseismic tomography. However, the latter techniques provide better horizontal resolution than surface wave tomography.

When looking at high velocity anomalies greater than $1.0 \%$ (Figures $2.8 \mathrm{a}$ ) we clearly see the slab and the delaminated block combined. The gap in the slab observed between Cerro Galan and Cerro Blanco correlates very well with the seismic gap and it might be just due to a thermal effect. We do not think that this is a real gap or tear in the slab but rather that the slab in this region is partially heated and could not be detected by the surface wave tomography method. The hypothesis of a thermally eroded slab could not be reconciled with the fact that there is no evidence for slab melting that reaches the surface. The idea of slab tear beneath Cerro Galan is very unlikely since the slab shows no tear further east down to around $500 \mathrm{~km}$. The low velocity region 
observed to the east of the delaminated block (Figures $2.7 \mathrm{a}-2.7 \mathrm{~b}$ ) is interpreted as postdelamination asthenospheric upwelling that experiences decompression melting as it raises. Part of the hot asthenosphere caused widespread partial crustal melting as it reached the lower crust (Figures 2.7a-2.7b, and Figure 2.6: 0.025 to $0.045 \mathrm{~Hz}$ ). Eventually, the melted crust reached the surface and created the Cerro Galan ignimbrite complex. These low velocities (Figures 2.7a-2.7b) correlate with the most recent nonarc related volcanism and ignimbrite complexes. Another part of the convecting asthenosphere reached the slab (gap observed in Figure 2.6: 0.007 to $0.009 \mathrm{~Hz}$ ) at about $120 \mathrm{~km}$ depth to the west of Cerro Galan (Figures 2.7a-2.7b) and heated the slab, causing the gap observed. This could also explain the low velocity zone observed in the dispersion curve for periods greater than $100 \mathrm{~s}$ (Figure 2.3a). We interpret the anomalous low velocities at depths below $200 \mathrm{~km}$ (Figure 2.3b) as caused by the welldocumented recent change in angle of subduction and the fact that the slab is partially heated by asthenospheric upwelling of hot asthenosphere that may have originated from depths as great as $250 \mathrm{~km}$. We would like to point out that low velocities at long periods are common for tectonically active regions like the Central Andean plateau or western United States (US). Pollitz and Snoke (2010) found Rayleigh wave phase velocities as low as $3.9 \mathrm{~km} / \mathrm{s}$ for $125 \mathrm{~s}$ for western US using local non-plane surface wave tomography. Wagner et al (2010) measured $4.16 \mathrm{~km} / \mathrm{s}$ for $142 \mathrm{~s}$ for north-western US using Rayleigh wave tomography, close to our $4.13 \mathrm{~km} / \mathrm{s}$ for the same period. Moreover, a study of the upper mantle structure of South America using joint inversion of wave forms by Feng et al. (2007) found negative shear wave velocity variations of $-3.5 \%$ respect to iasp91 $(4.506 \mathrm{~km} / \mathrm{s})$ at depths of $150 \mathrm{~km}$ for the southern Puna plateau. This 
is to a velocities of $4.348 \mathrm{~km} / \mathrm{s}$ (or $-4.01 \%$ deviation from AK135), which are even lower than our measured velocity of $4.47 \mathrm{~km} / \mathrm{s}$ at the same depth. The maximum negative deviation from AK135 from our current shear wave velocity model is $4.6 \%$ at depths around $250 \mathrm{~km}$, but this deviation decreases and the model approaches AK135 for greater depth (Figure 2.3b). This shows that, although unexpected, anomalous low phase velocities at long periods and shear wave velocities anomalies greater than $4 \%$ at depths below $150 \mathrm{~km}$ can actually be measured at tectonically active regions like the southern Puna plateau

We conjecture that delamination may have occurred in the region with the thinnest crust (region between Cerro Galan and Cerro Blanco) and that the delaminated block and asthenospheric flow may have migrated northward. A trench parallel asthenospheric flow could explain why the delaminated block and Cerro Galan are north of the region with the thinnest crust. This is seen in the predominantly north-south pattern of fast direction from shear wave splitting analysis (Calixto et. al., 2012). The slab geometry, flat in the south and steep in the north could also facilitate a northward flow of asthenosphere, which could be related to the idea of northward motion of the delaminated block. The primarily east-west NUVEL-1 convergence rate of $8.5 \mathrm{~cm} /$ year of the Nazca plate respect to the South American plate would not be enough to explain such a motion.

Delamination seems to be a very likely candidate that explains many of the geochemistry and geophysical observations throughout the Southern Puna Plateau. 
Although our images are not conclusive, there seems to be a delaminated block sinking and migrating northward beneath Cerro Galan. Such a block is causing asthenospheric upwelling and a number of other perturbations in the region, including regional changes in stress regime, rapid uplift and eruption of young ignimbrites. Heating of the slab by the upwelling of hot asthenosphere could be responsible for the gap in intermediate seismicity right beneath Cerro Galan, which precludes us from better constraining the subducting slab. The lower crust beneath Galan is also very hot as evidenced by the low velocities shown at high frequencies in Figure 2.6. This agrees with the impulsive P wave and almost no energy in the $\mathrm{S}$ waves observed in the few earthquakes detected in the gap (Mulcahy et al, 2010).

The size of the delaminated block estimated by Kay and Kay, 1993, using purely chemical methods, is in strong agreement with the size of the high velocity block imaged at 140-190 km depth slightly to the north of Cerro Galan (Figure 2.8b). Schurr et. al. $(2003,2006)$ found a similar formation in the back arc of the Puna at $23.1^{\circ} \mathrm{S}$. They see a region of high velocity and low attenuation interpreted as a $50 \mathrm{~km}$ thick delaminated lithosphere. Very similar thickness to the delaminated block imaged in this paper. We conjecture that this thickness has a direct link with the initialization of the instability leading to delamination.

Shear wave splitting (Calixto et al, 2012) gives further evidence for the current complex regional stress and strain patterns throughout the crust and upper mantle. A 
circular pattern of fast directions around Cerro Galan seems to be linked to asthenospheric upwelling around the delaminated block.

\subsection{CONCLUSIONS}

The evidence for delamination of the lithosphere 7-6 Ma beneath the largest ignimbrite in the southern Puna plateau, Cerro Galan, is very strong, though not conclusive. The change of surface wave phase velocities and shear wave velocities from anomalously low values at shallow depths to anomalously high values at greater depths may be the result of a downwelling or detachment of cold lithosphere followed by upwelling of hotter upper mantle filling the gap left by the downwelling lithosphere. A region of abnormally high shear wave velocities on top of the slab beneath the northern edge of Galan is interpreted as the delaminated block. This block is also seen in independent studies as a block of high Q (Liang et al in prep) and high P-wave velocity anomalies (Bianchi et. al. 2013)

The delamination hypothesis is consistent with the model of Kay and Coira (2009) in which a moderately shallowly dipping slab cause a significant amount of backarc volcanism and delamination of dense lithosphere as the slab steepened, followed by the eruption of the Cerro Galan ignimbrite with the most recent event occurring around $2 \mathrm{Ma}$. All this evidence indicates that the lower lithosphere, including the eclogitic root beneath the region between Cerro Galan and Cerro Blanco, detached and sank migrating northward, and led to post-delamination asthenosphere upwelling which probably underwent partial melting during its ascent. The insertion of hot 
asthenosphere from depths as great as $250 \mathrm{~km}$ into the mantle wedge caused widespread lower crust melting and an increase in temperature of the top of the slab at $120 \mathrm{~km}$ beneath the west of Cerro Galan, making it less brittle and reducing the friction with the mantle wedge. Over time the top of the slab and the injection of hot asthenosphere may have reached thermal equilibrium and it is the reason why we do not observe a geophysical difference between the slab and the mantle wedge in the seismic gap. The heated slab explains the scarce local seismicity in this part of the southern Puna plateau as compared to surrounding regions. It is also important to remark that all the evidence including the low velocities in the lower crust suggests that the ignimbrite flare up is not over.

Further investigation needs to be done in order to further resolve the high velocity block observed beneath Cerro Galan. This includes performing a joint inversion of surface waves and body waves.

\subsection{ACKNOWLEDGMENT}

We are grateful to Dayanthie Weeraratne for reviewing and providing outstanding comments that helped improve our long period measurements and the manuscript. We thank Thorsten Becker (associate editor of G-cubed) and an anonymous reviewer for their helpful comments and suggestions that lead to great improvements in the content and presentation of this article. We also thank IRIS and GEOFON for the archiving of continuous waveform. This work was funded by the NSF Grant Proposal EAR-0538245. 


\subsection{REFERENCES}

Allmendinger, R.W. (1986), Tectonic development of the southeastern border of the Puna Plateau, northwestern Argentine Andes, Geol. Soc. Am. Bull., 97, 1070-1082.

Allmendinger, R.W., Strecker, M.A., Eremchuk, J.E., and Francis, P.W. (1989), Neotectonic deformation of the southern Puna Plateau, northwestern Argentina., J. South Am. Earth Sci., 2, 111-130.

Babeyko, A.Y., Sobolev, S.V., Trumbull, R.B., Oncken, O., and Lavier, L.L. (2002), Numerical models of crustal scale convection and partial melting beneath the Altiplano-Puna Plateau, Earth and Planetary Science Letters, v. 199, p. 373-388, doi: 10.1016/S0012-821X(02)00597-6.

Beck, S., Zandt, G. (2002). The nature of orogenic crust in the central Andes, Journal of Geophysical Research, v. 107, no. B10, p. 2230, doi: 10.1029/2000JB000124.

Bianchi, M., Heit, B., Jakovlev, A., Yuan, X., Kay, S., Sandvol, E., Alonso, R., Coira, B., Brown, L., Kind, R., Comte, D., (2013). Teleseismic tomography of the southern Puna plateau in Argentina and adjacent regions, Tectonophysics, v. 586, p. 65-83.

Bird, P., 1979. Continental delamination and the Colorado Plateau. J. Geophys. Res., 84:7561-7571.

Cahill, T.A., Isacks, B.L. (1992), Seismicity and shape of the subducted Nazca plate, Journal of Geophysical Research, v. 97, p. 17,503-17,529, doi: 10.1029/92JB00493.

Calixto, F.J., Abt, D. L., Fischer., K. M., Heit, B., Yuan, X., Kay S.M., Comte, D., Alvarado, P., Sandvol E., (2012), Three dimensional anisotropic structure of the southern Puna plateau, American Geophysical Union 2012 meeting, poster session: S44A-07.

Ceylan, S., Ni, J., Chen, J.Y., Zhang, Q., Tilmann, F., Sandvol, E. (2013), Fragmented Indian plate and vertically coherent deformation beneath eastern Tibet, Journal of Geophysical Research: Solid Earth, v. 117, doi: 10.1029/2012JB009210.

Ducea, M., Kidder, S., and Zandt, G. (2003), Arc composition at mid-crustal depths: Insights from the Coast Ridge Belt, Santa Lucia Mountains, California, Geophysical Research Letters., v. 30, no. 13, 1703, doi:10.1029/2002GL016297.

England, P.C., Houseman, G.A. (1988), The mechanics of the Tibetan Plateau. Tectonic evolution of the Himalayas and Tibet. Philosophical Transactions of the Royal Society of London, Series A, Mathematical and Physical Sciences, 326, no. 1589, 301-320. 
Feng, M., van der Lee, S., and Assumpcao, M. (2007), Upper mantle structure of South America from joint inversion of waveforms and fundamental mode group velocities of Rayleigh waves, Journal of Geophysical Research, vol. 112, B04312, doi:10.1029/2006JB004449.

Forsyth, D.W., and A. Li (2005), Array-analysis of Two-dimensional Variations in Surface Wave Velocity and Azimuthal Anisotropy in the Presence of Multipathing Interference: Seismic Earth: Array Analysis of Broadband Seismograms, (A. Levander and G. Nolet, ed.), AGU Geophysical Monograph 157, 81-97.

Heit, B., M. Bianchi, X. Yuan, S.M. Kay, E. Sandvol, P. Kumar, R. Kind, R.N. Alonso, L.D. Brown, D. Comte, Structure of the crust and the lithosphere beneath the southern Puna plateau from teleseismic receiver functions, Earth and Planetary Science Letters, 2014, 385, 1-11.

Herquel, G., Wittlinger, G. and Guilbert, J., Anisotropy and crustal thickness of Northern-Tibet. New constraints for tectonic modelling., Geophysical Research Letters, v. 22, p. 1925-1928.

Holt, W. and Wallace, T. (2012), Crustal thickness and upper mantle velocities in the Tibetan Plateau Region from the inversion of regional Pnl waveforms: Evidence for a thick upper mantle lid beneath southern Tibet, Journal of Geophysical Research, v. 95, p. 12499-12525.

Isacks, B.L. (1988), Uplift of the Central Andean plateau and bending of the Bolivian orocline, Journal of Geophysical Research, Solid Earth and Planets, v. 93, no. 4, pp. 3211-3231.

Jull M and Keleman P.B. (2002), On the conditions for lower crustal convective instability, Journal of Geophysical Research, v. 106, p. 6423-6446.

Karsli, O., Dokuz, A., Uysal, I., Aydin, F., Kandemir, Raif., and Wijbrans, J., Generation of the Early Cenozoic adakitic volcanism by partial melting of mafic lower crust, Eastern Turkey: Implications for crustal thickening to delamination, Lithos, v. 114, p. 109-120, doi:10.1016/j.lithos.2009.08.003.

Kay, R.W. and Kay, S.M. (1993), Delamination and delamination magmatism, Tectonophysics, v. 219, pp. 177-189.

Kay, S.M., Coira, B. and Viramonte, J. (1994), Young mafic back arc volcanic rocks as indicators of continental lithospheric delamination beneath the Argentine Puna plateau, central Andes, Journal of Geophysical Research, v. 99, no. B12, p. 24,32324,339 
Kay, S.M., Godoy, E. and Kurtz, A. (2005), Episodic arc migration, crustal thickening, subduction erosion, and Miocene to Recent magmatism along the Andean Southern Volcanic Zone Margin, Geological Society of America Bulletin, v. 117, p. 67-88.

Kay, S.M. and Coira, B. (2009), Shallowing and steeping subduction zones, continental lithospheric loss, magmatism, and crustal flow under the Central Andean AltiplanoPuna Plateau, Geological Society of America Bulletin, v. 204, p. 229-259.

Li, A. (2011), Shear wave model of southern Africa from regional Rayleigh wave tomography with 2-D sensitivity kernels, Geophysical Journal International, v. 185, 832-844.

Liang Xiaofeng, Eric Sandvol, Suzanne Kay, Benjamin Heit, Xiaohui Yuan, Patrick Mulcahy, Chen Chen, Larry Brown, Diana Comte, Patricia Alvarado, (2014). Delamination of southern Puna lithosphere revealed by body wave attenuation tomography, Journal of Geophysical Research: Solid Earth, 119.

Marrett., R.A., Allmendinger, R.W., Alonso, R.N., and Drake, R.E. (1994), Late Ceonozoic tectonic evolution of the Puna Plateau and adjacent foreland northwestern Argentine Andes, Journal of South American Earth Sciences, v. 7, p. 179-207.

Mulcahy, P., Chen, C., Kay, S. M., Brown, L. D., Alvarado, P., Sandvol, E., Heit, B., and Yuan, X. (2010), The Southern Puna seismic experiment: Shape of the subducting Nazca plate, areas of concentrated mantle and crustal earthquakes, and crustal focal mechanisms. Americal Geophysical Union 2010 meeting, poster session: T11A2050 .

Pollitz, F. and Snoke, J. (2010), Rayleigh-wave phase-velocity maps and threedimensional shear velocity structure of the western US from local non-plane surface wave tomography. Geophys. J. Int, 180, 1153-1169.

Rudnick, R.L. (1995). Making continental crust, Nature, 378, 571-578.

Saito, M. (1988), DISPER80: a subroutine package for calculation of seismic normalmode solution, Seismological Algorithms, p. 293-319, ed. Doornbos, D.J., Elsevier, New York, NY.

Schurr, B., Asch, G., Rietbrock, A., Trumbull, R., and Haberland, C. (2003), Complex patterns of fluid and melt transport in the Central Andean subduction zone revealed by attenuation tomography: Earth and Planetary Science Letters, v. 215, p. 105-119, doi: 10.1016/S0012-821X(03)00441-2.

Schurr, B., Rietbrock, A., Asch, G., Kind, R., and Oncken, O. (2006), Evidence for lithospheric detachment in the central Andes from local earthquake tomography: Tectonophysics, v. 415, p. 203-223, doi: 10.1016/j.tecto.2005.12.007. 
Skolbeltsyn, G., R. Mellors, R. Gök, N. Türkelli, G. Yetirmishli, and E. Sandvol (2014), Upper mantle $S$ wave velocity structure of the East Anatolian-Caucasus region, Tectonics, 33, doi:10.1002/2013TC003334.

Smith, M.L., and Dahlen, F.A. (1973), The azimuthal dependence of Love and Rayleigh wave propagation in a slightly anisotropic medium. Journal of Geophysical Research, 78, 3, 321-3,333.

Sobolev, S.V., and Babeyko, A.Y. (2005), What drives orogeny in the Andes?, Geology, v.33, p. 617-620, doi: 10.1130/G21557.1.

Von Huene, R., and Scholl, D. W. (1991), Observations at convergent margins concerning sediment subduction, subduction erosion, and the growth of continental crust, Reviews of Geophysics, v. 29, pp. 279-316.

Wagner, L., Forsyth, D., Fouch, M., James, D. (2010), Detailed three-dimensional shear wave velocity structure of the northwestern United States from Rayleigh wave tomography, Earth and Planetary Science Letters, 299, 273-284.

Wang, Q., Chung, S., Li, X., Wyman, D., Li, Z., Sun, W., Qiu, H., Liu, Y., and Zhu, Y., Crustal Melting and Flow beneath Northern Tibet: Evidence from Mid-Miocene to Quaternary Strongly Peraluminous Rhyolites in the Southern Kunlun Range, Journal of Petrology, v. 53, p. 2523-2566.

Yang. Y., and Forsyth D.W. (2006a), Rayleigh wave phase velocities, small-scale convection, and azimuthal anisotropy beneath southern California, Journal of Geophysical Research, v. 111, B07306, doi:10.1029/2005JB004180.

Yang, Y., and Forsyth, D.W. (2006b), Regional tomographic inversion of amplitude and phase of Rayleigh waves with 2-D sensitivity kernels, Geophys. J. Int., v. 166, p. 1148-1160.

Zor, E., Sandvol, E., Gürbüz, C., Türkelli, N., Seber, D., and Barazangi, M. (2003), The crustal structure of the East Anatolian plateau (Turkey) from receiver functions, Geophysical Research Letters, v. 30, no. 24, 8044, doi:10.1029/2003GL018192.

\subsection{SUPPLEMENTARY FIGURES}



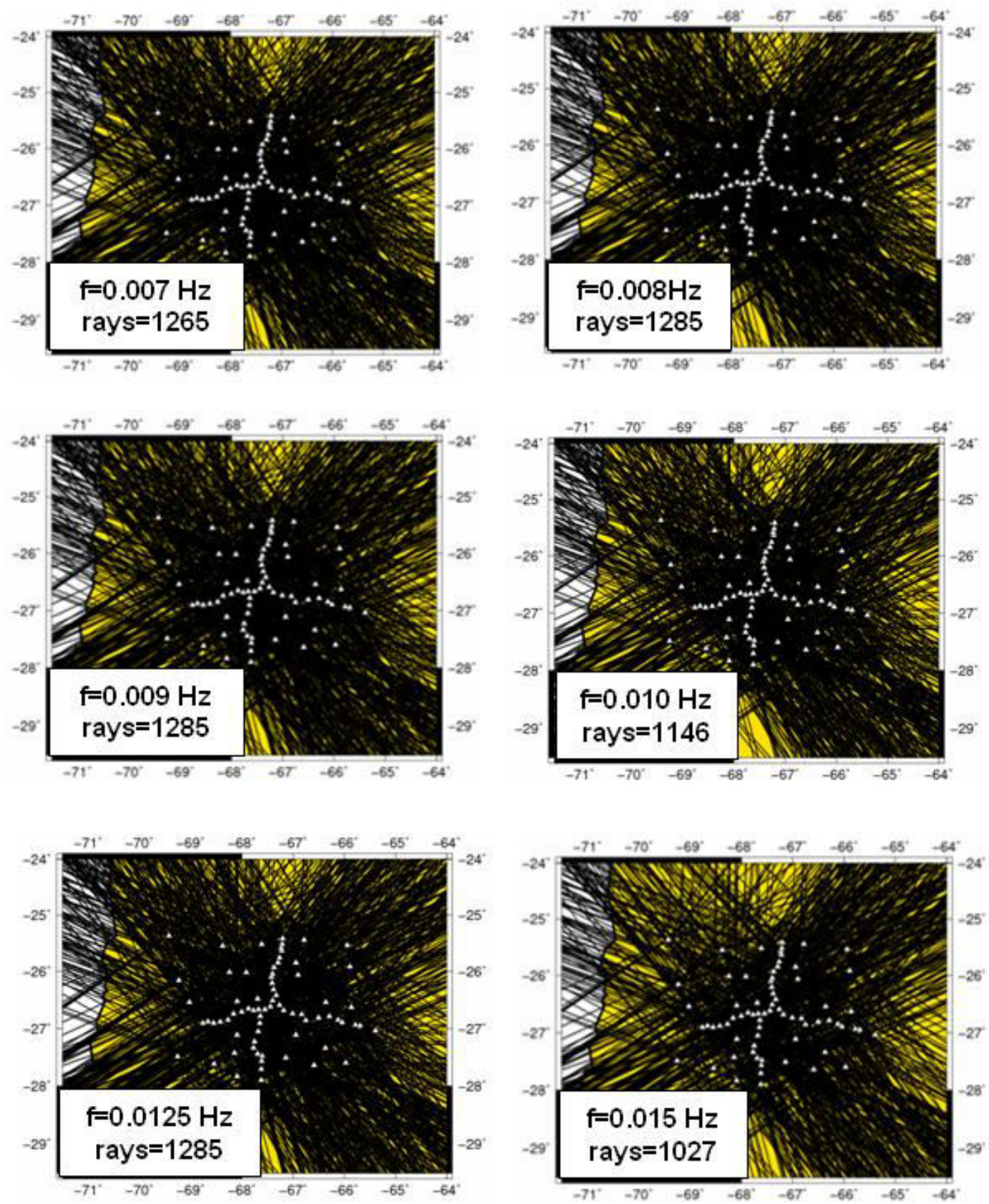

Figure 2.1.S. Ray paths of Rayleigh waves for frequency bands from $0.007 \mathrm{~Hz}$ to 0.015 Hz. The ray density is generally greater for low frequencies as oppose to high frequencies, where the ray density decreases. Overall, the figure shows that we have good coverage in the study area. 

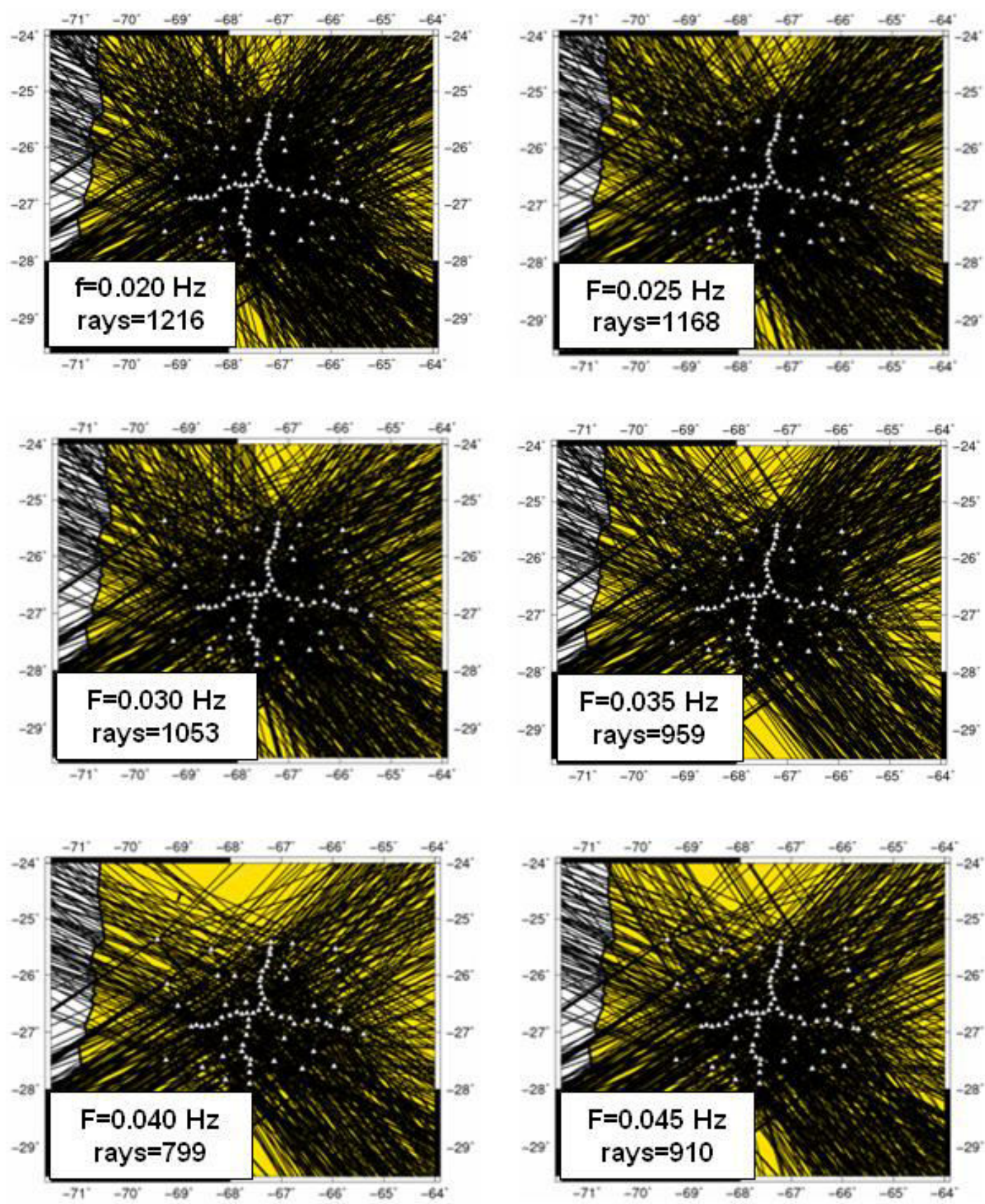

Figure 2.2.S. Ray paths of Rayleigh waves for frequency bands from $0.020 \mathrm{~Hz}$ to 0.045 $\mathrm{Hz}$. The ray density is generally greater for low frequencies as oppose to high frequencies, where the ray density decreases. Overall, the figure shows that we have good coverage in the study area. 

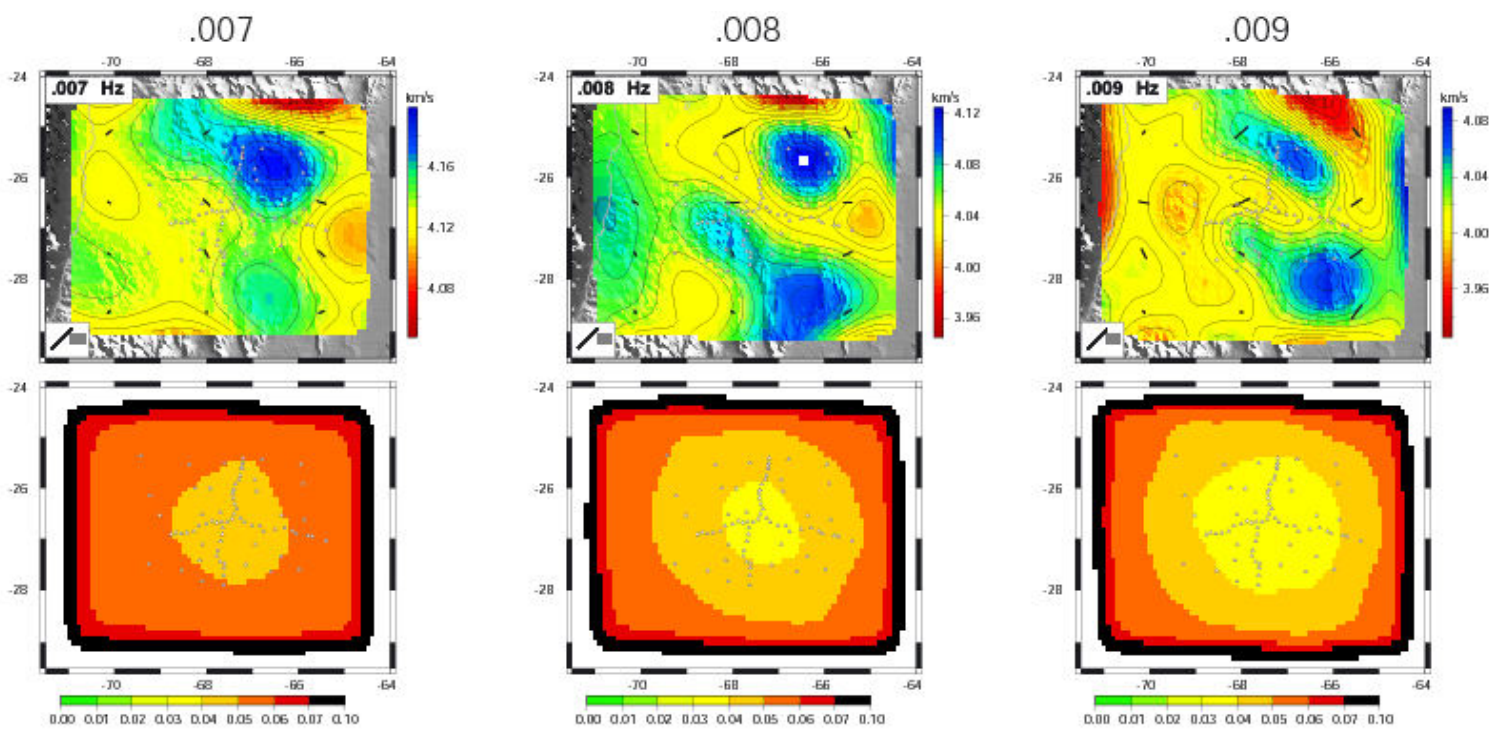

.01

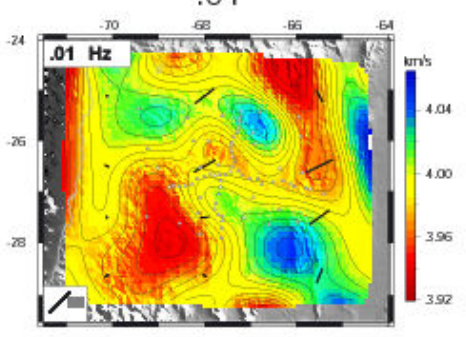

\section{.0125}

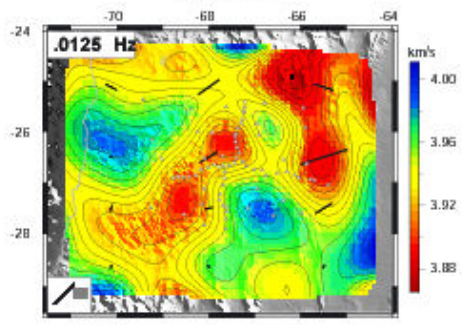

.015
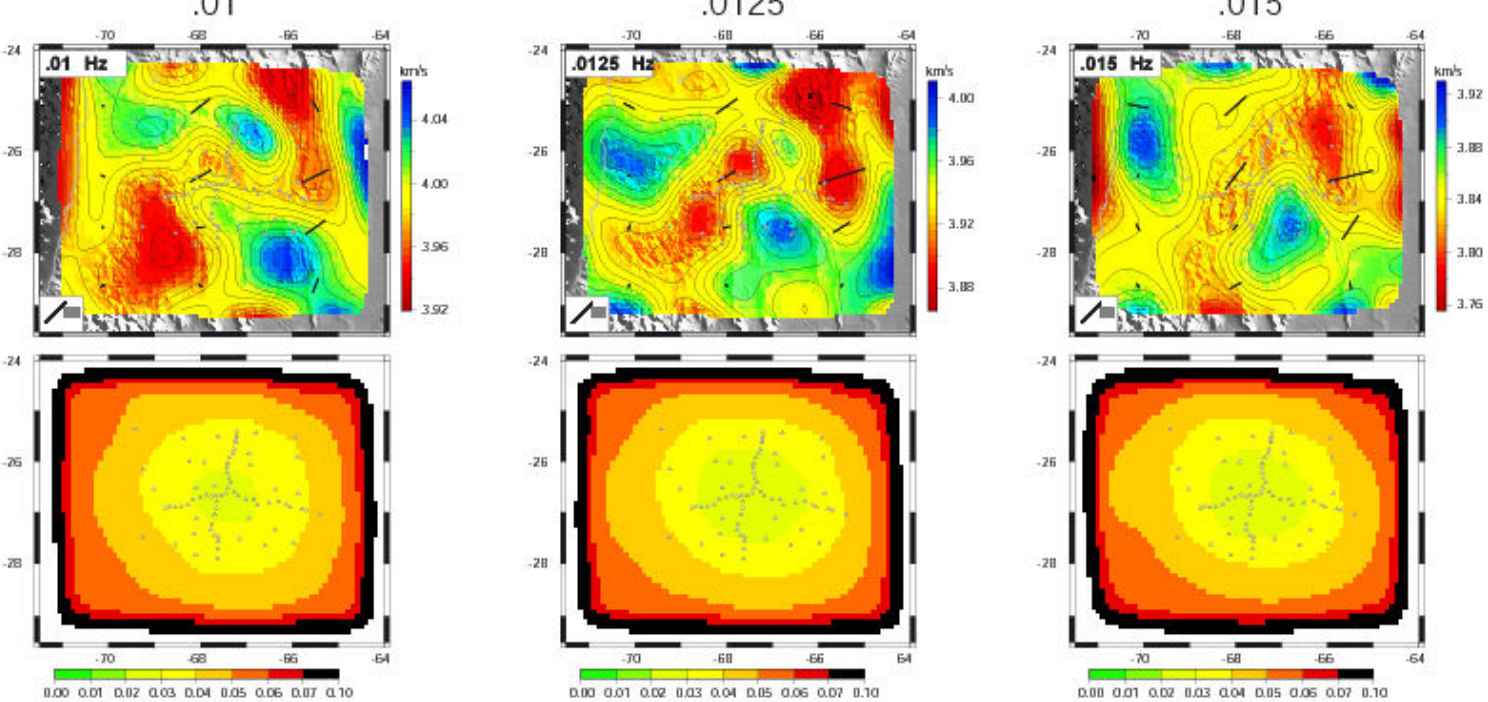

Figure 2.3.S. Rayleigh wave phase velocities from frequencies bands from $0.007 \mathrm{~Hz}$ to $0.015 \mathrm{~Hz}$. The corresponding standard deviation is plotted below each phase map. 
.02
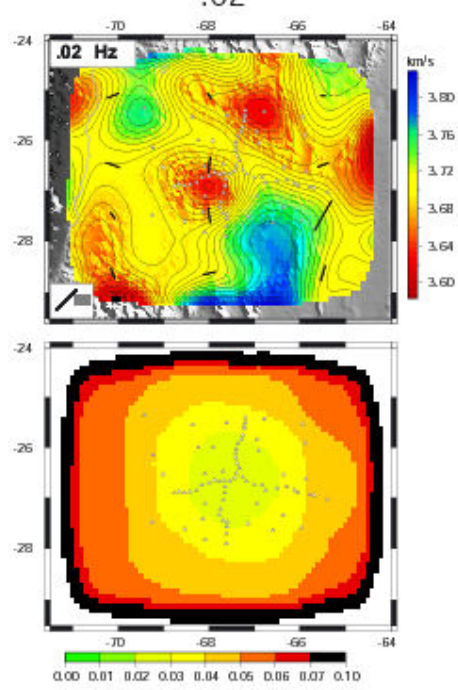

.035
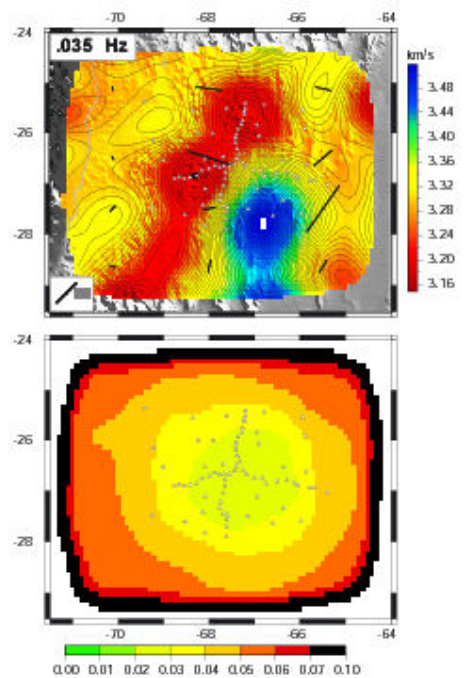

.025
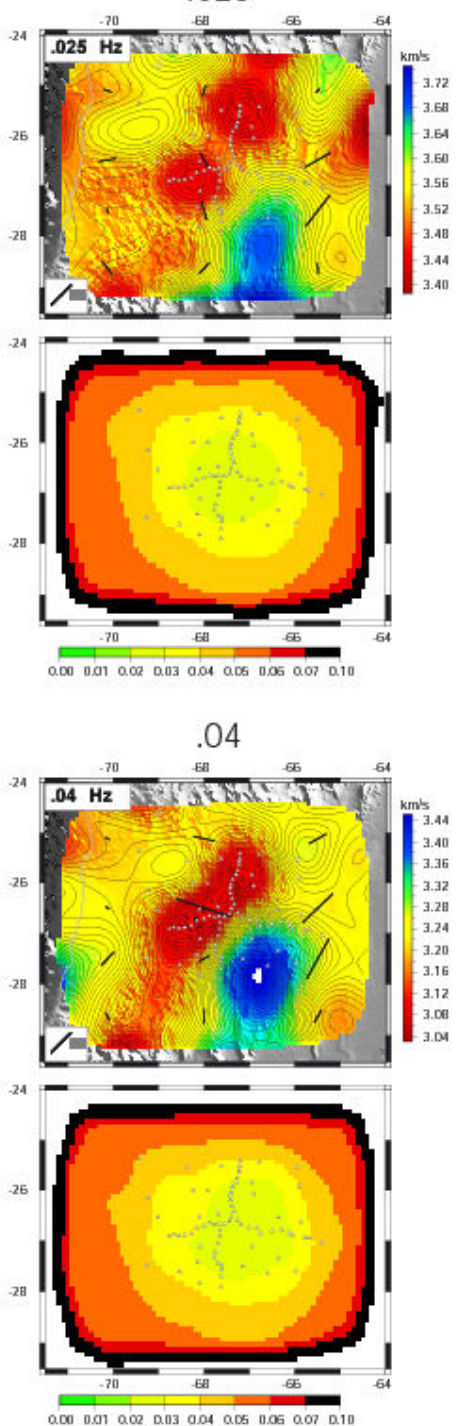

.03
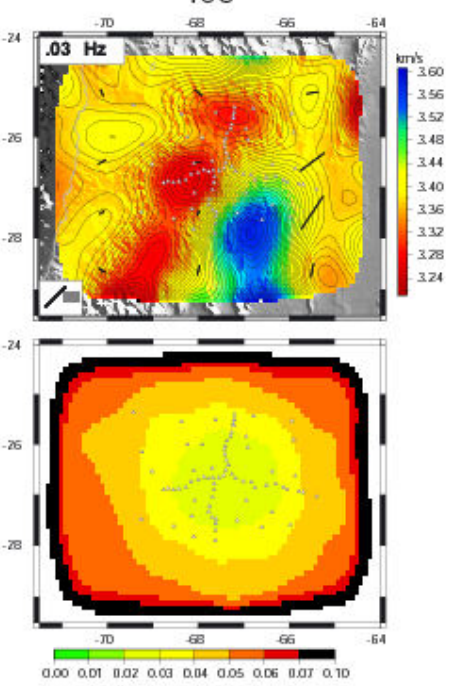

.045

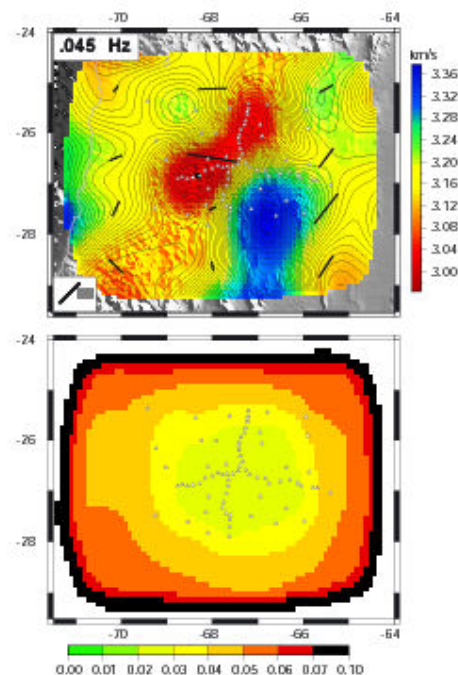

Figure 2.4S. Rayleigh wave phase velocities from frequencies bands from $0.020 \mathrm{~Hz}$ to $0.045 \mathrm{~Hz}$. The corresponding standard deviation is plotted below each phase map. 


\title{
CHAPTER 3
}

\section{SHEARWAVE SPLITTING AND SHEAR WAVE SPLITTING TOMOGRAPHY OF THE SOUTHERN PUNA PLATEAU}

\author{
Manuscript submitted for publication to \\ Geophysical Journal International
}

\begin{abstract}
I have investigated the seismic anisotropy beneath the Central Andean southern Puna plateau by applying shear wave splitting analysis and shear wave splitting tomography to local S-waves and teleseismic SKS, SKKS and PKS phases. Overall, a very complex pattern of fast directions throughout the southern Puna plateau region and a circular pattern of fast directions around the region of the giant Cerro Galan ignimbrite complex are observed. In general, teleseismic lag times are much greater than those for local events which are interpreted to reflect a significant amount of sub and inner slab anisotropy. The complex pattern observed from shear wave splitting analysis alone is the result of a complex three dimensional anisotropic structure under the southern Puna plateau. Our application of shear wave splitting tomography provides a three-dimensional model of anisotropy in the southern Puna plateau that shows different patterns depending on the driving mechanism of upper mantle flow and seismic anisotropy. The trench parallel a-axes in the continental lithosphere above the slab east of $68 \mathrm{~W}$ may be related to deformation of the overriding continental lithosphere
\end{abstract}


since it is under compressive stresses which are orthogonal to the trench. The more complex pattern below the Cerro Galan ignimbrite complex and above the slab is interpreted to reflect delamination of continental lithosphere and upwelling of hot asthenosphere. The a-axes beneath the Cerro Galan, Cerro Blanco and Carachi Pampa volcanic centers at $100 \mathrm{~km}$ depth show some weak evidence for vertically orientated fast directions, which could be due to vertical asthenospheric flow around a delaminated block. Additionally, our splitting tomographic model shows that there is a significant amount of seismic anisotropy beneath the slab. The sub-slab mantle west of $68 \mathrm{~W}$ shows roughly trench parallel horizontal a-axes that are probably driven by slab roll back and the relatively small coupling between the Nazca slab and the underlying mantle. In contrast, the sub-slab region (i.e. depths greater than $200 \mathrm{~km}$ ) east of $68 \mathrm{~W}$ shows a circular pattern of a-axes centered on a region with small strength of anisotropy (Cerro Galan and its eastern edge) which suggest the dominant mechanism is a combination of slab roll back and flow driven by an overlying abnormally heated slab or possibly a slab gap. There seems to be some evidence for vertical flow below the slab at depths of 200$400 \mathrm{~km}$ driven by the abnormally heated slab or slab gap. This cannot be resolved by the tomographic inversion due to the lack of ray crossings in the sub-slab mantle.

\subsection{INTRODUCTION}

The southern Puna plateau of the central Andes offers an excellent natural laboratory to study the distribution of seismic anisotropy in a region with a spatiallychanging subduction angle (e.g. Cahill and Isacks 1992; Mulcahy et al., 2014) and where crustal and mantle lithospheric delamination has been argued to have occurred 
(e.g. Kay et al., 1994; Calixto et al., 2013; Liang et al., 2014) to explain geologic and geophysical observations including the existence of mafic lavas and giant ignimbrites, a gap of intermediate-depth seismicity, and high topography with large deficit in crustal shortening. Regionally, the southern Puna constitutes the southernmost part of the central Andean Altiplano-Puna plateau (Figure 3.1 and 3.2; see review by Allmendinger et al., 1997). The region is generally characterized by a thin $60-80 \mathrm{~km}$ thick lithosphere with a crustal thickness varying from 40 to $70 \mathrm{~km}$ (Heit et al., 2014). Crustal thickening related to crustal shortening has been argued to account for $70-80 \%$ of the crustal thickness observed (Allmendinger et al., 1997) with the rest being attributed to magmatic addition, crustal flow, and thermal uplift (Isacks 1988; Whitman et al., 1996). The thermal uplift has been argued to be due to mechanical thinning of the lithosphere by delamination (e.g. Kay and Kay, 1993; Kay et al., 1994; Calixto et al., 2013, Bianchi et. al, 2013, Liang et. al, 2014) with decompression melting after delamination in an expanding mantle wedge over a steepening subduction zone being the source of the thermal uplift (Kay and Coira, 2009; Risse et al., 2013). The thermal effects of crustal and lithospheric delamination have been associated with the distinctive southern Puna mafic volcanism and giant ignimbrite eruptions, a gap in intermediate depth seismicity (e.g. Mulcahy et al., 2014) and a late Miocene change (Risse et al., 2008) from an uniformly compressive to more chaotic stress regime (e.g. Marret et al., 1994). A high velocity body above the slab under the Cerro Galan ignimbrite region has been interpreted as the most recent delaminated block (Calixto et al., 2013). 


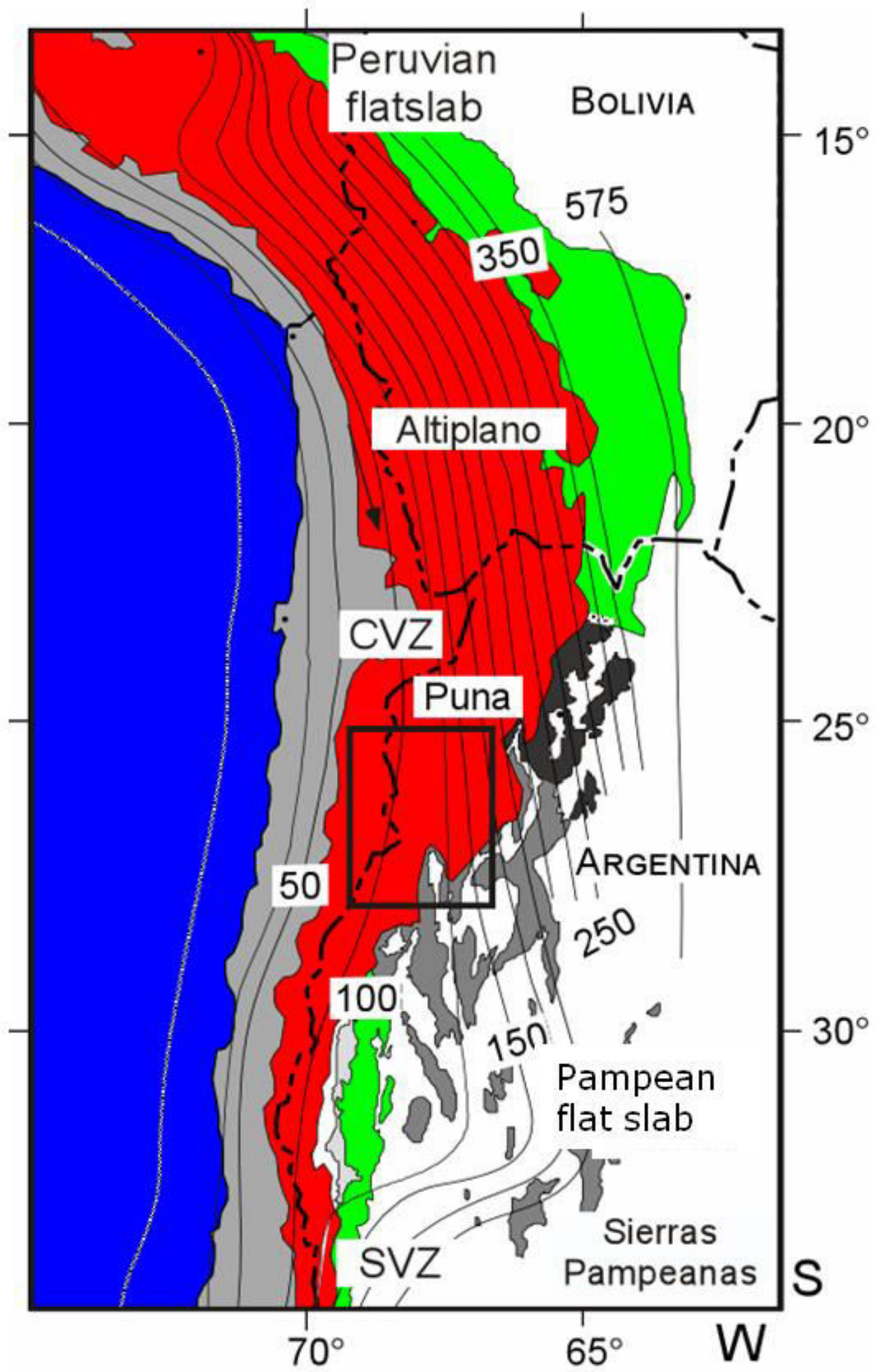

Figure 3.1. Andean Orogeny and region of study - Southern Puna Plateau, shown in the black rectangle. The central and southern volcanic zones (CVZ and SVZ) are shown. Slab contours (Cahill and Isacks, 1992) show the southward transition from shallow subduction to normal subduction. 


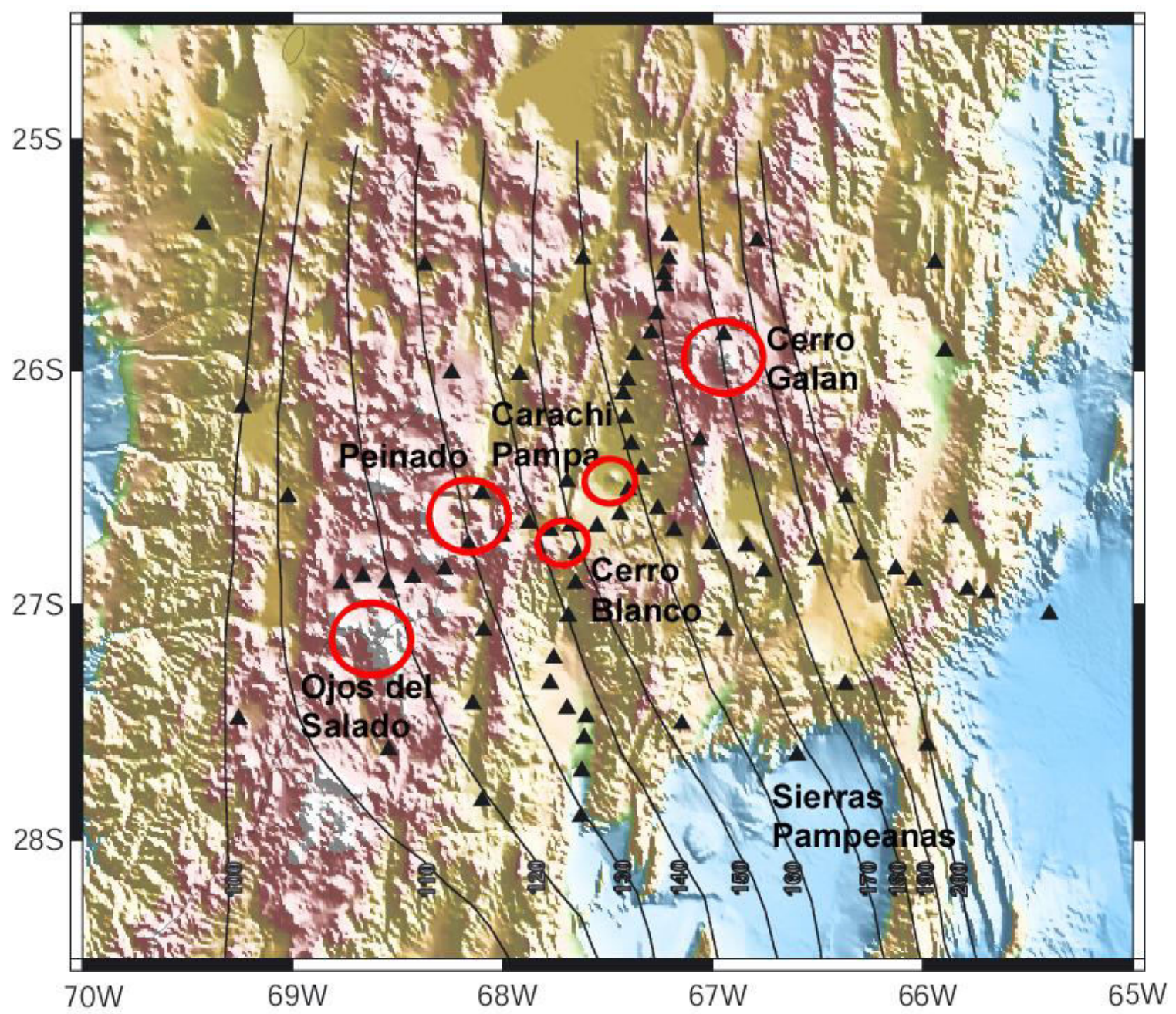

Figure 3.2. Seismic station distribution (black triangles) along the Southern Puna Plateau. Cerro Galan, Ojos del Salado, Cerro Blanco, Carachi Pampa, and Peinado volcanic centers are shown, as well as the Sierras Pampeanas flat subduction region. The slab contours from 100 to $200 \mathrm{~km}$ depth are also shown (Mulcahy et al., 2013)

In order to understand the geodynamics of a subduction zone, with the added complexity of delamination, it is important to investigate the seismic anisotropy related to mantle flow around the subducting slab. This seismic anisotropy is produced by strain-induced lattice preferred orientation of minerals in the upper mantle (Nicolas and Christensen, 1987; Ribe and Yu, 1991; Ribe, 1992, Kaminski and Ribe, 2002), which causes shear waves to split into fast and slow polarized waves. Seismic anisotropy in 
the asthenosphere is likely due to flow controlled by the subducting plate dynamics (Long and Silver, 2008), and possibly by spatial variation of mantle density (e.g. Silver and Holt, 2002). In the case of the Puna plateau, slab geometry (Mulcahy et. al, 2014), partially heated slab or possibly a slab gap (Calixto et. al, 2013) and delamination (Kay and Coira, 2009; Calixto et. al, 2013) could play an additional role in generating the spatial contrast in density and consequently, cause localized flow and complex patterns of seismic anisotropy. Here, we use shear wave splitting analysis and shear wave splitting tomography to estimate the seismic anisotropy structure of the region and to investigate the effect of delamination on asthenospheric and lithospheric mantle flow. The seismic data used in the study were recorded on 43 US and 30 German broadband three component seismic stations in an array, which was deployed for approximately two years in the southern Puna project (Figure 3.2; see Heit et al., 2014 and Mulcahy et al., 2014).

\subsection{SHEAR WAVE SPLITTING ANALYSIS}

\subsubsection{METHODOLOGY}

This study uses both teleseismic SKS, SKKS and PKS and local shear waves to measure shear wave splitting, which occurs when a shear wave travels through an anisotropic medium, and investigate the seismic anisotropy in the southern Puna plateau. In general, mantle seismic anisotropy generally occurs when aggregates of anisotropic mantle minerals, particularly olivine and orthopyroxene, align in a coherent direction; also know as lattice preferred orientation (LPO). Previous studies have found that in the case of olivine this direction tends to be parallel to the direction of maximum finite 
strain (Ribe, 1989). More recent studies have found that the relationship between LPO and maximum finite strain could be more complex involving other factors such as: strain rate (Kaminski and Ribe, 2002), strain history, shear direction and dynamic recrystallization (Karato, 1987), water and stress (Jung et al., 2006), pressure (Couvy, 2007; Mainprice 2005), and melt (Holtzman, 2003; Kaminski, 2006). Karato et al., 2008, summarizes most of these factors. In summary, olivine a-axes align close to the direction of mantle flow in regions where flow patterns change slowly in space; however the relationship of LPO to strain is more complex where the mantle flow is more complex. This means that the olivine a-axes will align close to the direction of flow only if the time it takes the LPO to develop is smaller than time over which the geometry of strain changes along the flow-lines (Kaminski and Ribe, 2002).

If the LPO can be related with the direction of flow, or deformation, then shear wave splitting can be used to study the flow in the upper mantle. Shear wave splitting is then calculated using two parameters: the polarization of the fast shear wave component $(\varphi)$ and the lag time between fast and slow split shear waves (dt). Here, both splitting parameters are estimated following Silver and Chan (1991) by minimizing the second eigenvalue in the covariance matrix formed by the horizontal components. In the case of teleseismic shear waves the splitting parameters were obtained by grid searching around the best parameters that minimize the energy in the tangential component. Quality control was performed by visually inspecting the radial versus tangential particle motion plot for all of the events after correcting for splitting. A linear particle motion indicates that the splitting has been successfully removed and estimated parameters are most likely reliable. In contrast, residual elliptical or more complex particle motions 
indicate the estimated parameters are unreliable, most commonly due to a low signal to noise ratio.

\subsubsection{DATA AND OBSERVATIONS}

Shear wave splitting analysis was applied to both local and teleseismic events recorded by the southern Puna array (Figure 3.2). The local events provide information on anisotropy between the slab and the surface whereas the teleseismic events elucidate anisotropy between the core-mantle boundary and the surface. Incidence angles for local events can vary between 0 and 90 degrees whereas teleseismic incidence angles are typically less than 10 degrees. In this study, we used local events with depths greater than $100 \mathrm{~km}$ and incidence angles less than 35 degrees to avoid free surface effects, shallow interface phase shifts and phase conversions. Since local events have a variety of polarization directions and angles of incidence, they give more detailed information on anisotropy than teleseismic events.

Figures 3.3a-c summarizes the shear wave splitting measurements discussed in this paper. The teleseismic events in Figure 3.3b show an average lag time of 1.96 seconds with the westernmost stations showing mostly trench parallel with a slight east component fast directions. The fast directions transition to mostly trench orthogonal further east but west of Cerro Blanco (west of $68 \mathrm{~W}$ ). Further east, the fast directions measured in stations around the Cerro Galan ignimbrite complex seem to outline a circular pattern. The lag times measured in the stations around Cerro Galan drop to an average of around 1 second and can be seen in the significantly short lines in Figure 
$3.3 \mathrm{~b}$ as compared to surrounding regions. Fast directions south of $27 \mathrm{~S}$ tend to have complex mix of trench parallel and trench orthogonal fast directions.

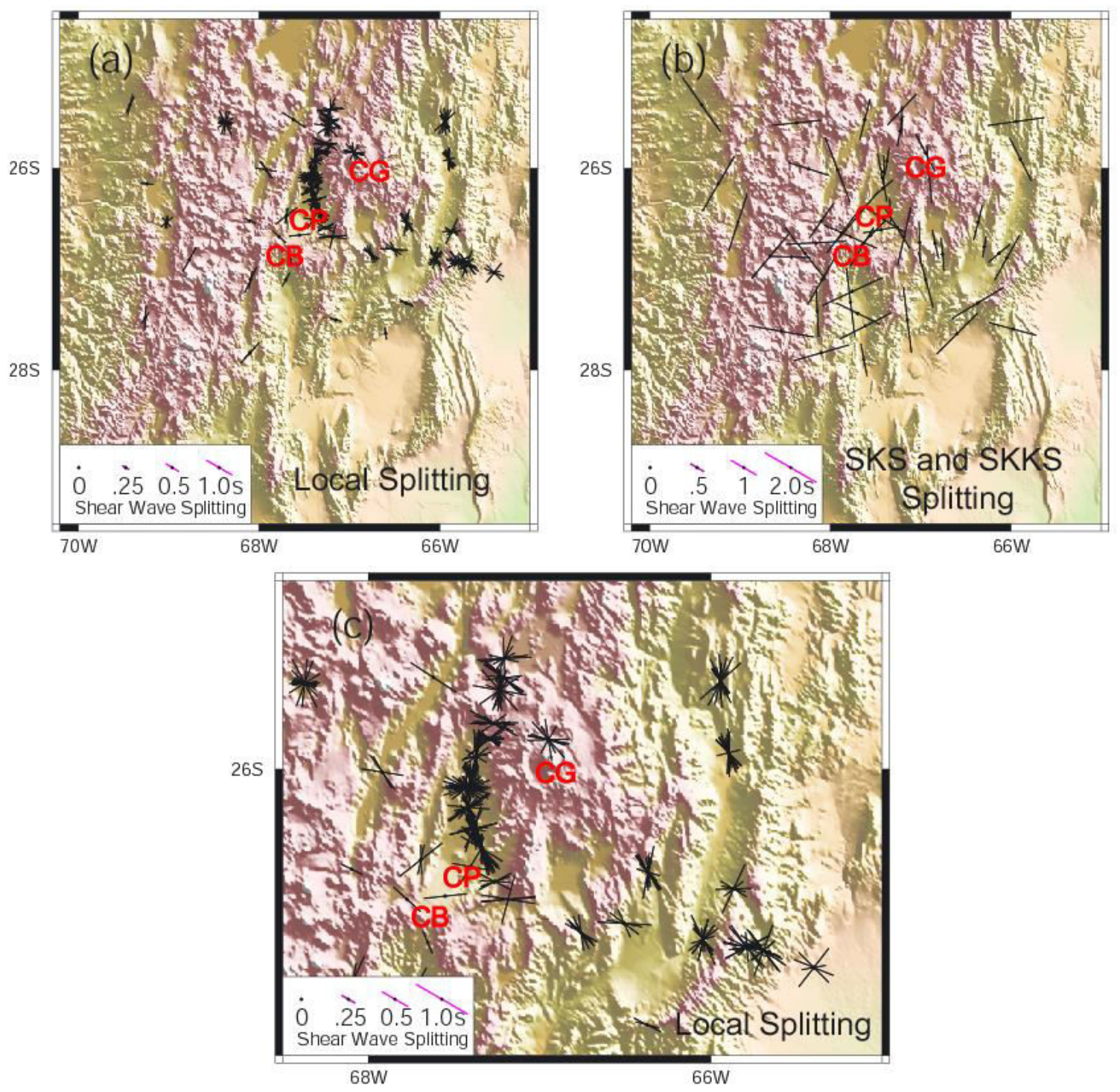

Figure 3.3. (a) Local and (b) teleseismic (SKS and SKKS) shear wave splitting results (black lines) plotted at the stations that recorded the respective seismic phase.(c) Zoom in for the Cerro Galán ignimbrite complex shown in (a). Cerro Galan ( CG), Carachi Pampa (CP) and Cerro Blanco (CB) volcanic centers are shown for reference. Average local lag time is $0.5 \mathrm{~s}$ and average teleseismic lag time is $2 \mathrm{~s}$. 
The local splitting events displayed in Figures 3.3a and 3.3c show a much more complex pattern both in fast direction orientations and lag times averaging 0.58 seconds. Like the teleseismic events, they show a rotation of fast directions around Cerro Galan and approximately trench parallel fast directions towards the west of the array. The lag times drop to less than 0.4 seconds to the southeast of the Cerro Galan region where the slab shallows. Significant differences in fast directions at the same station from different sources (paths) are suggested to be indicative of the 3-D anisotropic structure beneath the southern Puna plateau.

\subsection{SHEAR WAVE SPLITTING TOMOGRAPHY}

\subsubsection{METHOD}

Shear wave splitting is generally characterized by good lateral resolution with very poor vertical resolution (Savage, 1999). Although it is possible to get an idea of the depth of anisotropy by direct comparison between the lag times of teleseismic and local events, a tomographic inversion can be done in order to determine a three dimensional anisotropic structure. We performed a tomographic inversion using a recently developed method that has been used to resolve the three-dimensional anisotropic structure beneath Nicaragua and Costa Rica (Abt and Fischer, 2008; Abt et al., 2009). The inversion assumes a mantle composed of $70 \%$ olivine and $30 \%$ orthopyroxene. Experimentally determined elastic constants, pressure and temperature derivatives for olivine are also considered. At crustal depths the inversion continues to assume mantle mineralogy because the local events considered are deeper than $100 \mathrm{~km}$, resulting in ray 
paths that are primarily in the mantle. In addition, we have consistently observed crustal shear wave splitting lag times are smaller $(\sim 0.2 \mathrm{~s})$ than the average local event splitting lag times of $0.58 \mathrm{~s}$ and are not likely to cause significant differences when making the above simplification.

Using the orthorhombic symmetry of both minerals we set the lattice preferred orientation such that the "a" axis of olivine is parallel to the "c" axis of orthopyroxene, and the "b" axis of olivine is parallel to the "a" axis of orthopyroxene. We assume the "c" axis of olivine to be horizontal yielding a hexagonal symmetry defined solely by two angles: $\theta$ (azimuth of the [ $\left[\begin{array}{lll}1 & 0 & 0\end{array}\right]$ axis) and $\psi$ (dip of the $\left[\begin{array}{lll}1 & 0 & 0\end{array}\right]$ axis). The degree of anisotropy is controlled by a parameter " $\alpha$ " called the strength parameter, which varies from $0 \%$ to $100 \%$. This strength parameter reduces the effect of anisotropy on the predicted delay time in each model block relative to that from its single crystal value. Hence, our model vector is defined by the combination of the three parameters $\theta, \psi$ and $\alpha$.

The forward calculation of predicted shear wave splitting parameters $(\varphi, d t)$ is done using the approximate particle motion perturbation method of Fischer et al. (2000) which allows for 3-D distributions and orientations of anisotropy. The effects of anisotropy in each block along a ray path are calculated by progressively rotating and time-shifting the horizontal components of a simple wavelet that has an initially linear particle motion. We use initial polarizations estimated from our local events shear wave 
splitting observations that were estimated using a grid search algorithm that minimizes the energy in the radial component.

For the inversion we investigated starting models in which the distribution of anisotropy parameters is uniform, random and based on averaging of our shear wave splitting measurements. In an average starting model, the orientation and strength of anisotropy were obtained by averaging the splitting parameters that sample the block, weighting them by their path lengths in the block. We settled on the average starting models presented here, as they show the smallest residuals (differences between observed splitting parameters and those predicted by the best-fitting model) considering our station-earthquake distribution. Abt and Fischer (2008) also reported smaller residuals in Central America with an average starting model.

In order to determine the seismic anisotropy beneath and within the subducting Nazca lithosphere, we include teleseismic shear wave splitting measurements. We assume that these teleseismic phases integrate anisotropy from $400 \mathrm{~km}$ depth to the surface. This is a common assumption and is based on the observation that splitting fast directions are similar regardless of propagation direction, which indicates that the region below the upper mantle is fairly isotropic (Savage, 1999; Silver and Chan, 1991; Niu and Perez, 2004). In addition, other studies have also found the mantle transition zone to be approximately isotropic (Mainprice and Silver, 1993; Barruol and Mainprice, 1993; Vinnik et al., 1992, 1995, 1996) and the lower mantle is generally regarded as being isotropic. While this is likely to be true beneath ocean basins, it may not be 
necessarily the case in subduction zones (Long and Becker, 2010). Specifically, the base of the lower mantle, D', is believed to exhibit both azimuthal and polarization anisotropy (Yamazaki and Karato, 2007; Lynner and Long, 2012) and the lower mantle beneath Southern America is not exception (Vanacore and Niu, 2011).

Using this approach, we considered a set of virtual hypocenters for a given teleseismic event. The number of virtual hypocenters depends upon the number of stations that recorded a particular event. We calculated the angles at which the rays reached $400 \mathrm{~km}$ depth and then back projected the location of the virtual hypocenters with respect to each station down to $400 \mathrm{~km}$. Because the teleseismic rays are close to being vertical and very few of them cross, anisotropy within and below the slab cannot be separately resolved, and only average anisotropy is estimated at these depths.

We used a linearized damped least squares inversion (Tarantola, 1987) to find the best fitting model of anisotropy $(\theta, \psi$ and $\alpha$ : crystallographic orientation and strength of fabric alignment combination). This was done by minimizing the misfit between the observed and predicted shear wave splitting parameters. The G matrix (the matrix of partial derivatives used in the inversion) was numerically calculated by varying model parameters and measuring the resulting changes in predicted splitting parameters (fast direction and lag time). The G matrix was recalculated when the model parameters changed by more than 1 degree (in the case of $\theta, \psi$ ) or $1 \%$ (in the case of $\alpha$ ) between iterations. We also weighted the data using their errors. In order to keep the changes in model parameters small enough that the linear partial derivatives are valid 
during all iterations, we damped the inversion. A total of 100 iterations and $50 \mathrm{~km}^{3}$ size blocks were used. We ran two inversions, the first one using only the 115 teleseismic rays containing our best shear wave splitting results (results not shown here), and the second using 556 rays that come from combining the best teleseismic rays (115) with the 441 rays from the local shear wave splitting measurements.

\subsubsection{RESOLUTION}

\subsubsection{RESOLUTION MATRIX}

One of the advantages of the matrix inversion technique is that it provides a direct way to calculate the resolution of the model parameters. Plots of the resolution matrix in the supplementary material show the diagonal values of the model resolution matrix for the three model parameters: the strength of anisotropy $(\alpha)$, azimuth $(\theta)$ and $\operatorname{dip}(\psi)$. As expected, the highest resolution tends to be concentrated at the shallower depths and around the stations. For depths $50-200 \mathrm{~km}$, the region of good resolution tends to move towards the epicenter of the local events, north and south of the array. For depths below $200 \mathrm{~km}$ we observe some isolated regions of high resolution centered on virtual epicenters of the teleseismic events. In general, the resolution is highest for the strength of anisotropy, lower for the azimuth and lowest for the dip. In the case of the dip, there are no regions of good resolution beneath $150 \mathrm{~km}$ as there are few crossing rays at those depths. Overall, the resolution is fairly good at the depth range 0$100 \mathrm{~km}$, which is where most of the rays cross. 


\subsubsection{CHECKERBOARD TEST}

Using the distribution of local event and teleseismic paths in the real dataset, we tested model resolution using a checkerboard test. Figure 3.4a shows the input checkerboard model of a-axes orientations with alternating horizontal east-west and north-south orientations in blocks of $100 \mathrm{~km}^{3}$. Figures $3.4 \mathrm{~b}$-e show the models obtained from an average starting model after 100 iterations at depth ranges of $0-100,100-200$, 200-300 and 300-400 km; only the blocks sampled by phase paths are shown.

The recovery of the input model is best in the $0-100 \mathrm{~km}$ layer within the blocks spanned by the stations. Recovery decreases with increasing depth as expected from the resolution matrix results.

Figure 3.5 shows the difference between checkerboard a-axes orientations and inverted orientations using synthetic shear waves and the real station and event distribution for depth ranges of $0-100,100-200,200-300$ and $300-400 \mathrm{~km}$. The fit is good (blue) for regions covering the stations and local events for depths of $0-300 \mathrm{~km}$ (Figure 3.5a-c) but decreases as depth increases. Regions of good fit cover part of the station array but not the local events at depths of $300-400 \mathrm{~km}$. 
(a) checkerboard

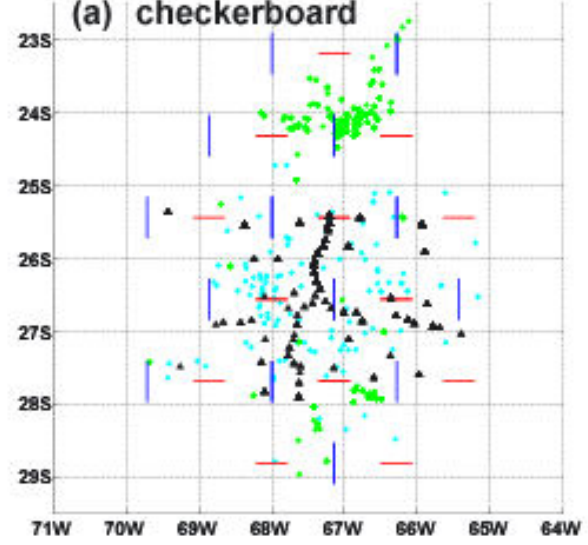

(b) $0-100 \mathrm{~km}$
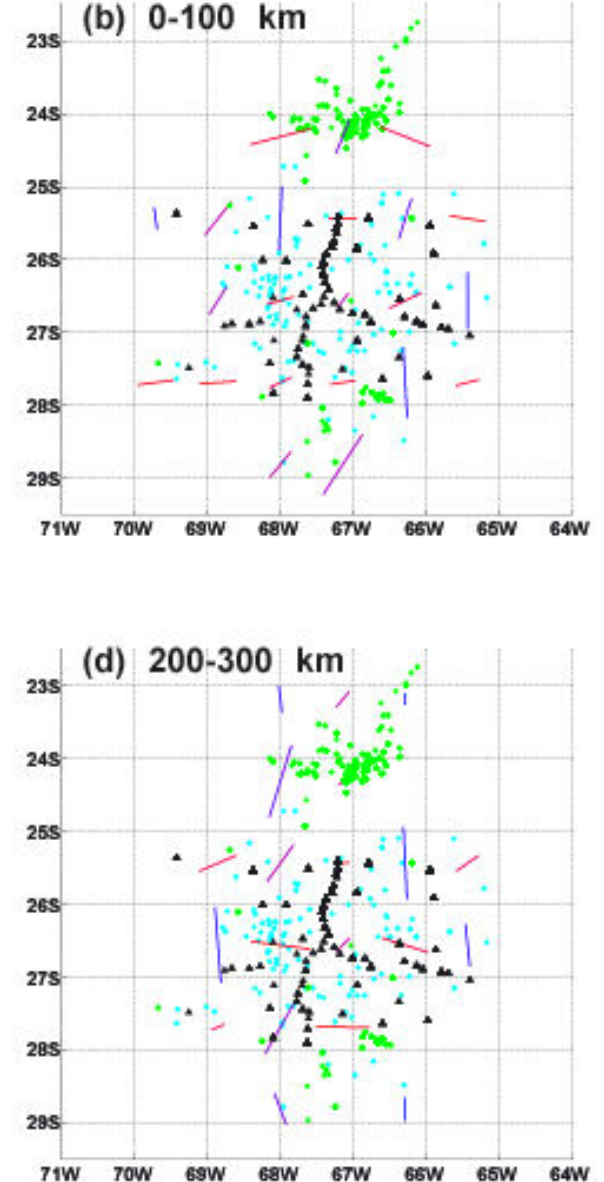

(c) $100-200 \mathrm{~km}$

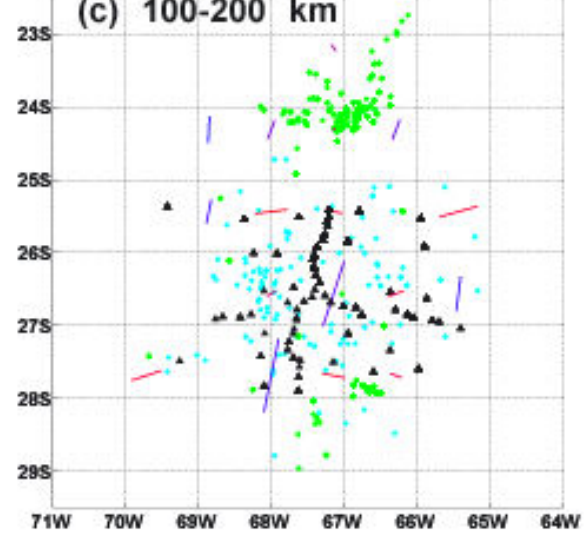

(e) $300-400 \mathrm{~km}$

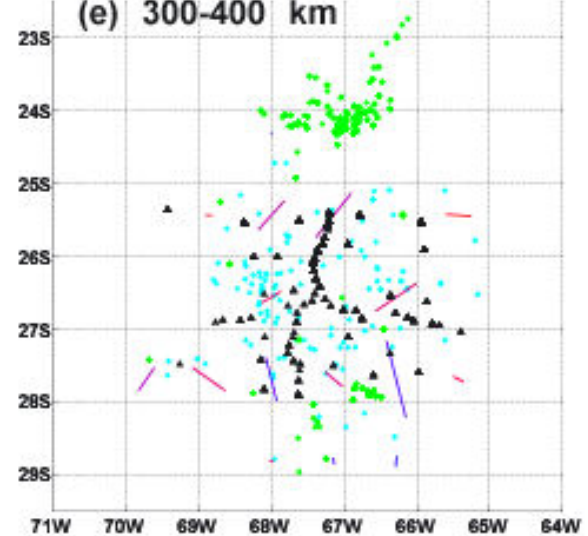

Figure 3.4. (a) Checkerboard with east-west and north-south fast direction with block sizes of $100 \mathrm{~km}$. This pattern repeats for every depth up to $400 \mathrm{~km}$. Local seismicity is shown as green dots and teleseismic pseudo epicenters are shown as cyan dots. The stations are represented by black triangles. (b) Checkerboard results for depths 0-100 $\mathrm{km}$, (c) $100-200 \mathrm{~km}$, (d) $200-300 \mathrm{~km}$ and (e) 300-400 km. Overall the checkerboard is roughly recovered with resolution decreasing with increasing depth. 

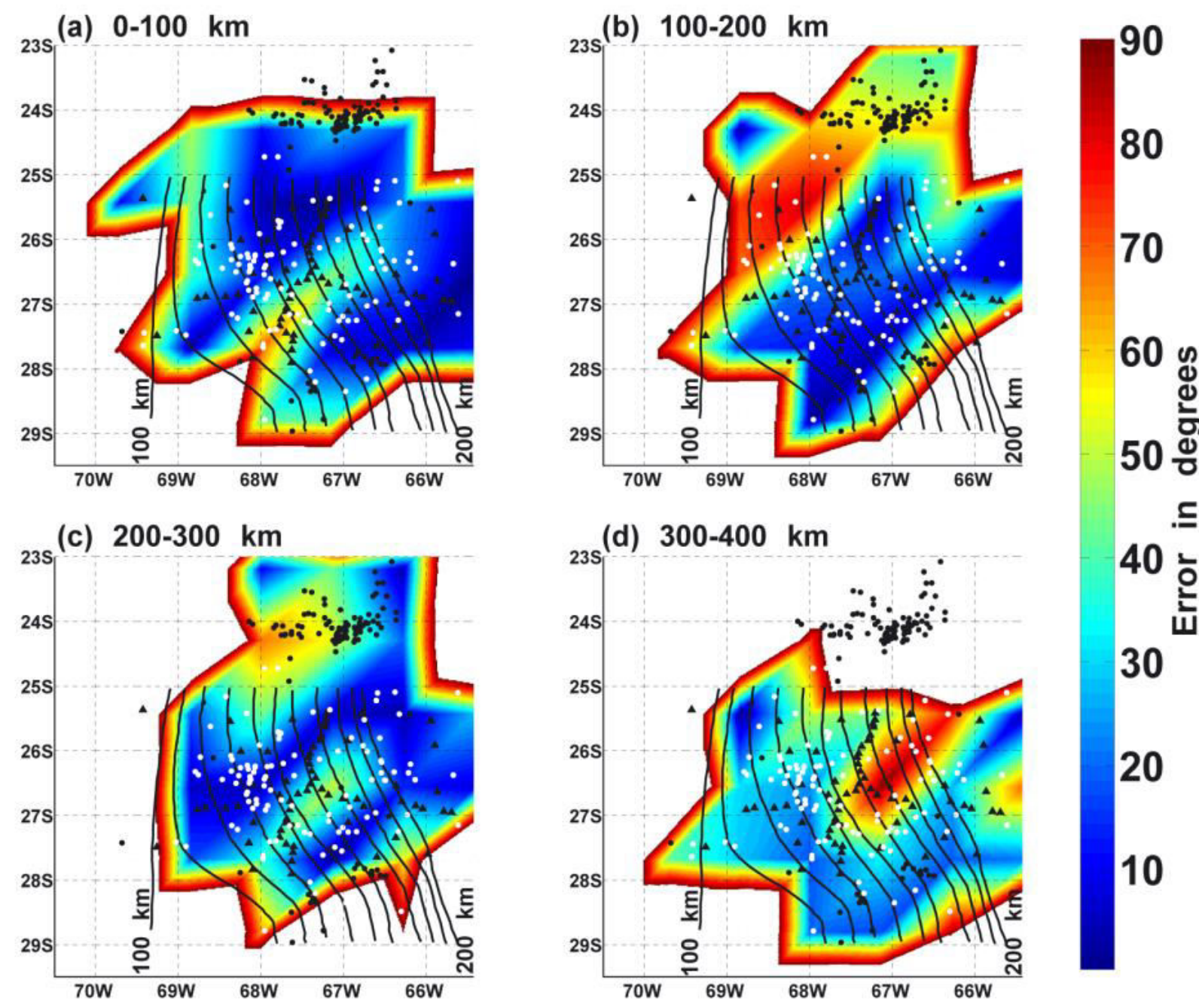

Figure 3.5. Difference between checkerboard fast direction azimuths and inverted azimuths using synthetic shear waves and the real seismic station and earthquake distribution for depth ranges of (a) 0-100 km, (b) 100-200 km, (c) 200-300 km and (d) $300-400 \mathrm{~km}$. The seismic stations are shown as black triangles, local events as black dots and pseudo teleseismic epicenters as white dots. The slab contours (Mulcahy et al., 2010) for depths $100-200 \mathrm{~km}$ in intervals of $10 \mathrm{~km}$ are shown as black solid lines. 
(a) $0-100 \mathrm{~km}$
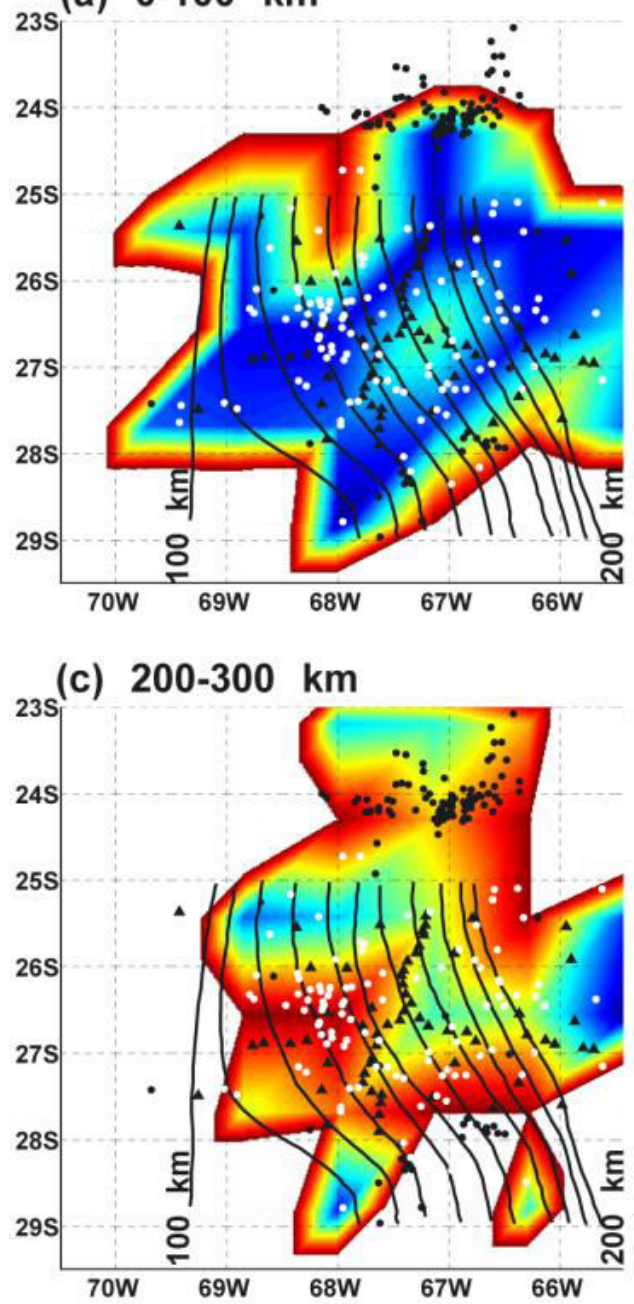

(b) $100-200 \mathrm{~km}$
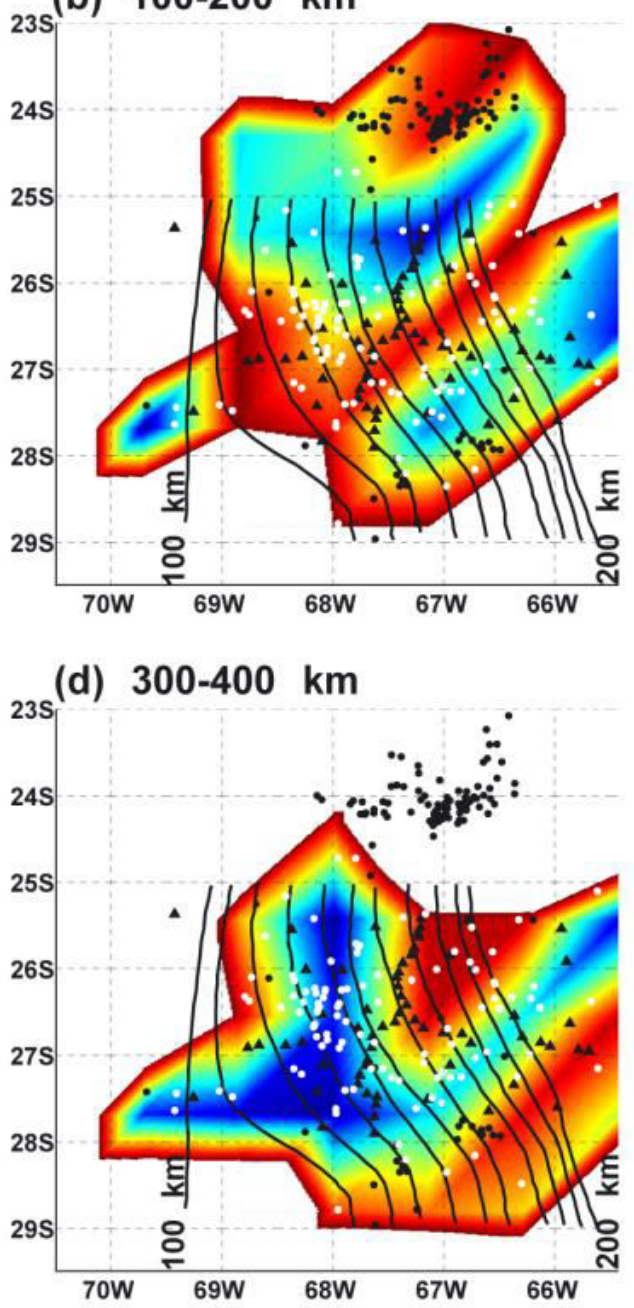

Figure 3.6. Difference between checkerboard strength of anisotropy values and inverted strength of anisotropy values using synthetic shear waves and the real seismic station and earthquake distribution for depth ranges of (a) 0-100 km, (b) 100-200 km, (c) 200$300 \mathrm{~km}$ and (d) $300-400 \mathrm{~km}$. The seismic stations are shown as black triangles, local events as black dots and pseudo teleseismic epicenters as white dots. The slab contours (Mulcahy et al., 2010) for depths 100-200 km in intervals of $10 \mathrm{~km}$ are shown as black solid lines.

Figure 3.6 shows the difference between checkerboard strength of anisotropy values and inverted strength of anisotropy values using synthetic shear wave and the real station-event distribution for ranges of 0-100, 100-200, 200-300 and 300-400 km. In this case, we only observe good fit (blue regions) for depths of 0-100 km (Figure 3.6a) 
that covers most of the stations and part of the region where the local events are originated.

\subsubsection{SHEAR WAVE SPLITTING TOMOGRAPHY RESULTS}

Figure 3.7 and 3.8 show the results when using 556 ray paths in the inversion, which combines 115 teleseismic ray paths with 441 local shear wave splitting measurements. The blue and red lines' orientation and length represent the a-axes orientation and strength of anisotropy, respectively. The blue lines are most closely oriented north-south, and the red lines are most closely oriented east-west. Figure 3.7 shows the views of a-axes and strength of anisotropy for 0-100, 100-200, 200-300 and $300-400 \mathrm{~km}$ depth slices. Beneath the western part of the array, we observe a-axes mainly oriented parallel to the trench and exhibiting a slight change to a north-east direction with increasing depth. On average, the strength of anisotropy decreases towards the west of the array, where the mantle wedge thins. At depths of less than 200 km (Figures 3.7a-b), a rotation of the a-axes beneath Cerro Galan and Cerro Blanco occurs, and in some cases they transition to an east-west direction. At greater depths (see Figures 3.7c-d), there is evidence for both trench parallel and trench orthogonal aaxes orientations throughout the southern Puna plateau with some complexities around Cerro Galan. 

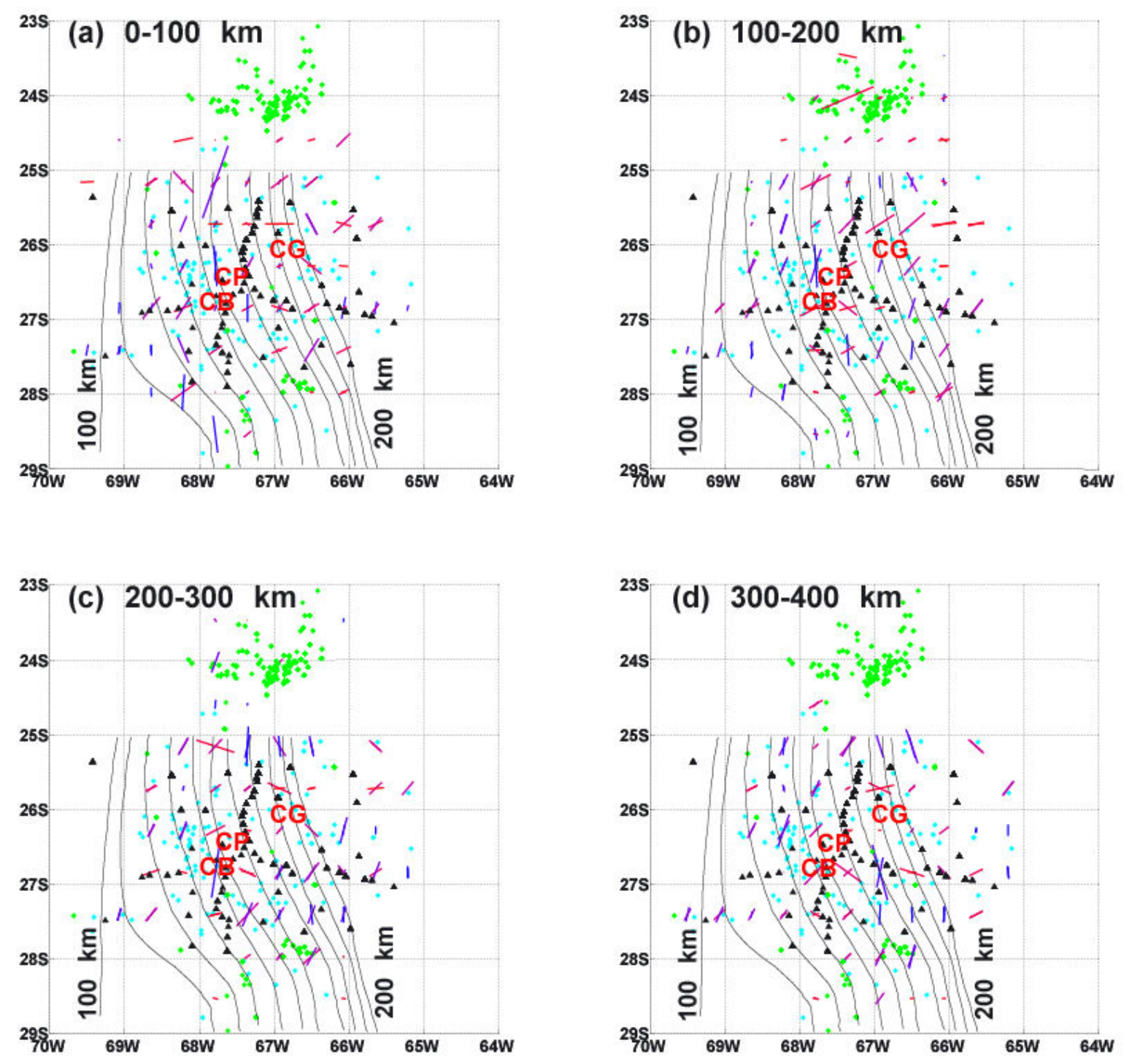

Figure 3.7. Map view of shear wave splitting tomography with 556 (teleseismic and local earthquake) rays for various depth ranges. The blue and red lines' orientation and length represent the a-axis orientation and strength of anisotropy, respectively. The blue lines are most closely oriented north-south, and the red lines are most closely oriented east-west. Slab contours for 100-200 km depth in $10 \mathrm{~km}$ increments are shown in black thin lines (Mulcahy et al., 2014). The local events are shown as green dots and the teleseismic events as cyan dots. The stations are shown as black triangles. At depths of 0-100 and 100-200 $\mathrm{km}$ there is a rotational pattern around Cerro Galan (CG) that also involves Cerro Blanco (CB) and Carachi Pampa (CP) volcanic centers. Below the slab (200-300 and 300-400 km depth) There is evidence for both trench parallel and trench orthogonal a-axis orientations (blue and red lines) throughout the region except beneath Cerro Galan where the strength of anisotropy decreases significantly and the rotational pattern is not clear. 

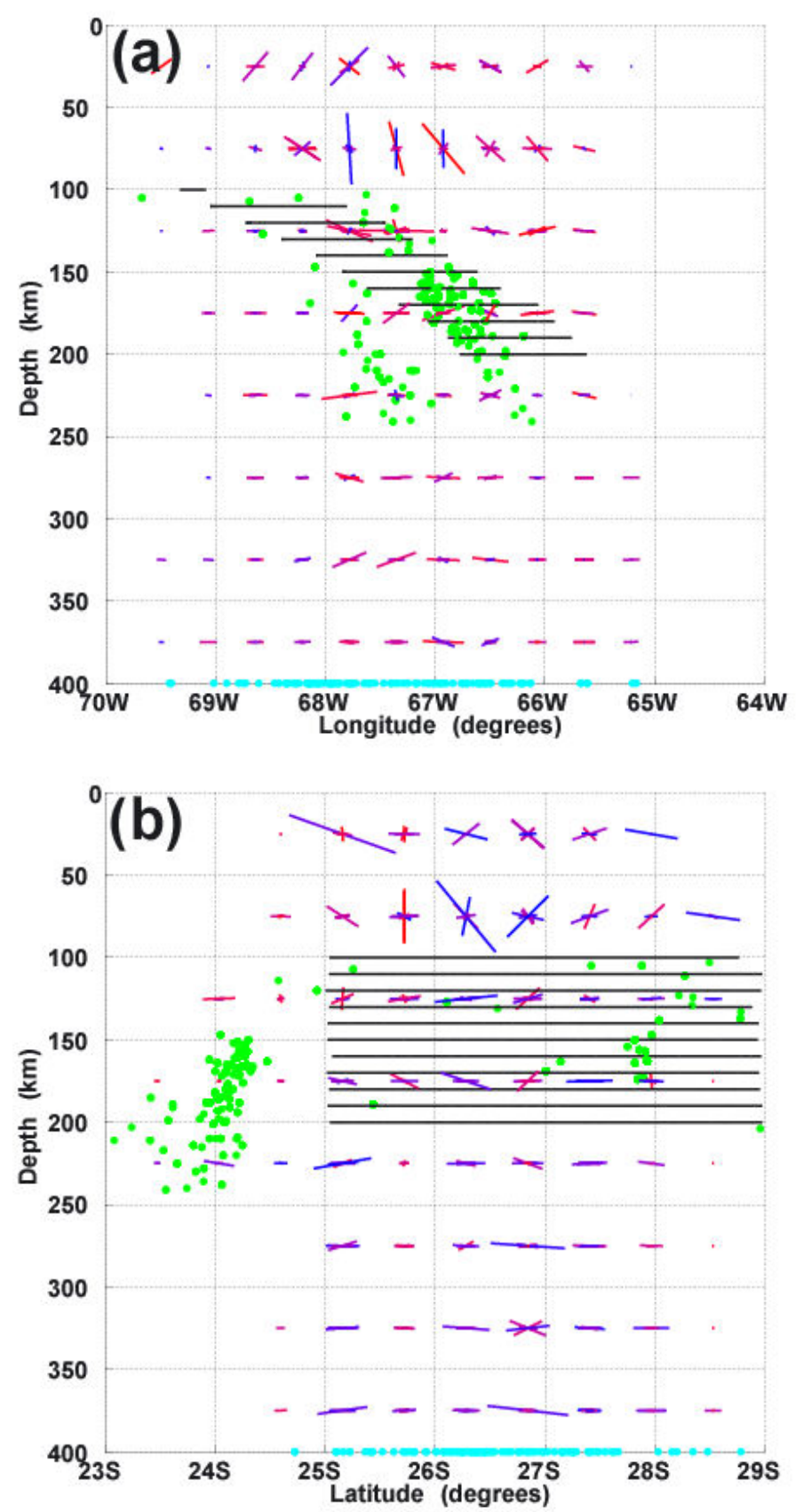

Figure 3.8. (a) Across longitude and (b) across latitude view of the shear wave splitting results with 556 (teleseismic and local earthquake) rays. The blue and red lines' orientation and length represent the a-axis orientation and strength of anisotropy, respectively. The blue lines are most closely oriented north-south, and the red lines are most closely oriented east-west The slab contours are shown as black lines (Mulcahy et al., 2014). Local seismicity is shown as green dots and teleseismic pseudo epicenters are shown as cyan dots at $400 \mathrm{~km}$ depth. There is some evidence for close to vertical fast directions beneath Cerro Galan (CG) and Cerro (CB) Blanco ignimbrite complexes. aaxis are mostly horizontal below the slab. 
Interestingly, the results beneath Cerro Galan show that the strength of anisotropy is smaller than that of adjacent regions (Figures 3.7c-d). Figure 3.8 shows the results versus depth as viewed from the south and west of the seismic station array. Figure 3.8 shows that the slab and sub-slab anisotropy tend to be mainly horizontal and that there is a region in the mantle wedge (depth range of 50-100 km) between longitudes $66.8^{\circ} \mathrm{W}$ and $68^{\circ} \mathrm{W}$, and latitudes $25.5^{\circ} \mathrm{S}$ and $27^{\circ} \mathrm{S}$ (beneath Cerro Blanco, Carachi Pampa and the west part of Cerro Galan) with evidence of vertical a-axes. It is important to mention that these are better resolved than those in prior inversions using only local splitting measurements or only teleseismic splitting measurements. We have examined the resolution of jointly inverting both observations and found that the resolution degrades when only using local shear wave splitting data.

\subsection{DISCUSSION}

Subduction zones where the slab dip has varied rapidly through time are likely to lead to complex mantle flow and seismic anisotropy and thus complex patterns of shear wave splitting fast directions and delay times (Long, 2012; Druken et. al, 2011). The southern Puna region offers a mantle wedge with such complex anisotropic patterns due to the change in subduction angle from normal to the north to flat south of $27 \mathrm{~S}$ (Mulcahy et. al, 2014), episodes of crustal and lithospheric delamination with upwelling of hot asthenosphere (Kay and Coira, 2009; Calixto et. al, 2013), and a heated slab or, possibly, a slab gap associated with a gap of intermediate depth seismicity (Mulcahy et. al, 2014; Calixto et. al, 2013). The recent episodes of delamination started around $6 \mathrm{Ma}$ 
with the most recent large delamination event at around $2 \mathrm{Ma}$ (e.g. Kay and Coira, 2009) possibly triggered by slab roll back. Cerro Galan is associated with a high velocity-low attenuation body (delaminated crust and lithosphere) at around $140 \mathrm{~km}$ depth beneath the northern edge of Cerro Galan (Calixto et. al, 2013; Liang et. al, 2014, Bianchi et. al, 2013), with widespread crustal melting and an abnormally heated slab (possibly a slab gap) beneath the south-western edge of Cerro Galan. The region has also been subjected to an evolving stress regime with a change from a mainly NW-SE compressive regime during most of the Miocene to a more chaotic regime after the latest Miocene (e.g. Marrett et al., 1994; Risse et al., 2008; Mulcahy et al., 2014).

Given that the region where delamination is observed (west of $68 \mathrm{~W}$ ) might reveal totally different patterns than other regions, we have decided to divide the following

part of the discussion into two sections outlining the patterns observed west and east of $68 \mathrm{~W}$ instead of the usual mantle wedge, slab and subslab division

\subsubsection{WEST OF $68 \mathrm{~W}$}

The western stations of the PUNA array show a clear trend of trench parallel fast directions both in the local and teleseismic shear wave splitting measurements (Figure 3.3). This is also seen in the tomographic inversion at depths of 0-100 and 100-200 km (Figure 3.7a-b) with mostly trench parallel a-axes and a slight rotation to north-east orientation for depths below $200 \mathrm{~km}$ (Figure 3.7c-d). At depths above $130 \mathrm{~km}$ this pattern is most likely not related to mantle wedge corner flow (Long, 2013; Behn et. al, 2007) or 3D flow around the slab (Long and Silver 2008) as the slab depth in this region is around $100-120 \mathrm{~km}$ and there is probably little to no mantle wedge since the 
lithosphere thickness is around 100-130 km in the southern Puna (Calixto et. al, 2013). Moreover, Figure 3.7 shows no major variation in the strength of anisotropy (length of lines in Figure 3.7) with respect to depth west of $68 \mathrm{~W}$, which agrees with the mantle wedge not significantly contributing to the seismic anisotropy in this region. Thus, this pattern is interpreted as splitting produced by horizontal shortening of the continental lithosphere and slab caused by the compressive regime due to the collision of the Nazca and South American plates.

At sub-slab depths (Figures 3.7c-d), the observed trench parallel pattern may reflect anisotropy beneath the slab as affected by slab rollback (Long, 2013; Long and Silver 2009) which causes trench orthogonal flow due to the retreating or steepening slab in the mantle wedge above the slab but trench parallel flow beneath the retreating or steepening slab. This is in agreement with other studies in subduction zones showing sub-slab trench parallel fast directions (Yu and Park, 1994; Gledhill and Stuart, 1996; Gledhill and Gubbins, 1996; Vinnik et al., 1992, Russo and Silver, 1994, Kaneshima and Silver, 1995; Long and Silver, 2008, Abt et al., 2010; MacDougall et al., 2012). The central Andes have a history of trench migration or change subduction angle (Kay and Coira, 2009) which may have lead to a significant amount of sub-slab anisotropy and likely trench parallel splitting (Long and Silver 2008).

The fact that the a-axes at depths below the slab (see west of $68 \mathrm{~W}$ in Figures 3.7c-d) show a slight rotation to the east might indicate a slight, though not significant, coupling of the sub-slab mantle with the subducting slab (Long, 2013; Paczkowski, 
2012). This slight rotation could also be an indicator of roll back being the dominant mechanism driving the flow in the sub-slab area. There are mainly two mechanisms of flow acting at sub-slab depths, namely roll back and the downward motion of the subducting plate (Faccenda and Capitanio, 2012), that tend to produce trench parallel and trench perpendicular fast direction patterns, respectively. However, the observation that most sub-slab a-axes in the western part the array are either trench parallel or slightly rotated to the east suggest that the stronger mechanism driving the flow in this sub-slab area is linked to slab roll back and that the effect of plate advance, or downward motion of the Nazca plate, is less significant. Subduction dip angle, normal in the north and flat in the south, could also be another factor accounting for the nontrench parallel component a-axes in the sub-slab region as it may cause pressure gradients as the slab subducts.

The consistent sub-slab trench parallel a-axes orientations across the western part of the array (west of $68 \mathrm{~W}$ ) suggest that the inversion assumption that all anisotropy is contained in the upper $400 \mathrm{~km}$ is a good approximation and that most sub-slab anisotropy is generated near the slab affected mostly by slab roll back and by a simple shear mechanism. It is known that the D" layer is anisotropic beneath South America (Vanacore and Niu, 2011), but it is not included in the present study for simplicity. If it were included, the tomographic inversion would most likely just spread the anisotropy in the upper mantle to the lower mantle and D". Moreover, the D"' layer may produce both SPO (shape preferred orientation) and LPO (Yamasaki and Karato, 2007) making the results potentially more difficult to interpret. 


\subsubsection{EAST OF 68W}

The region east of $68 \mathrm{~W}$ shows a totally different pattern of seismic anisotropy including more complicated patterns both in local and teleseismic splitting results (Figure 3.3) with mixed evidence for trench parallel and trench perpendicular fast direction. Interestingly, this is sometimes also observed in splitting measurements seen at the same stations (Figure 3.3a), which is consistent with a three-dimensional anisotropic fabric. The region around the volcanic centers of Cerro Galan, Cerro Blanco and Carachi Pampa seems to exhibit a rotation of fast directions in local splittings (Figure 3.7a) and is less pronounced in teleseismic splittings which show a reduction in lag times to an average of 1 second as compared to the $\sim 2$ seconds regional average. The complexity of the patterns is also seen in the splitting tomography results (Figure 3.7) where there seems to be a transition from trench parallel to trench orthogonal aaxes towards the east for at depths of 0-100 and 100-200 km.

At depths of $0-100 \mathrm{~km}$ (Figure 3.7a), the pattern just east of $68 \mathrm{~W}$ most likely still reflects the compression of the lithosphere but it rapidly changes eastward beneath the Cerro Galan ignimbrite, where the inferred delamination of a 50 thick high velocity block and subsequent upwelling of hot asthenosphere (Calixto et. al, 2013, Bianchi et. al, 2013; Liang et. al, 2014) is likely to be the predominant mechanism driving the flow. In this region, the lithosphere is significantly thinner and the patterns start to reflect flow that at some point reached the surface and resulted in the generation of large amounts of crustal melt. The lower crust in this part of the southern Puna is slow and partially molten as shown by shear wave velocity models (Calixto et. al, 2013) and by the blocked high frequency local S-waves traveling beneath Cerro Galan (Liang et al., 
2013, Mulcahy et. al, 2014). Figures 3.8a-b shows some evidence for near vertical aaxes beneath the Cerro Galan, Cerro Blanco and Carachi Pampa volcanic regions at depths of 50-100 km. Importantly, these are all regions where dip resolution is fairly good (see Figure 3.3S of supplementary material). These near vertical fast directions are interpreted to indicate post-delamination asthenospheric upwelling, (Calixto et al., 2013), and manifested by volcanic complexes at the surface. There is no other evidence for fast directions being aligned vertically or close to vertical anywhere else in our model.

At depths of 100-200 km, Figure 3.8 shows only horizontal a-axes orientations. It is important to note that the dip resolution at depths below $100 \mathrm{~km}$ is very poor (See Figure 3.3S) and it is very unlikely that the inversion could resolve any vertical flow. Figure 3.7b shows some trench orthogonal a-axes (red lines) just east of $68 \mathrm{~W}$ and also a very abrupt change in inferred a-axes orientations over short distances. This might be due to the fact that at these depths we are seeing a combination of anisotropy from the slab, sub-slab and also the mantle wedge (see slab contours in Figure 3.7b). In addition, the presence of a heated slab or, possibly, a slab gap beneath the western edge of Cerro Galan at 25.5-26.0S could also influence the patterns observed. The recent delamination events could have imposed a rapid regional change of flow causing a less coherent flow field and a weak LPO (Long and Silver, 2008).

South of $27 \mathrm{~S}$ and east of $68 \mathrm{~W}$ (i.e. southeast of the Cerro Galan region) the local splitting lag times drop to less than 0.4 seconds (Figure 3.3a). This is also observed in 
Figure $3.8 \mathrm{~b}$ as a decrease in the strength of anisotropy. This region is characterized by shallow subduction angle and thus, the observations could be linked to a southward thinning of the mantle wedge rather than to changes in the mantle flow regime.

At sub-slab depths of $200-300 \mathrm{~km}$ and $300-400 \mathrm{~km}$ and east of $68 \mathrm{~W}$, the a-axes are mostly horizontal (Figure 3.8) and there is evidence for both trench parallel and trench orthogonal a-axes throughout the region (Figures 3.7c-d). In particular, there seems to be a rotational pattern around Cerro Galan that can be seen from $25 \mathrm{~S}$ to $28 \mathrm{~S}$ at depths of 200-300 km (Figure 3.7c) and it is not as clear at depths below $300 \mathrm{~km}$ (Figure 3.7d). In addition, it is also observed that the region just east of Cerro Galan and the eastern edge of Cerro Galan (region between 67W-68W and 25.5S-26.5S) shows significantly reduced strength of anisotropy (length of lines in Figure 3.7). This is consistent with the teleseismic lag times for the stations in this region (Figure 3.3b). This region of less seismic anisotropy is directly beneath the region where a hot slab or, possibly, a slab gap is observed (Calixto et. al, 2013). The large rotational pattern observed around the region with small lag times can be interpreted as indirect evidence suggesting vertical flow through a slab gap. Even if we assume no slab gap, the inferred hotter slab (based on Qs and Vs) could locally influence the sub-slab flow south of Cerro Galan and possibly account for this pattern. North and south of Cerro Galan, the dominant mantle flow driving mechanism seems to be roll back and the effect of the heated slab is producing small rotations in the a-axes (Figure 3.7c). The area beneath $300 \mathrm{~km}$ is not in direct contact with the slab and therefore the rotational pattern is not expected to be as clear. At these depths, roll back also seems to overcome the effect of 
the heated slab north and south of Cerro Galan, where nearly trench parallel a-axes re observed (blue lines in Figure 3.7d). The fact that the inferred vertical a-axes beneath $200 \mathrm{~km}$ are not observed in the shear wave splitting tomography results (Figure 3.8) can probably be attributed to the lack of dip resolution at these depths (see Figure 3.3S of supplementary material).

\subsection{CONCLUSIONS}

A complex pattern of shear wave splitting under the southern Puna is the product of the three dimensional anisotropic structure resulting from distinct LPO regimes in the sub-slab mantle, the slab, the mantle wedge and the lithosphere. In addition, delamination, a partially heated slab and a change in slab subduction angle also play important roles in regionally changing the patterns of seismic anisotropy. Combining teleseismic and local shear wave splitting measurements aides in estimating the depth extent and three-dimensional anisotropy beneath and within the slab as well as improving the resolution in the mantle wedge. Overall, there is probably a significant amount of anisotropy beneath and possibly within the slab. The lithosphere west of 68W tends to produce trench parallel fast directions and inferred a-axes, which may be attributed to the compression and deformation of the Southern American plate. The dominant mechanism in the sub-slab mantle west of $68 \mathrm{~W}$ seems to be slab rollback and a slight coupling between the subducting Nazca plate and the underlying mantle. This makes the sub-slab region west of $68 \mathrm{~W}$ exhibit mainly trench parallel a-axes with slight trench orthogonal components. The deformation in the mantle wedge (east of $68 \mathrm{~W}$ ) is controlled by plate motion and also, regionally, by delamination and a heated slab (or 
slab gap) making the shear wave splitting patterns more complex and variable over relatively small length scales. Some evidence for close to vertical a-axes seems to suggest vertical flow beneath the main non-arc volcanic centers of the region and just west of the recently imaged delaminated block (Calixto et. al, 2013). The sub-slab mantle deformation and flow east of $68 \mathrm{~W}$ and north and south of the Cerro Galan region appears to be mostly driven by slab roll back, whereas the inferred mantle flow beneath Cerro Galan seems to be controlled by a heated subducting slab or possible slab gap. This explains the observed rotational pattern centered on a region with small anisotropy strength and small lag times. This is considered to be an indirect evidence for vertical flow through a slab gap.

It is important to mention that we have our best resolution above the slab, where most of the rays (teleseismic and locals) cross, but not beneath or within the slab, where few teleseismic rays cross and we have not local events; therefore, in such a region we are just estimating the average bulk anisotropic parameters.

\subsection{ACKNOWLEDGMENT}

The work was funded by the NSF Grant Proposal EAR-05 382 45. Thanks to David Abt and Karen Fischer for valuable discussion during the realization of this work. Danielle Robinson contributed greatly with preliminary shear wave splitting measurements that were the foundation for this work. 


\subsection{REFERENCES}

Abt, D. L. \& Fischer, K. M., 2008. Resolving three-dimensional anisotropic structure with shear wave splitting tomography. Geophysical Journal International, 173: 859-886. doi: 10.1111/j.1365-246X.2008.03757.x

Abt, D. L., Fischer, K. M., Abers, G. A., Strauch, W., Protti, J. M, \& González, V., 2009. Shear wave anisotropy beneath Nicaragua and Costa Rica: Implications for flow in the mantle wedge, Geochem. Geophys. Geosyst., 10, Q05S15, doi:10.1029/2009GC002375.

Abt, D. L., Fischer, K. M., Abers, G. A., Protti, J. M., González, V., \& Strauch, W., 2010. Constraints on upper mantle anisotropy surrounding the Cocos slab from SK (K) S splitting. Journal of Geophysical Research: Solid Earth (1978-2012), 115(B6).

Allmendinger, R. W., Jordan, T. E., Kay, S. M., \& Isacks, B. L., 1997. The evolution of the Altiplano-Puna plateau of the Central Andes. Annual Review of Earth and Planetary Sciences, 25(1), 139-174.

Barruol, G., \& Mainprice, D., 1993. A quantitative evaluation of the contribution of crustal rocks to the shear-wave splitting of teleseismic SKS waves. Physics of the Earth and Planetary Interiors, 78(3), 281-300.

Bianchi, M., Heit, B., Jakovlev, A., Yuan, X., Kay, S. M., Sandvol, E., Alonso, R. N., Coira, B., Brown, L., Kind. R., \& Comte, D., 2012. Teleseismic tomography of the southern Puna plateau in Argentina and adjacent regions. Tectonophysics.

Cahill, T. A., \& Isacks, B.L., 1992. Seismicity and shape of the subducted Nazca plate, J. Geophys. Res., 97, 17.503-17,529.

Calixto, F. J., Sandvol, E., Kay, S., Mulcahy, P., Heit, B., Yuan, X., Coira, B., Comte, D. \& Alvarado, P. , 2013. Velocity structure beneath the southern Puna plateau: Evidence for delamination. Geochemistry, Geophysics, Geosystems.

Druken, K. A., Long, M. D., \& Kincaid, C., 2011. Patterns in seismic anisotropy driven by rollback subduction beneath the High Lava Plains. Geophysical Research Letters, 38(13), L13310.

Faccenda, M., \& Capitanio, F. A., 2012. Development of mantle seismic anisotropy during subduction- induced 3- D flow. Geophysical Research Letters, 39(11).

Fischer, K. M., Parmentier, E. M., Stine, A. R., \& Wolf, E. R., 2000, Modeling anisotropy and plate-driven flow in the Tonga subduction zone back arc, J. Geophys. Res., 105(B7), 16181-16191, doi:10.1029/1999JB900441. 
Gledhill, K., \& Gubbins, D., 1996. SKS splitting and the seismic anisotropy of the mantle beneath the Hikurangi subduction zone, New Zealand. Physics of the earth and planetary interiors, 95(3), 227-236.

Gledhill, K., \& Stuart, G., 1996. Seismic anisotropy in the fore-arc region of the Hikurangi subduction zone, New Zealand. Physics of the earth and planetary interiors, 95(3), 211-225.

Heit, B., Bianchi, M., Yuan, X., Kay, S. M., Sandvol, E., Kumar, P., ... \& Comte, D., 2014. Structure of the crust and the lithosphere beneath the southern Puna plateau from teleseismic receiver functions. Earth and Planetary Science Letters, 385, 1-11.

Isacks, B.L., 1988. Uplift of the Central Andean plateau and bending of the Bolivian orocline, Journal of Geophysical Research, Solid Earth and Planets, v. 93, no. 4, pp. 3211-3231.

Jung, H., Katayama, I., Jiang, Z., Hiraga, T., \& Karato, S., 2006. Effect of water and stress on the lattice-preferred orientation of olivine. Tectonophysics, 421(1), 1-22.

Kaminski, É., \& Ribe, N. M., 2002. Timescales for the evolution of seismic anisotropy in mantle flow. Geochemistry, Geophysics, Geosystems, 3(8), 1-17

Kaneshima, S., \& Silver, P. G., 1995. Anisotropic loci in the mantle beneath central Peru. Physics of the Earth and Planetary Interiors, 88(3), 257-272.

Kay, R.W. \& Kay, S.M., 1993. Delamination and delamination magmatism, Tectonophysics, v. 219, pp. 177-189.

Kay, S.M., Coira, B., \& Viramonte, J., 1994. Young mafic back arc volcanic rocks as indicators of continental lithospheric delamination beneath the Argentine Puna plateau, central Andes, J. Geophys. Res., 99, 24,343-24,339.

Kay, S.M., \& Coira, B., 2009. Shallowing and steeping subduction zones, continental lithospheric loss, magmatism, and crustal flow under the Central Andean AltiplanoPuna Plateau, Geol. Soc. Am. Bull., 229-259.

Karato, S.-I., 1987. Seismic Anisotropy Due to Lattice Preferred Orientation of Minerals: Kinematic or Dynamic?, in High-Pressure Research in Mineral Physics: A Volume in Honor of Syun-iti Akimoto (eds M. H. Manghnani and Y. Syono), American Geophysical Union, Washington, D. C.. doi: 10.1029/GM039p0455

Karato, S. I., Jung, H., Katayama, I., \& Skemer, P., 2008. Geodynamic significance of seismic anisotropy of the upper mantle: new insights from laboratory studies. Annu. Rev. Earth Planet. Sci., 36, 59-95.

Liang, X., Sandvol, E., Kay, S., Heit, B., Yuan, X., Mulcahy, P., Chen, C., Brown, L., Comte, D., \& Alvarado, P., 2014. Delamination of southern Puna lithosphere 
revealed by body wave attenuation tomography. Journal of Geophysical Research: Solid Earth.

Lynner, C., \& Long, M. D., 2012. Evaluating contributions to SK (K) S splitting from lower mantle anisotropy: A case study from station DBIC, Côte D'Ivoire. Bulletin of the Seismological Society of America, 102(3), 1030-1040.

Long, M. D., \& Silver, P. G., 2008. The subduction zone flow field from seismic anisotropy: A global view. Science, 319(5861), 315-318.

Long, M. D., \& Silver, P. G., 2009. Mantle flow in subduction systems: The sub-slab flow field and implications for mantle dynamics. Journal of Geophysical Research: Solid Earth (1978-2012), 114(B10).

Long, M. D., \& Becker, T. W., 2010. Mantle dynamics and seismic anisotropy. Earth and Planetary Science Letters, 297(3), 341-354.

Long, M. D., 2013. Constraints on subduction geodynamics from seismic anisotropy. Reviews of Geophysics.

MacDougall, J. G., Fischer, K. M., \& Anderson, M. L., 2012. Seismic anisotropy above and below the subducting Nazca lithosphere in southern South America. Journal of Geophysical Research: Solid Earth (1978-2012), 117(B12).

Mainprice, D., \& Silver, P. G., 1993. Interpretation of SKS-waves using samples from the subcontinental lithosphere. Physics of the Earth and Planetary Interiors, 78(3), 257-280.

Marrett, R. A., Allmendinger, R. W., Alonso, R. N., \& Drake, R. E., 1994. Late Cenozoic tectonic evolution of the Puna Plateau and adjacent foreland, northwestern Argentine Andes. Journal of South American Earth Sciences, 7(2), 179-207.

Mulcahy, P., Chen, C., Kay, S. M., Brown, L. D., Alvarado, P., Sandvol, E., Heit, B., \& Yuan, X., 2010. The Southern Puna seismic experiment: Shape of the subducting Nazca plate, areas of concentrated mantle and crustal earthquakes, and crustal focal mechanisms. Americal Geophysical Union 2010 meeting, poster session: T11A2050.

Mulcahy et al., 2014, in press.

Nicolas, A., \& Christensen, N. I., 1987. Formation of Anisotropy in Upper Mantle Peridotites - A Review. Composition, structure and dynamics of the lithosphereasthenosphere system, 111-123.

Niu, F., \& Perez, A. M., 2004. Seismic anisotropy in the lower mantle: A comparison of waveform splitting of SKS and SKKS. Geophysical research letters, 31(24). 
Paczkowski, K., 2012. Dynamic analysis of modifications to simple plate tectonics theory. Ph.D. thesis, Yale University.

Ribe, N. M., 1989. Seismic anisotropy and mantle flow. Journal of Geophysical Research, 94(B4), 4213-4223.

Ribe, N. M., \& Yu, Y., 1991. A theory for plastic deformation and textural evolution of olivine polycrystals. Journal of Geophysical Research: Solid Earth (1978-2012), 96(B5), 8325-8335.

Ribe, N. M., 1992. On the relation between seismic anisotropy and finite strain. Journal of Geophysical Research: Solid Earth (1978-2012), 97(B6), 8737-8747.

Risse, A., Trumbull, R. B., Coira, B., Kay, S. M., \& Bogaard, P. V. D., 2008. ${ }^{40} \mathrm{Ar} /{ }^{39} \mathrm{Ar}$ geochronology of mafic volcanism in the back-arc region of the southern Puna Plateau, Argentina. Journal of South American Earth Sciences, 26(1), 1-15.

Risse, A., Trumbull, R. B., Kay, S. M., Coira, B., \& Romer, R. L., 2013. Multi-stage Evolution of Late Neogene Mantle-derived Magmas from the Central Andes Backarc in the Southern Puna Plateau of Argentina. Journal of Petrology, 54(10), 19631995.

Russo, R. M., \& Silver, P. G., 1994. Trench-parallel flow beneath the Nazca plate from seismic anisotropy. Science, 263(5150), 1105-1111.

Savage, M. K., 1999. Seismic anisotropy and mantle deformation: What have we learned from shear wave splitting?. Reviews of Geophysics, 37(1), 65-106.

Silver, P. G., \& Chan, W. W., 1991. Shear wave splitting and subcontinental mantle deformation. Journal of Geophysical Research: Solid Earth (1978-2012), 96(B10), 16429-16454.

Silver, P. G., \& Holt, W. E., 2002. The Mantle Flow Field Beneath Western North. Science, 1066878(1054), 295.

Tarantola, A., 2002. Inverse problem theory: Methods for data fitting and model parameter estimation. Elsevier Science, p. 613.

Vanacore, E., \& Niu, F., 2011. Characterization of the D "beneath the Galapagos Islands using SKKS and SKS waveforms. Earthquake Science, 24(1), 87-99.

Vinnik, L. P., Makeyeva, L. I., Milev, A., \& Usenko, A. Y., 1992. Global patterns of azimuthal anisotropy and deformations in the continental mantle. Geophysical Journal International, 111(3), 433-447.

Vinnik, L., Romanowicz, B., Le Stunff, Y., \& Makeyeva, L., 1995. Seismic anisotropy in the D "layer. Geophysical research letters, 22(13), 1657-1660. 
Vinnik, L. P., Green, R. W. E., \& Nicolaysen, L. O., 1996. Seismic constraints on dynamics of the mantle of the Kaapvaal craton. Physics of the earth and planetary interiors, 95(3), 139-151.

Whitman, D., Isacks, B. L., \& Kay, S. M., 1996. Lithospheric structure and along-strike segmentation of the Central Andean Plateau: seismic magmatism, flexure, topography and tectonics. Tectonophysics, 259(1), 29-40.

Yamazaki, D., \& Karato, S. I., 2007. Lattice- preferred orientation of lower mantle materials and seismic anisotropy in the D "layer. Post-Perovskite: The Last Mantle Phase Transition, 69-78.

Yu, Y., \& Park, J., 1994. Hunting for azimuthal anisotropy beneath the Pacific Ocean region. Journal of Geophysical Research: Solid Earth (1978-2012), 99(B8), 1539915421. 


\subsection{SUPPLEMENTARY FIGURES}
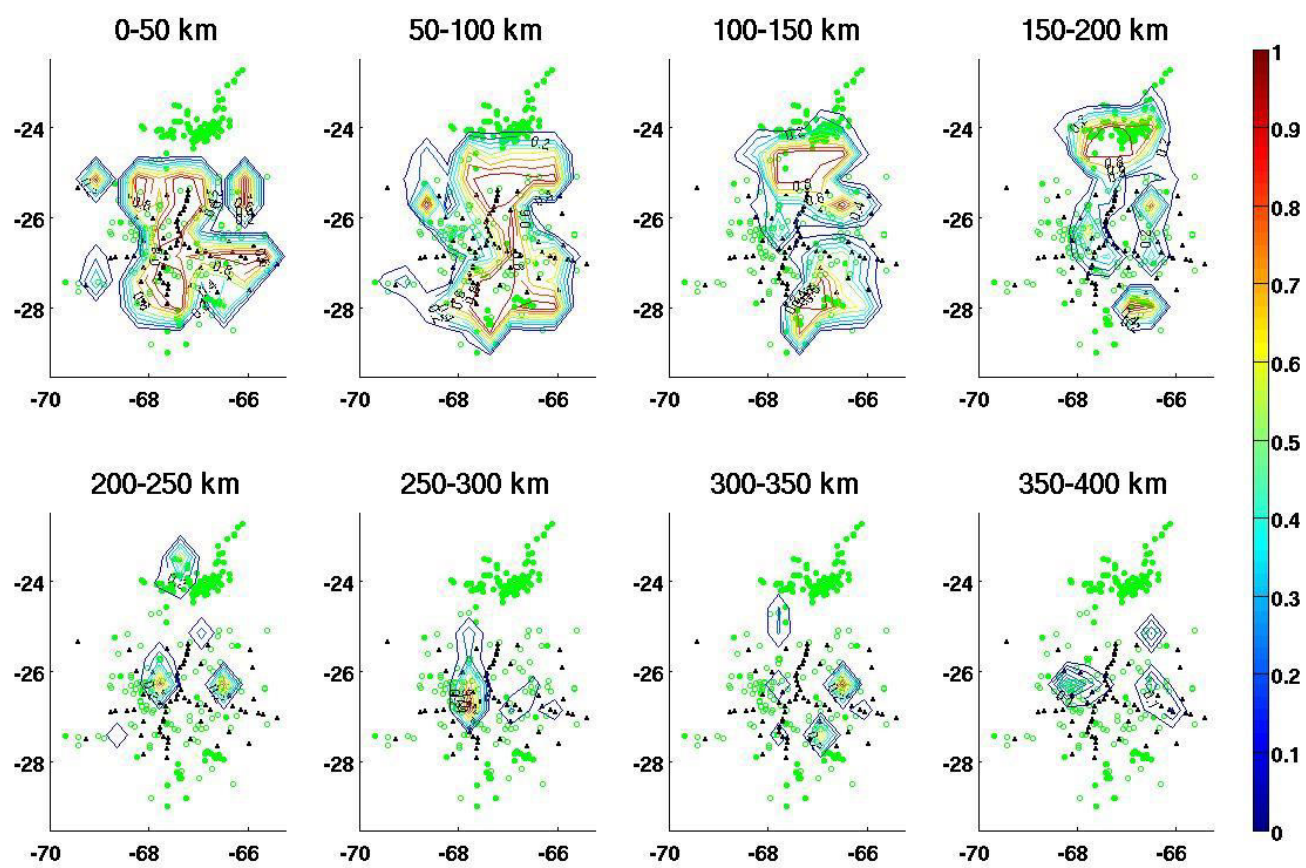

Figure 3.1S. Resolution of the strength of azimuthal anisotropy for depth intervals of $50 \mathrm{~km}$ from 0 to $400 \mathrm{~km}$. The resolution is shown as coloured contours. The seismic stations are shown as black triangles. 

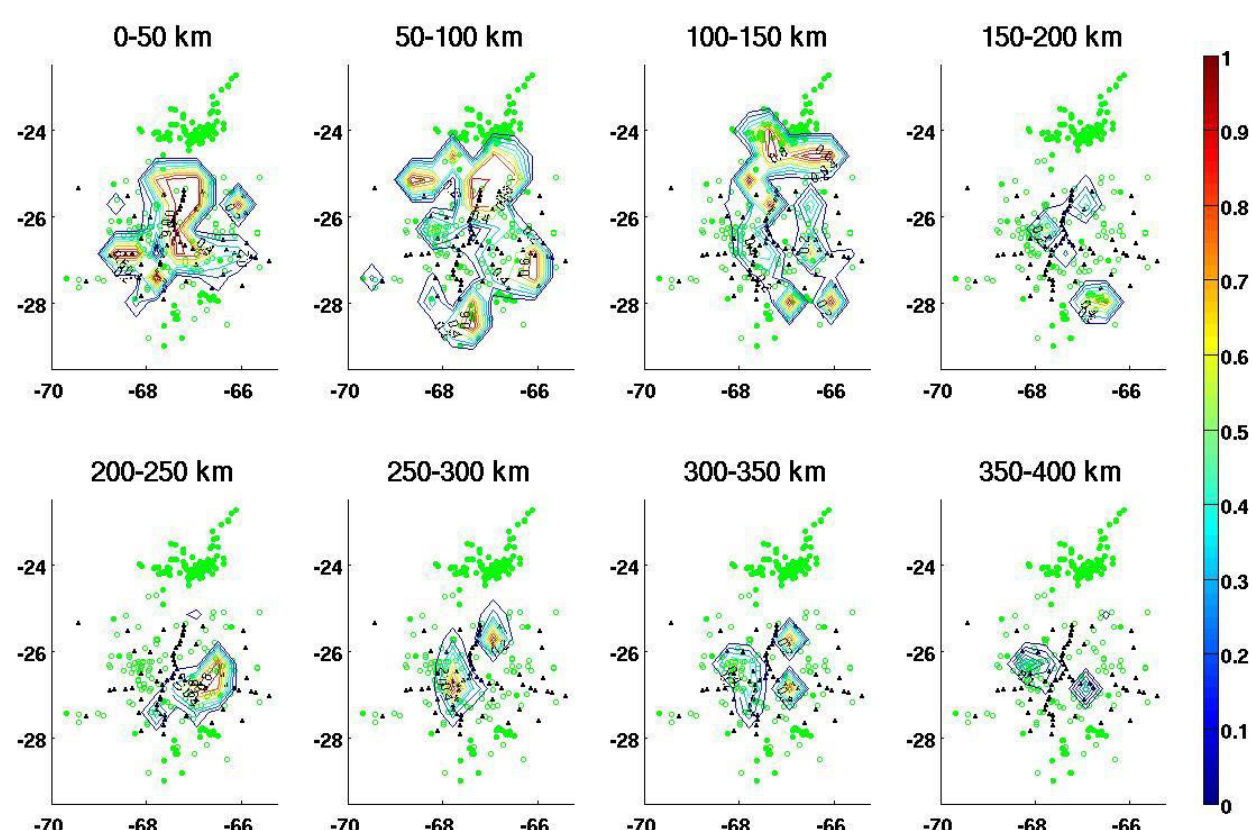

Figure 3.2S. Resolution of the azimuth of the $\left[\begin{array}{lll}1 & 0 & 0\end{array}\right]$ axis for depth intervals of $50 \mathrm{~km}$ from 0 to $400 \mathrm{~km}$. The resolution is shown as coloured contours. The seismic stations are shown as black triangles.
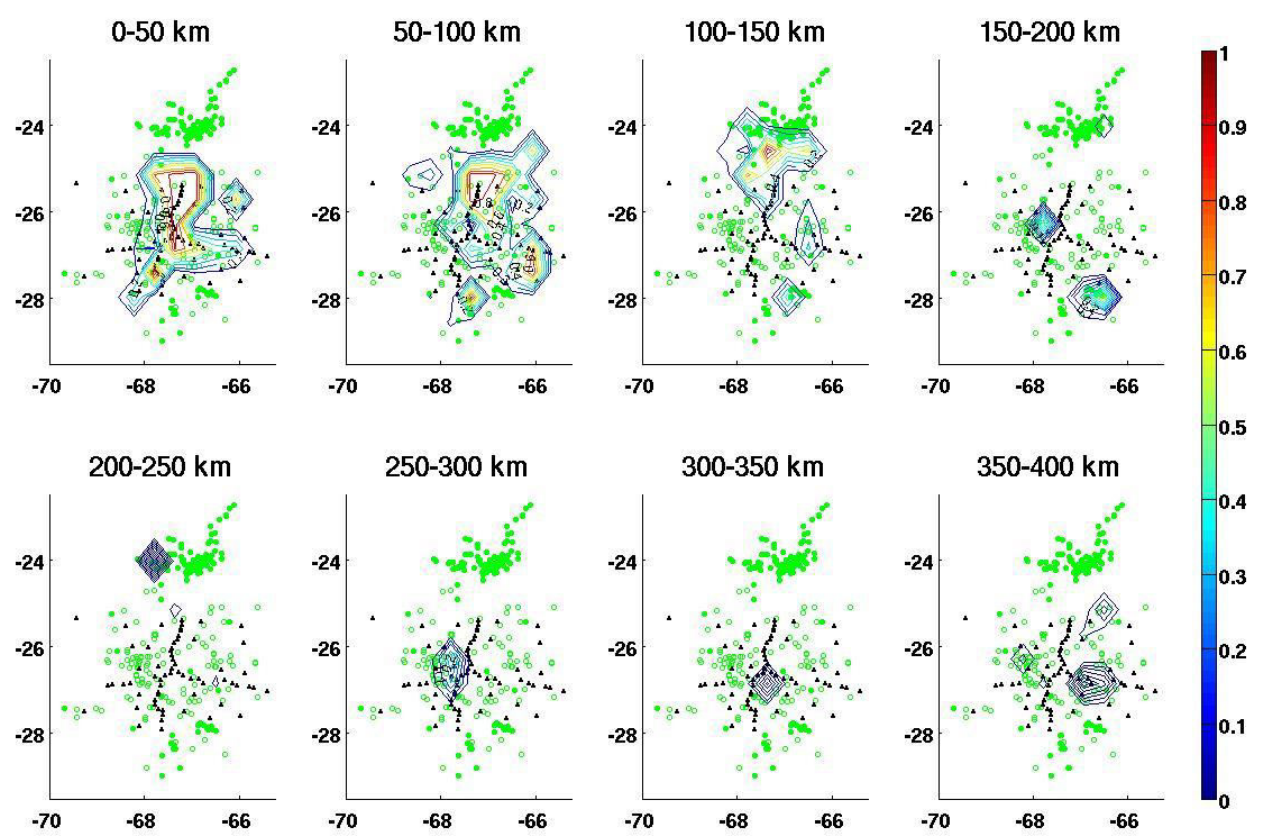

Figure 3.3S. Resolution of the dip of the $\left[\begin{array}{lll}1 & 0 & 0\end{array}\right]$ axis for depth intervals of $50 \mathrm{~km}$ from 0 to $400 \mathrm{~km}$. The resolution is shown as coloured contours. The seismic stations are shown as black triangles. 


\section{CHAPTER 4}

\section{REGIONAL SEISMIC ATTENUATION IN PERU}

\section{ABSTRACT}

Lg Q tomographic models for Central and Southern Peru were obtained with a total of 126 stations that included permanent and temporary broadband and short period seismometers. Q measurements were obtained using the two-station (TSM) and reverse two-station methods (RTM). The images show a large variation of Q values across the region most likely associated with different attenuation mechanisms. Low Q values (50150) are observed in the western cordillera of northern and central Peru that correlate with the location of the extinct volcanic arc. In general, low $Q$ values (50-150) are observed beneath the volcanic arc in southern and are related with intrinsic attenuation caused by partial crustal melting. Low Q values beneath northern Cuzco and Puno regions correlate with a crustal root as thick as $70 \mathrm{~km}$ and the active thrust faults that border the region to the northwest suggesting scattering attenuation. The Altiplano-Puna plateau containing the Titicaca Lake shows moderate Q values (400-600) in a region characterized by an almost flat Moho with a constant crustal thickness of around $60 \mathrm{~km}$. The region east of the eastern cordillera has moderately high $Q$ values $(600-800)$ associated with under thrusting of the tectonically stable Brazilian shield. Overall, the high attenuation observed in many areas seems to suggest low seismic hazard for southern Peru. The exception is seen in Coastal areas and, in particular, beneath the city of Pisco which shows the highest values of Q (1000-1500) associated with possible high degree of site effect that makes this city very susceptible to regional earthquakes. 


\subsection{INTRODUCTION}

The process of one tectonic plate being pushed beneath another plate is called subduction. This process is generally responsible for the generation of the largest volcanic belts and largest earthquakes on planet earth. More specifically, the subduction of the Nazca plate beneath the South American plate is responsible for most of the seismic and volcanic activity in Peru and the majority of Southern America. Subduction of the Nazca plate started around 200 Ma. Along the Peruvian coast, the convergence between the two plates is taking place at a rate of 7-8 $\mathrm{cm} / \mathrm{year}$ (De Mets et.al., 1980; Norabuena et.al., 1999). Consequently, coastal Peru has a history of very large earthquakes (Dorbath et.al, 1990; Tavera and Buforn, 2001), all of them associated with the seismogenic interplate contact. The earthquakes with the largest magnitudes have produced severe damage over a large area. For example, the Pisco earthquake that occurred in Peru on August 15, $2007(\mathrm{Mw}=8.0)$ resulted in a 513 dead, 2,291 injured, and 76,000 houses totally collapsed, affecting around 413,000 people.

Depending on the angle at which a subducting plate dips downward, it can also heat the crust. Generally, regions with typical angles of subduction have relatively hot crust while regions with shallow (flat) subduction have cold crust. As expected, Peru's active volcanoes are concentrated at the northern and southern ends of the country, where there is normal dipping angle of subduction. Surprisingly, however, there is evidence of a hot crust in the western cordillera of northern and central Peru above the flat subduction. Heat flow measurements ranging from 17 to $39 \mathrm{Mw} / \mathrm{m}^{2}$ (Henry and Pollack, 1988) and geothermal activity (Instituto Geografico Nacional, 1989) suggest that the western cordillera north of $10^{\circ} \mathrm{S}$ may have potential for geothermal energy even 
though it overlies a region with a low angle subduction. One of the best tools seismologists have for identifying hot crust is to measure the attenuation of seismic waves. Hot partially molten crust tends to attenuate seismic waves much more than cold crust. It is important to note that seismic waves can be attenuated by two different physical processes: intrinsic attenuation, which is related to the anelasticity of crustal rocks, and scattering attenuation, which is caused by structures within the crust that redirect seismic energy away from a particular path. In order to estimate crustal temperatures seismologist need to be able to separate intrinsic from scattering attenuation. The two-station method and reverse two-station method allow to measure Q anisotropy and separate the intrinsic from scattering contribution (Bao et al., 2011). Therefore, performing high resolution seismic attenuation measurements will help to identify regions of high seismic attenuation which will help us map zones of possible crustal melting.

Ground shaking from earthquakes is a function of a number of different factors: the size of the earthquake, path-based attenuation of the seismic wave, and the localized site response. All of these factors combine to generate very complex patterns in stronger and weaker ground motion and thus present a real challenge to predicting ground shaking strength for a given earthquake location. The present work addresses two of these three factors using a new method recently developed (Bao et al., 2011). Furthermore, this type of work has never been done before along any part of the Andean margin. 


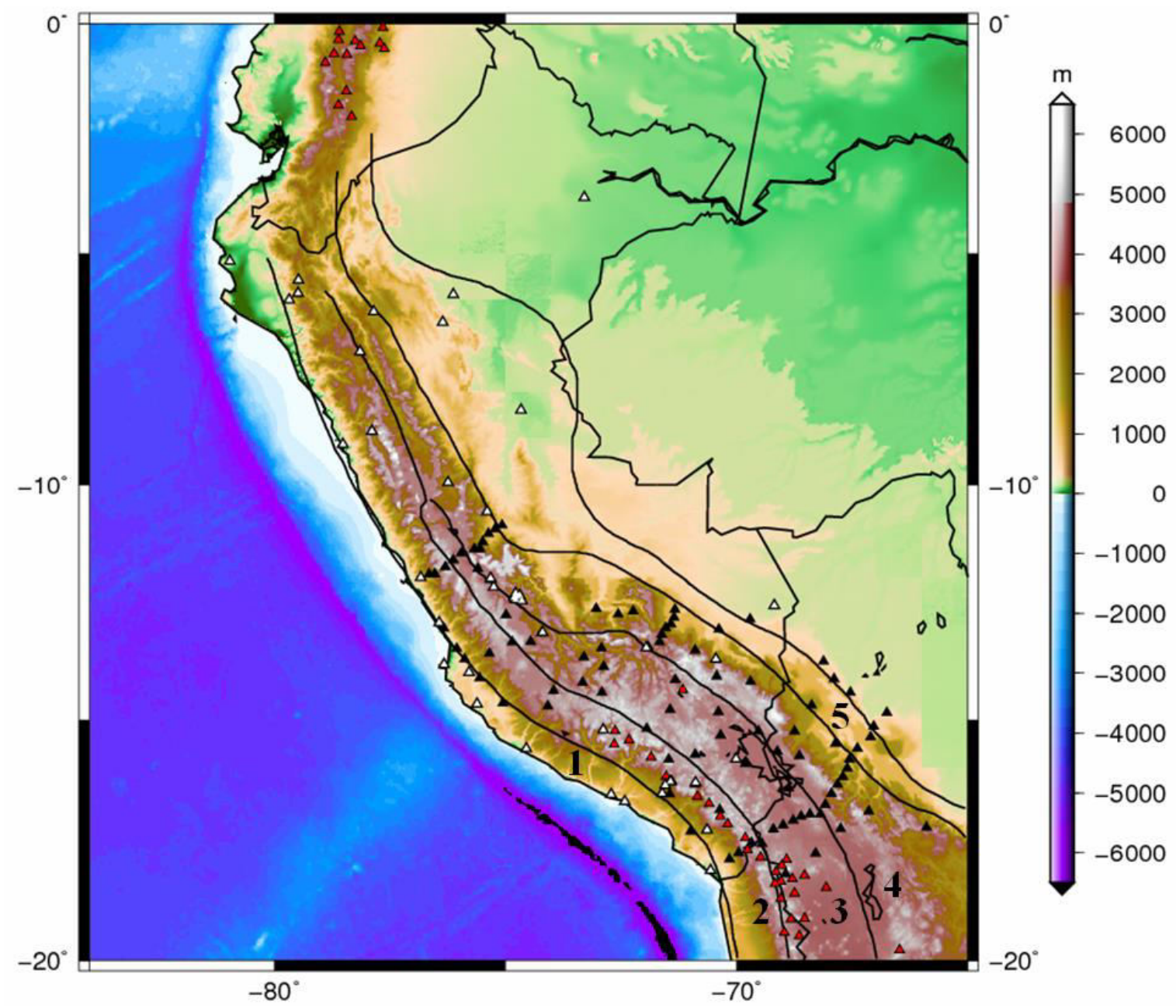

Figure 4.1 Topography of Central Andes of Peru including parts southern Ecuador, northern Chile and western Bolivia. The white triangles are stations from the Peruvian seismic network. Black triangles represent stations from the PULSE and CAUGHT experiments. Red triangles show the locations of the volcanoes that also correlate with the region of normal subduction. The five distinct Andean regions are also shown: (1) coastal plains, (2) western cordillera, (3) Altiplano plateau, (4) eastern cordillera and (5) the Subandes.

The method utilizes a seismic phase called Lg which is very sensitive to bulk properties of the crust. Seismologists use the term "seismic phase" to refer to a wave with a specific path through the earth. Lg travels only through the earth's crust as a guided wave. $\mathrm{Lg}$ propagates primarily as an $\mathrm{S}$ wave (shear wave) and is the largest amplitude seismic phase at distances between 200 and 2,000 $\mathrm{km}$ from the earthquake 
epicenter (e.g Figure 4.3). Pg is essentially the same as Lg only it propagates as a P wave through the earth's crust. Variations in the amplitude of these phases allow us to accurately measure seismic attenuation without being biased by site effects, source contributions or instrumental response. We have used data from the Peruvian national seismic network (Figure 4.1) through a special agreement between the Geophysical Institute of Peru (IGP) and the University of Missouri. In addition we have used data recorded by seismic stations that were deployed as part of the Peru Lithospheric and Slab experiment (PULSE) and Central Andes Uplift and Geodynamics of High Topography experiment (CAUGHT) through agreements with the University of North Carolina, University of Arizona and Yale University. Seismometers from the PULSE and CAUGHT experiments were deployed in central and southern Peru starting in late 2010.

\subsection{TECTONIC SETTING}

The area between $0^{\circ} \mathrm{S}$ and $45^{\circ} \mathrm{S}$ in western southern America, where subduction of the Nazca Plate beneath the South American plate can be divided into regions of normal and flat subduction (e.g., Stauder, 1975; Baranzagi and Isacks 1976; Jordan et al, 1983). Most of Peru is characterized by flat subduction (e.g. Figure 4.1) with no active volcanoes except at the northern and southern borders. This study focuses in the segment between $0^{\circ} \mathrm{S}$ and $20^{\circ} \mathrm{S}$, which includes the Peruvian flat slab $\left(2^{\circ} \mathrm{S}-15^{\circ} \mathrm{S}\right)$ and the Altiplano plateau (a region undergoing normal angle subduction) $\left(15^{\circ} \mathrm{S}-20^{\circ} \mathrm{S}\right)$. The region of flat slab subduction is associated with a volcanic gap (Mc Geary et al., 1985; Gustcher et al., 1999, 2000a) and is the largest zone of flat subduction in the world. 
Intermediate adakitic felsic rocks are found in northern Peru and are characteristic of flat subduction regions (Gustcher et al., 2000b). Buoyancy effects seem to be the dominant mechanism causing the Peruvian flat slab. The high buoyancy from this part of the slab is proposed to be from the subducted Inca Plateau (located between $2^{\circ} \mathrm{S}-7^{\circ} \mathrm{S}$ and $73^{\circ}-76^{\circ} \mathrm{W}$ ) in northern Peru (Gutscher et al., 1999a; 1999b; Rosenbaum 2005) and by the subduction of the Nazca Ridge in Central Peru (delimited by $11^{\circ}-15^{\circ} \mathrm{S}$ and $72^{\circ}$ $76^{\circ} \mathrm{W}$ ). In the flat slab region, the Nazca plate dips at about $30^{\circ}$ below the South American plate (Hasegawa and Sacks, 1981). At $100 \mathrm{~km}$ downdip, the slab bends to a nearly horizontal angle, and at $300 \mathrm{~km}$ it dips steeply beneath the thick South American continental lithosphere (Hasegawa and Sacks, 1981). The Nazca Ridge started to subduct around 11.2 $\mathrm{Ma}$ at about $11^{\circ} \mathrm{S}$ (Hampel, 2002) and shifted southward where it is currently entering the trench at around $15^{\circ} \mathrm{S}$ and $76^{\circ} \mathrm{W}$. Others have proposed alternative mechanisms: such as the absolute motion of the overriding plate (Olbertz et al., 1997), the age of the oceanic lithosphere (Sacks, 1983), the curvature of the Peruvian margin (Cahill and Isacks, 1992) and detaching of the deeper slab leading to a bounce back mechanism for the shallower part of the slab (Haschke et al, 2002). However, it is not clear whether any of these alternative mechanisms are equally or more important than buoyancy cause by the subduction of oceanic plateaus and ridges.

Southern Peru (south of $15^{\circ} \mathrm{S}$ ) shows few evidence for adakites which suggests bending of the slab just north of the Altiplano-Puna plateau. At these latitudes, the volcanic arc resumes. Most of the region is presumed to have experienced thermal uplift probably as a result of lithospheric removal (Ramos and Folguera, 2009), although the 
lithospheric thickness is still to be mapped in this region. Upwelling of asthenosphere as the slab rolled back is another possibility. Shortening (Allmendinger, 1997) and overthrusting of the crust on the Brazilian shield could also contribute to the uplift of the region. This regions is also characterized by intense deformation in the foreland exhibited in the Subandean fold and thrust belt. The transition from flat slab to normal subduction appears to depict a bending of the slab rather than a tear with Moho depths as shallow as $30 \mathrm{~km}$ beneath the coast and as deep as $75 \mathrm{~km}$ beneath the Altiplano (Phillips and Clayton, 2013), which is in agreement with other receiver function studies (Ryan, 2012). Beck et al. (1996) found large crustal thickness variations south of $14^{\circ} \mathrm{S}$. $55-60 \mathrm{~km}\left(\right.$ at $\left.16^{\circ} \mathrm{S}\right)$ and $70-74 \mathrm{~km}\left(\right.$ at $\left.20^{\circ} \mathrm{S}\right)$ beneath the Western and Eastern Cordillera, 60-65 km beneath the Altiplano plateau, 43-47 km thickness in the Subandean region.

The Peruvian Andes morphology (Figure 4.1) consists of five different regions (Suarez et al., 1983; Audebaud et al., 1973). The eastward region is called the coastal plains and is bordered by the shoreline and the western cordillera. It contains Mesozoic volcanic and sedimentary rocks. The coastal region widens in southern Peru (south of $\left.14^{\circ} \mathrm{S}\right)$. The second region is called the Cordillera Occidental or western cordillera and is characterized by Mesozoic and Cenozoic volcanic and plutonic rocks. It is where most of the late Cenozoic volcanism took plate. The western cordillera widens south of $15 \mathrm{~S}$ which correlates with the resumption of arc volcanism. The third region is the central high plateau and Altiplano that contain the highest navigable lake in the world (Titicaca, $3812 \mathrm{~m}$. of surface elevation). The Altiplano is bordered by the western cordillera to the west and the eastern cordillera to the east. The plateau is located south of $10^{\circ} \mathrm{S}$ and 
progressively widens from $50 \mathrm{~km}$ in central Peru to almost $200 \mathrm{~km}$ in southern Peru. The fourth region is the Cordillera Oriental or eastern cordillera and contains mainly rocks from pre-Mesozoic times. Central Peru also has Precambrian crystalline and Paleozoic plutonic rocks, which form a presumably weak upper crust. The fifth region is called the Subandes and exhibits shallow water and continental sedimentary rocks of Paleozoic and Pliocene times that are folded and located mainly parallel to the eastern cordillera. This regions also contains reverse faults dipping to the west probably caused by crustal shortening

\subsection{METHOD}

The reverse two-station method (RTS) (Chun et al., 1987) uses the configuration show in Figure 4.2. The Lg quality factor $\left(\mathrm{Q}_{\mathrm{Lg}}\right)$ can be calculated using the following expression:

$$
\frac{1}{Q_{\mathrm{lg}}}=\frac{V_{\mathrm{lg}}}{\pi f\left(d_{a j}+d_{b i}+d_{a i}-d_{b j}\right)} \ln \left[\frac{A_{a i} A_{b j}}{A_{a j} A_{b i}}\left(\frac{d_{a i} d_{b j}}{d_{a j} d_{b i}}\right)^{m}\right]
$$

where $A_{a i}, A_{a i}, A_{b i}, A_{b j}$ represent the spectral amplitudes of the $L g$ phase measured at stations $\mathrm{i}$ and $\mathrm{j}$ for events a and $\mathrm{b}$. Distances are represented with $\mathrm{d}_{\mathrm{ai}}, \mathrm{d}_{\mathrm{aj}}, \mathrm{d}_{\mathrm{bi}}, \mathrm{d}_{\mathrm{bj}}$. Frequency is $f$ and $m$ is the geometrical spreading coefficient (for $\operatorname{Lg} m=0.5$ ). $\mathrm{V}_{\mathrm{Lg}}$ is $\mathrm{Lg}$ velocity which normally exhibits values of $3.5 \mathrm{~km} / \mathrm{s}$, however, higher and slower velocities were observed in central and southern Peru.

The frequency dependence of $\mathrm{Q}_{\lg }$ can be examined using the power law: 


$$
Q_{L g}(f)=Q_{L g 0} f^{\eta}
$$

where high values of $\eta$ (Eta) are usually associated with scattering attenuation whereas low values are associated with intrinsic attenuation.

The RTS is able to isolate both the site amplification effect and site response terms by taking the ratio of two sets of spectral ratios. Typically we can effectively remove the instrument response because it is usually well known; however, measurements of the site response are also very important in understanding small scale variations in ground shaking. Ground shaking can be very heterogeneous in a large earthquakes and it has been shown the local site response is very important in understanding the hazards associated with large earthquakes. Furthermore, it has been shown that the reverse two-station method is, in many aspects, superior to other methods for estimating $\mathrm{Q}_{\mathrm{Lg}}$ (Ford et. al., 2008). This is because it can extract the relative site term and it is insensitive to parameterization choice. The direct two-station method, on the other hand, is very sensitive to frequency bandwidth, believed to be due to its incomplete extraction of the site term. The coda normalization method is highly affected by changes in distance ranges caused by its fixed coda-measurement window. The coda-source method is very sensitive to assumptions of geometrical spreading. The source pair/receiver pair evidences significant errors in the power-law model parameters, and thus is strongly affected by changes in method parameterization. 


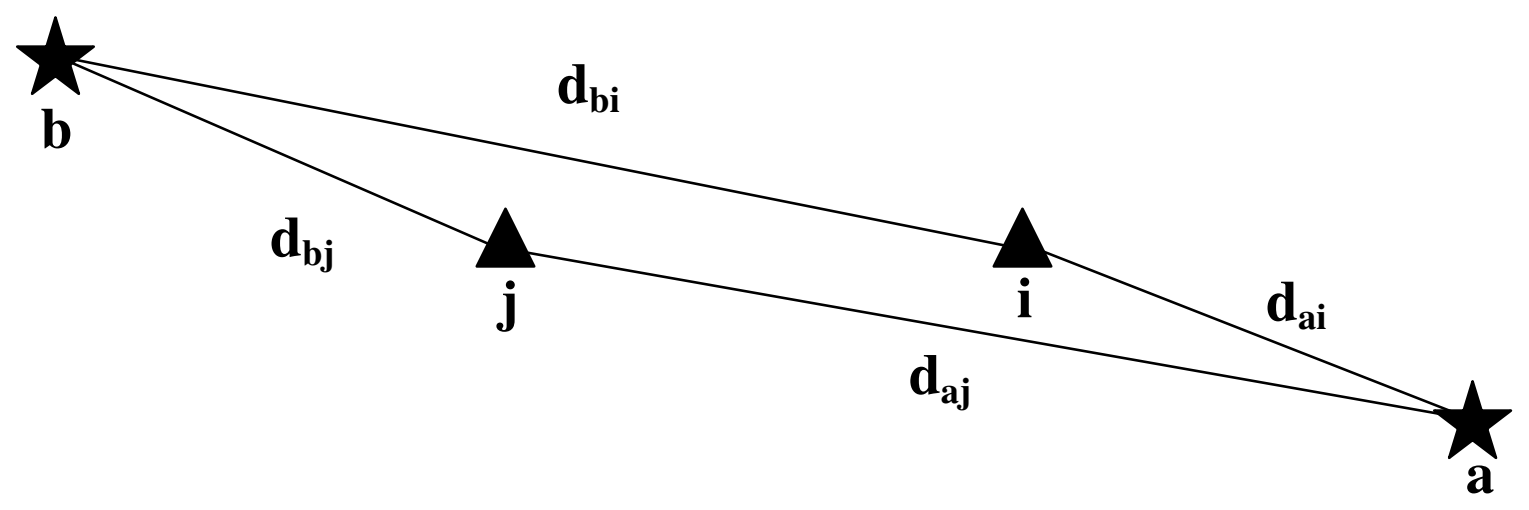

Figure 4.2 Schematic drawing illustrating the reverse two station method to obtain the interstation $\mathrm{Lg}$ attenuation. The triangles are seismic stations and the stars are earthquakes. The distances are represented with the letter "d".

\subsection{DATA PROCESSING}

This study uses waveform data recorded during December 2010 and April 2013 at the Peruvian seismic network that includes 18 broadband stations and 17 telemetric short period stations. Additionally, data from 91 temporary broad band stations deployed in southern Peru as part of the Central Andes Uplift and Geodynamics of High Topography (CAUGHT) and Peru Lithosphere and Slab Experiment (PULSE) projects has been included. The Peruvian network covers central and eastern Peru whereas the CAUGHT and PULSE stations cover central and southern Peru including parts of Bolivia. Shallow earthquakes of less than $40 \mathrm{~km}$ depth and epicentral distance greater than $3^{\circ}$ with mainly continental raypaths were selected. Only the vertical components with windows of 10 minutes were used; we manually reviewed and picked the Lg phase arrival at each of the stations (e.g Figure 4.3). 

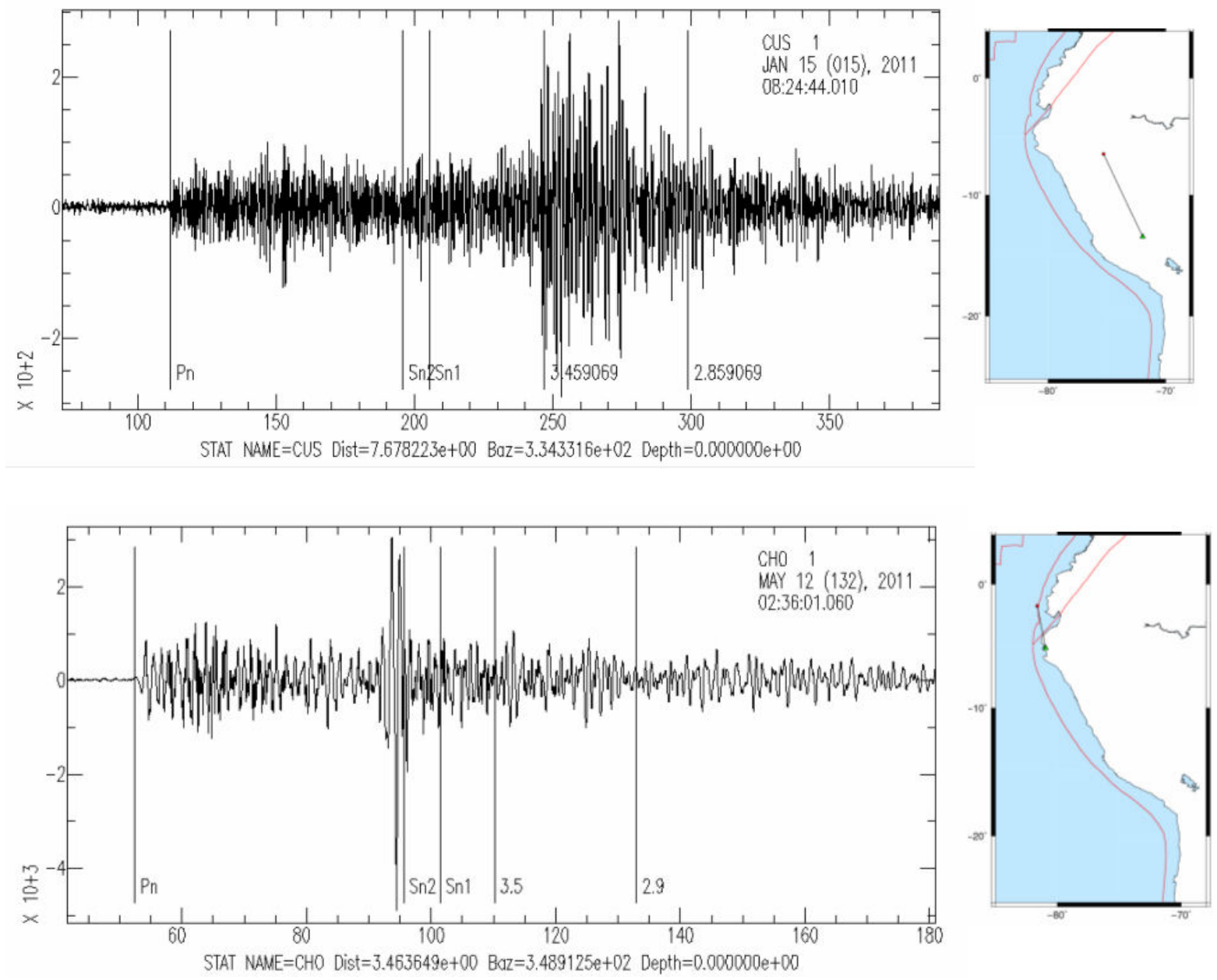

Figure 4.3 (Top) Example of Lg phase in Peru. This particular example shows that $\mathrm{Sn}$ is inefficient and Lg propagates efficiently through the Peruvian crust and thus shows large amplitudes. Lg velocities range from 2.85 to $3.45 \mathrm{~km} / \mathrm{s}$ in this example. (Bottom) Example seismogram with an oceanic ray-path. In this case, $\mathrm{Lg}$ is not generated and a large Sn phase is observed.

Event magnitudes of $4.5 \mathrm{Mw}$ or greater were used to guarantee a sufficient signal to noise ratio to correctly characterize Lg amplitudes. The method of Xie (2002) was used to cut Lg windows and calculate Lg amplitude spectra in the frequency domain. Over 2000 two-station paths were selected and their corresponding Lg spectra was calculated and compared with noise spectra prior to the arrival of the first $\mathrm{P}$ wave arrival. Paths with signal to noise ratios less than 1.5 were discarded to avoid biases in 
the results caused by noise. The RTM paths were calculated using a maximum azimuthal angle difference of $15^{\circ}$ and a minimum inter-station distance of $120 \mathrm{~km}$. The LSQR algorithm is used to tomographically invert lateral variations of $\mathrm{Q}_{\mathrm{Lg}}$.

\subsection{RESULTS}

Figure 4.4 shows the results of $\mathrm{LgQ}$ values for $1 \mathrm{~Hz}$ across the Peruvian Andes. Northern and central Peru show mix evidence for low to moderate values of Q (50-600). The coastal region of Chiclayo and Piura shows values of Q between 400 and 800 . The eastern cordillera between $6^{\circ} \mathrm{S}$ and $10^{\circ} \mathrm{S}$ show low $\mathrm{Q}$ values of less than 100 . The western cordillera at the same latitudes shows moderate Q values (600-800) and the Subandean basin shows a transition from Q values of 600-800 to the west to less 100 the east. Further south, below northern Cuzco and Puno (between $70-74^{\circ} \mathrm{W}$ and $11-13^{\circ} \mathrm{S}$ ) in the eastern cordillera and where the subducting slabs starts to transition to steeper angles, low $Q$ values (50-150) are observed. The city of Pisco $\left(76^{\circ} \mathrm{W}, 14^{\circ} \mathrm{S}\right)$ shows particularly large values of Q (1000-1500). In the western cordillera, where the volcanic arc resumes (south of $15^{\circ} \mathrm{S}$ ), I find very low Q values (50-100). Further east, the Altiplano-Puna plateau and the eastern cordillera east of the plateau shows moderately high values of Q (400-600). The Subandean region in Bolivia just east of the border with Peru shows high values of Q (600-800). 


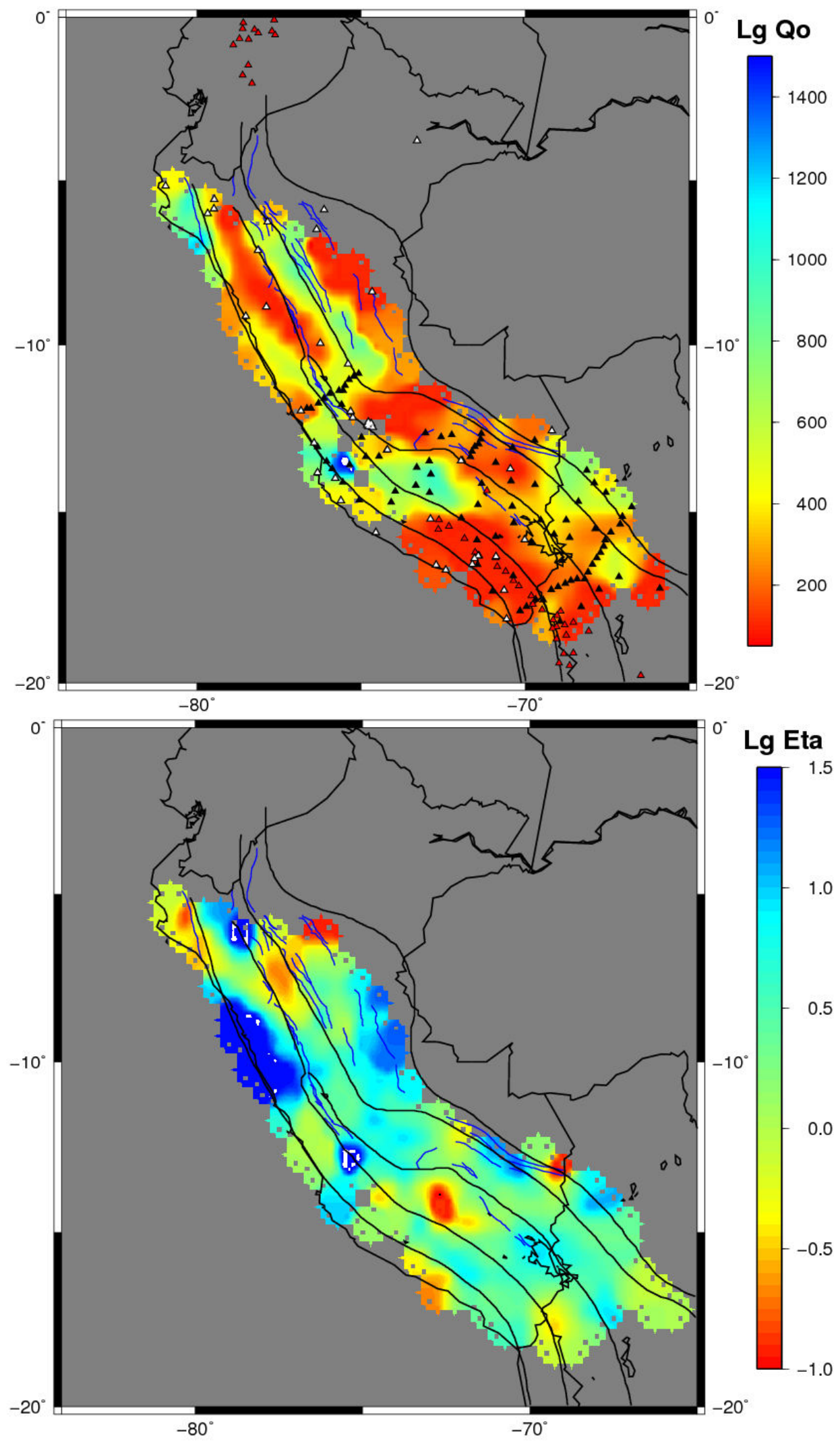


Figure 4.4 (Top) $\mathrm{Q}_{\mathrm{Lg}}$ values for $1 \mathrm{~Hz}$ across the Peruvian Andes using the two-station method. Black lines across north-south in Peru represented the boundaries of the Andean regions (see Figure 4.1). Black lines represent the country borders. The black contour in southern Peru shows the location of the Titicaca Lake in the Altiplano-Puna plateau. Blue lines show the locations of the main thrust faults on the Peruvian Andes. (Bottom) Eta $(\eta)$ values across the Central Andes of Peru and Bolivia. High values of Eta suggest scattering attenuation whereas low values of Eta suggest intrinsic attenuation. Most of the regions are dominated by intrinsic attenuation.

\subsection{DISCUSSION}

The degree of seismic attenuation is described by the seismic quality factor Q. Q is defined as the total loss in energy divided by the initial energy thus it is a dimensionless parameter that increases for lower attenuation and decreases with higher attenuation. This study presents measurements of $\mathrm{Q}$ for the $\mathrm{Lg}$ phase $\left(\mathrm{Q}_{\mathrm{Lg}}\right)$ across the Peruvian Andes. Myers et al. (1998) measured Qp and Qs values across the Bolivian Andes (Figure 4.5) and found that Qs crustal values are around 300 beneath the Western Cordillera and around 100 beneath the Altiplano plateau. Myers et al. found Qs values as low as 80 on the western side of the Eastern Cordillera and up to 900 on the eastern side of the Eastern Cordillera and the Sub-Andes. However, it is necessary to point out that their method has the limitation of assuming a frequency independent $\mathrm{Q}$ and constant receiver site response spectrum, which could have biased their results. 


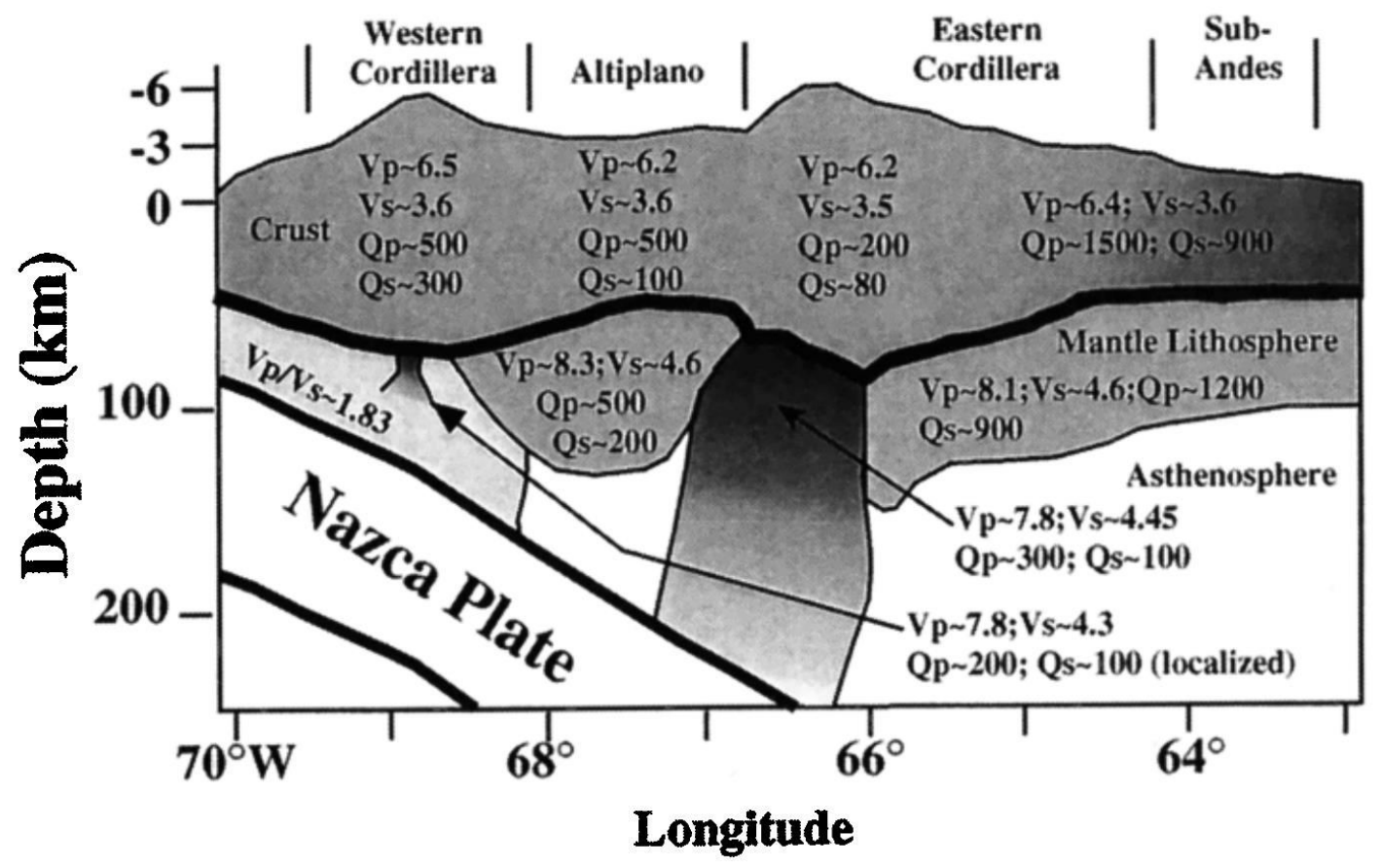

Figure 4.5 Qs and Qp measurements across the Bolivian Andes obtained by Myers et al. 1998.

The present measurements of $\mathrm{Q}_{\mathrm{Lg}}$ range from 50 to 1000 across most Peru and reach 1500 only beneath the city of Pisco. The low $\mathrm{Q}_{\mathrm{Lg}}$ values observed beneath North and Central Peru correlate very well with the location of the Western Cordillera. Dating of volcanic rocks in the western cordillera of the Peruvian flat slab suggest the volcanism may have stopped around 18 Ma (Noble et al., 1979). However, plate kinematics reconstruction suggests that the volcanic arc may have stopped as early as $10 \mathrm{Ma}$ (Rosenbaum et al., 2005) after the subduction of the Inca plateau (10-12 Ma). The Inca plateau is associated with the initiation of flat subduction in Northern Peru. The Western Cordillera also contains active thrust faults some of which were responsible for the emplacement of the Cordillera Blanca batholith around $8 \mathrm{Ma}$ in part due to the Nazca-South American oblique converge (McNulty et al., 1998). Moreover, 
heat flow estimates are in this region range from 17 to $39 \mathrm{Mw} / \mathrm{m}^{2}$ (Henry and Pollack, 1988). These observations suggest that the mechanism driving the low $\mathrm{Q}-$ high attenuation - in the Western Cordillera in Northern and Central Peru may be a combination of remnant heat flow from the extinct arc and active faulting. Slab dehydration that does not generate arc volcanism could also regionally increase the heat flow in this region.

Southern Peru presents a totally different history as expected since it is the region where the slab subduction angle changes from flat to normal resuming the volcanic arc. This region is also characterized by a broadening of the Altiplano Plateau. In general, $\mathrm{Q}_{\mathrm{Lg}}$ in southern Peru increases from west to east. The low $\mathrm{Q}_{\mathrm{Lg}}$ values in the western cordillera where the crustal thickness is between 40-50 km (Ryan, 2012) are associated with intrinsic attenuation caused partial melting within the crust possibly related to magma chambers feeding the active arc volcanoes. Further east, the Altiplano-Puna plateau in southern Cuzco and Puno exhibits moderate values of $\mathrm{Q}_{\mathrm{Lg}}$ associated with a relatively cold and highly uniform crust with an average crustal thickness of $60 \mathrm{~km}$. The Low $\mathrm{Q}_{\mathrm{Lg}}$ values beneath northern Cuzco and Puno correlate with a crustal root of $70 \mathrm{~km}$ thick. This region exhibits high values of $\eta$ (Eta) indicating that the attenuation is strongly frequency dependent. This is consistent with the attenuation mechanism being caused by scattering of $\mathrm{Lg}$ waves due to dramatic variations in crustal thickness. The region east of the eastern cordillera and the subandes shows high values of $Q_{\mathrm{Lg}}$ which can be explained by under thrusting of the Brazilian 
shield or over thrusting of the weak Andean crust over the Brazilian shield caused by shortening.

The city of Pisco's high values of $\mathrm{Q}_{\mathrm{Lg}}(1000-1500)$ is a particular case since these extremely low attenuations are not observed in any other region within the Peruvian Andes. Modeling of the Mw8.0, August 15 ${ }^{\text {th }}$ 2007, Pisco earthquake (Calixto, 2009; Pulido et al., 2012) suggests directivity or site effect as the possible cause of the high accelerations measured in stations in Pisco (2 to 5 times larger than simulated acceleration amplitudes). Thus, the high $\mathrm{Q}_{\mathrm{Lg}}$ measured may not reflect the $\mathrm{Q}$ of the crust beneath Pisco. Lg attenuation beneath Pisco is most likely the same as its surrounding regions ( $\mathrm{Q}_{\mathrm{Lg}}$ of 600-800) but it is biased by site effect. This is confirmed with $\mathrm{Q}_{\mathrm{Lg}}$

measurements obtained using the reverse two-station method (Figures 4.1S and Figure 4.2S) that show $\mathrm{Q}_{\mathrm{Lg}}$ values beneath Pisco are similar to those of surrounding areas. These observations suggest that the city of Pisco exhibits, in fact, a high degree of site effect, which makes Pisco a region with high seismic hazard and susceptible to regional earthquakes. On the other hand, the intermediate to moderately high values of $\mathrm{Q}_{\mathrm{Lg}}$ in most of the other Coastal regions of Peru suggest those regions may also have significant seismic hazard but not as high as Pisco city.

\subsection{CONCLUSIONS}

The large variation in $\mathrm{Q}_{\mathrm{Lg}}$ from low values in the volcanic arc and northern Western Cordillera to moderate values in the Altiplano plateau to high values in the Subandes, together with the isolated pockets of low $\mathrm{Q}_{\mathrm{Lg}}$ values in Cuzco and northern 
Puno suggest that different attenuation mechanisms are causing those variations across the north-central Andes. Furthermore, significant variations in the frequency dependence of the attenuation would suggest that scattering and intrinsic attenuation are dominant in different regions. Intrinsic attenuation seems to be the dominant mechanism across most of southern Peru and could be caused by a number of factors including partial crustal melting within the lower crust associate with magma chambers (Low $\mathrm{Q}_{\mathrm{Lg}}$ ) in the western cordillera; regions of with no large variation in crustal thickness as in the Altiplano-Puna plateau (moderate $\mathrm{Q}_{\mathrm{Lg}}$ ); or regions being pushed over the Brazilian shield (high $\mathrm{Q}_{\mathrm{Lg}}$ ) as in the Subandes. On the other hand, scattering attenuation seems to dominate in isolated regions with thick crustal roots and large active fault zones in Cuzco and northern Puno. The mostly high to moderate attenuation

observed in several regions of southern Peru suggests that distant earthquakes will produce only modest ground shaking. Contrary, Coastal regions and, particularly, Pisco, may be susceptible to strong ground shaking by regional earthquakes.

\subsection{ACKNOWLEDGEMENTS}

I would like to thank the Peruvian Institute of Geophysics (IGP) and Hernando Tavera for valuable collaboration during the realization of this work. Special thanks to Susan Beck for valuable cooperation that led to improvements of this work. This study was funded by the Research Board of the University of Missouri. 


\subsection{REFERENCES}

Allmendinger, R. W., Jordan, T. E., Kay, S. M., \& Isacks, B. L. (1997). The evolution of the Altiplano-Puna plateau of the central Andes. Annual Review of Earth and Planetary Sciences, 25(1), 139-174.

Audebaud, E., Capdevilla, R., Dalmayrac, B., Debelmas, J., Laubacher, G., Lefevre, C., Marocco, R., Martinez, C., Mattauer, M., Megard, F., Paredes, J. \& Tomasi, P. (1973). Les traits géologiques essentiels des Andes centrales (Pérou-Bolivie). Revue de géographie physique et de géologie dynamique, 15(1-2), 73-114.

Bao, X., Sandvol, E., Ni, J., Hearn, T., Chen, Y. J., \& Shen, Y. (2011). High resolution regional seismic attenuation tomography in eastern Tibetan Plateau and adjacent regions. Geophysical Research Letters, 38(16).

Barazangi M. and B. Isacks (1976), Spatial distribution of earthquakes and subduction of the Nazca plate beneath South America. Geology, 4, 686-692.

Beck S., G. Zandt, S. Myers, T. Wallace, P. Silver and L. Drake, (1996). Crustal thickness variations in the central Andes. Geology, 24, 407-410.

Cahill, T., \& Isacks, B. L. (1992). Seismicity and shape of the subducted Nazca plate. Journal of Geophysical Research: Solid Earth (1978-2012), 97(B12), 1750317529.

Calixto, F. (2009). Seismic source kinematic models and their Application to Calculate Seismic Signals in the near-source-near-field condition. Post-graduate diploma dissertation. Earth System Physics. International Centre for Theoretical Physics. Italy.

Chun, K. Y., West, G. F., Kokoski, R. J., \& Samson, C. (1987). A novel technique for measuring Lg attenuation-Results from eastern Canada between 1 to $10 \mathrm{~Hz}$. Bulletin of the Seismological Society of America, 77(2), 398-419.

De Mets C., R. Gordon, A. Aarhus and S. Stein (1980). Current plate motions. Geophys. J. Int., 101, 425-478.

Dorbath L., A. Cisternas, and C. Dorbath (1990). Assesment of the size of large and great historical earthquakes in Peru. Bull. Seism. Soc. Am., 80, 551-576.

Ford S., D. Dreger, K. Mayeda, W. Walter, L. Malagnini, and W. Phillips (2008). Regional Atenuattion in Northern California: A Comparison of Five 1D Q Methods, Bull. Seism. Soc. Am., 98, 2033-2046.

Gutscher, M. A., Olivet, J. L., Aslanian, D., Eissen, J. P., \& Maury, R. (1999). The "lost Inca Plateau": cause of flat subduction beneath Peru?. Earth and Planetary Science Letters, 171(3), 335-341. 
Gutscher, M. A., Spakman, W., Bijwaard, H., \& Engdahl, E. R. (2000a). Geodynamics of flat subduction: Seismicity and tomographic constraints from the Andean margin. Tectonics, 19(5), 814-833.

Gutscher, M. A., Maury, R., Eissen, J. P., \& Bourdon, E. (2000b). Can slab melting be caused by flat subduction?. Geology, 28(6), 535-538.

Hampel, A. (2002). The migration history of the Nazca Ridge along the Peruvian active margin: a re-evaluation. Earth and Planetary Science Letters, 203(2), 665-679.

Haschke, M. R., Scheuber, E., Günther, A., \& Reutter, K. J. (2002). Evolutionary cycles during the Andean orogeny: repeated slab breakoff and flat subduction?. Terra nova, 14(1), 49-55.

Hasegawa, A., \& Sacks, I. S. (1981). Subduction of the Nazca plate beneath Peru as determined from seismic observations. Journal of Geophysical Research: Solid Earth (1978-2012), 86(B6), 4971-4980.

Henry, S. G., \& Pollack, H. N. (1988). Terrestrial heat flow above the Andean subduction zone in Bolivia and Peru. Journal of Geophysical Research: Solid Earth (1978-2012), 93(B12), 15153-15162.

Instituto Geográfico Nacional (1989). Fuentes Termominerales. Atlas del Perú. P. 151.

McNulty, B. A., Farber, D. L., Wallace, G. S., Lopez, R., \& Palacios, O. (1998). Role of plate kinematics and plate-slip-vector partitioning in continental magmatic arcs: Evidence from the Cordillera Blanca, Peru. Geology, 26(9), 827-830.

Jordan T., B. Isacks, R. Allmendinger, J. Brewer, V. Ramos, and C. Ando (1983). Andean tectonics related to geometry of subducted Nazca plate. Geological Study of America Bulletin 94, 341-361.

McGeary, S., Nur, A., \& Ben-Avraham, Z. (1985). Spatial gaps in arc volcanism: The effect of collision or subduction of oceanic plateaus. Tectonophysics, 119(1), 195221.

Noble, D. C., McKEE, E. H., \& Mégard, F. (1979). Early Tertiary “Incaic” tectonism, uplift, and volcanic activity, Andes of central Peru. Geological Society of America Bulletin, 90(10), 903-907.

Norabuena, E. O., Dixon, T. H., Stein, S., \& Harrison, C. G. (1999). Decelerating Nazca - South America and Nazca - Pacific Plate motions. Geophysical Research Letters, 26(22), 3405-3408.

Olbertz, D., Wortel, M. J. R., \& Hansen, U. (1997). Trench migration and subduction zone geometry. Geophysical Research Letters, 24(3), 221-224.

Pulido, N., Tavera, H., Aguilar, Z., Nakai, S., \& Yamazaki, F. (2013). Strong Motion Simulation of the M8. 0 August 15, 2007, Pisco Earthquake; Effect of a MultiFrequency Rupture Process. Journal of Disaster Research Vol, 8(2), 235. 
Ramos, V. A., \& Folguera, A. (2009). Andean flat-slab subduction through time. Geological Society, London, Special Publications, 327(1), 31-54.

Rosenbaum, G., Giles, D., Saxon, M., Betts, P. G., Weinberg, R. F., \& Duboz, C. (2005). Subduction of the Nazca Ridge and the Inca Plateau: Insights into the formation of ore deposits in Peru. Earth and Planetary Science Letters, 239(1), 18-32.

Ryan, J., Beck, S., Zandt, G., Wagner, L., Minaya, E., \& Tavera, H., (2012). The underside of the Andes: using receiver functions to map the North Central Andean Subsurface. AGU fall meeting 2012, poster T21E-2626.

Suárez, G., Molnar, P., \& Burchfiel, B. C. (1983). Seismicity, fault plane solutions, depth of faulting, and active tectonics of the Andes of Peru, Ecuador, and southern Colombia. Journal of Geophysical Research: Solid Earth (1978-2012), 88(B12), 10403-10428.

Stauder, W. (1975). Subduction of the Nazca plate under Peru as evidenced by focal mechanisms and by seismicity. Journal of Geophysical Research, 80(8), 10531064.

Tavera, H., \& Buforn, E. (2001). Source mechanism of earthquakes in Perú. Journal of Seismology, 5(4), 519-540.

Whitman, D., Isacks, B. L., Chatelain, J. L., Chiu, J. M., \& Perez, A. (1992).

Attenuation of high - frequency seismic waves beneath the central Andean

Plateau. Journal of Geophysical Research: Solid Earth (1978-2012), 97(B13), 19929-19947.

Xie, J. (2002). Lg Q in the eastern Tibetan Plateau. Bulletin of the Seismological Society of America, 92(2), 871-876. 


\subsection{SUPPLEMENTARY FIGURES}

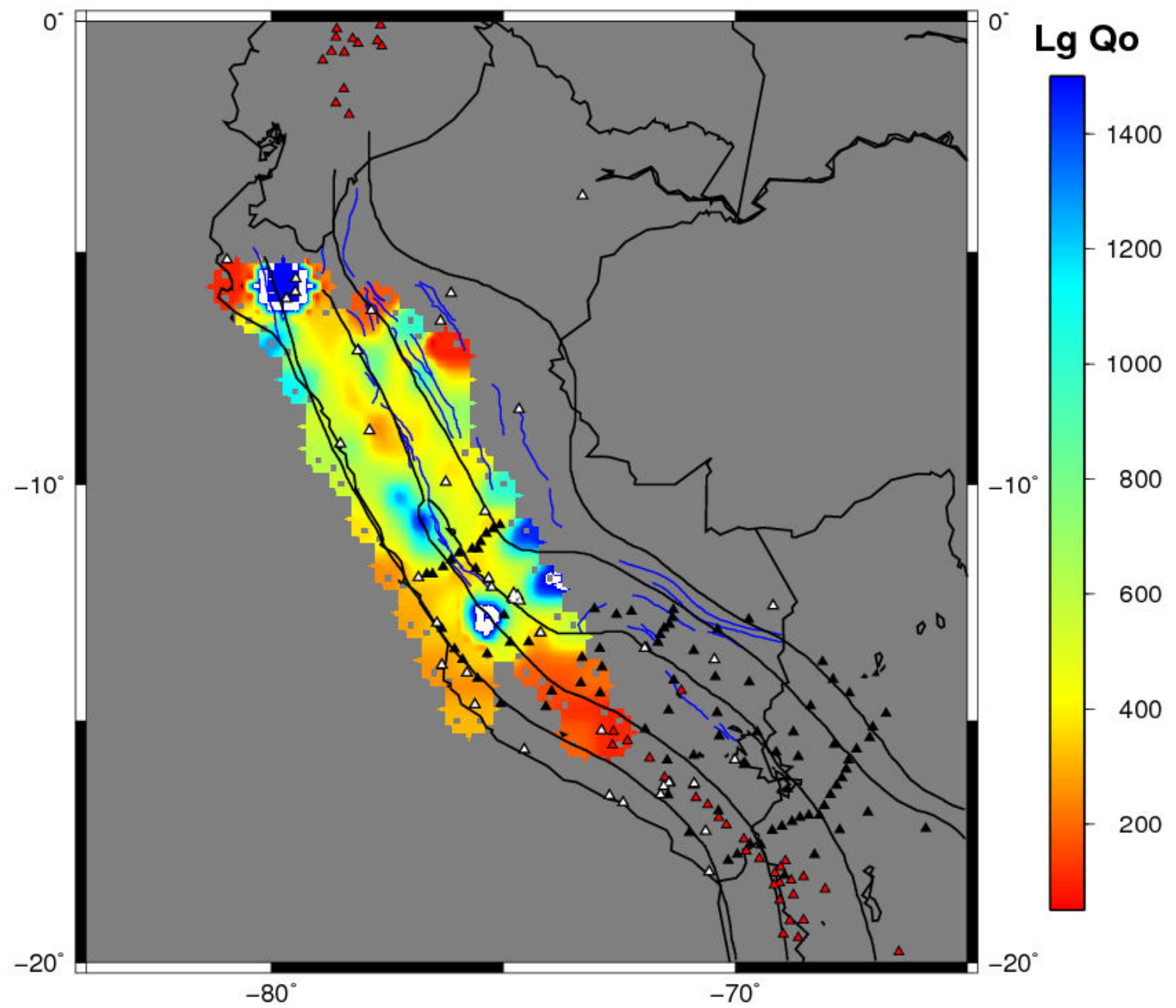

Figure 4.1S $\mathrm{Q}_{\mathrm{Lg}}$ values for $1 \mathrm{~Hz}$ across the Peruvian Andes using the reverse twostation method Black lines across north-south in Peru represented the boundaries of the Andean regions (see Figure 4.1). Black lines represent the country borders. The black contour in southern Peru shows the location of the Titicaca Lake in the Altiplano-Puna plateau. Blue lines show the locations of the main thrust faults on the Peruvian Andes. Pisco region shows $Q$ values of around 400 . 


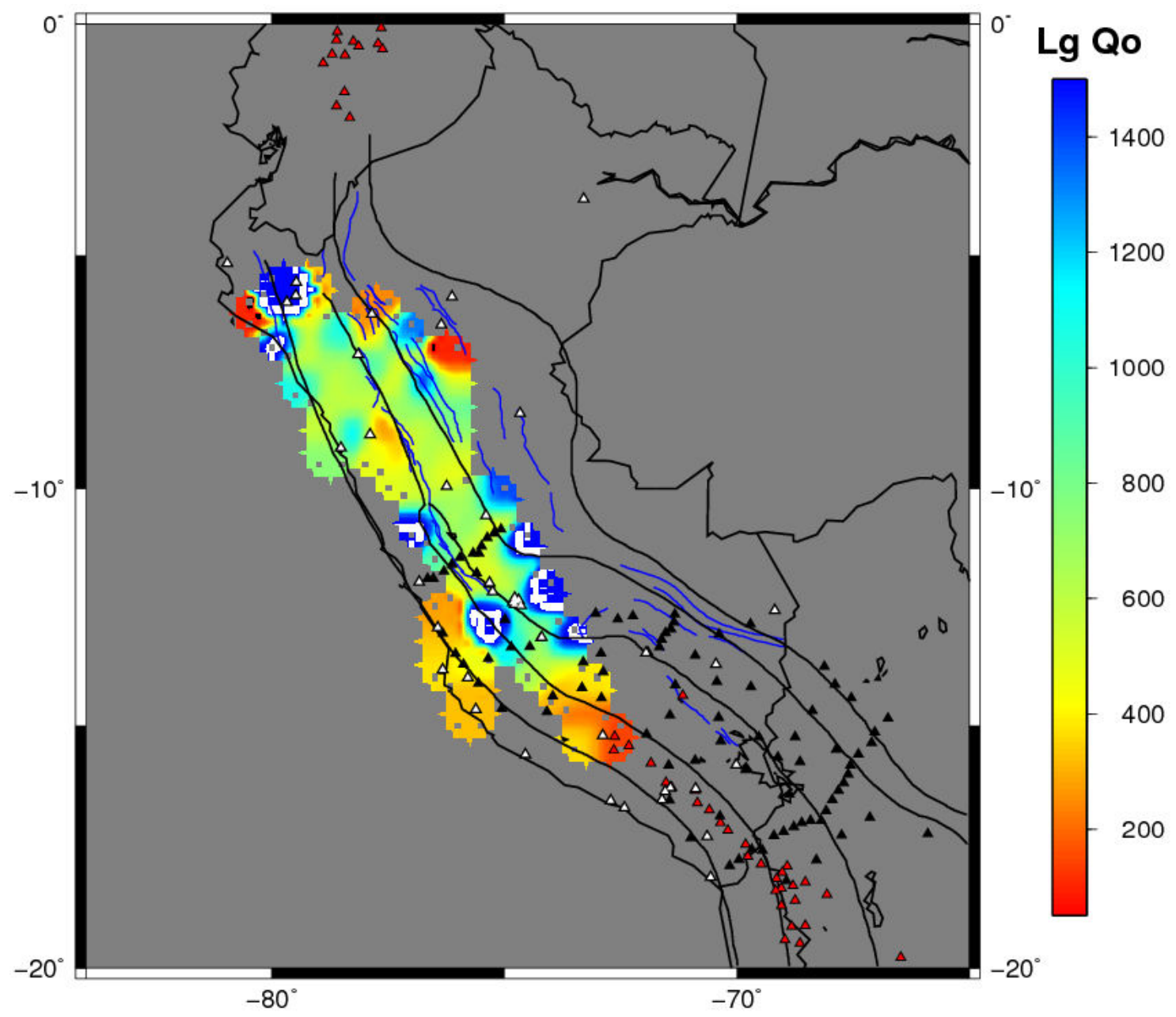

Figure 4.2S $\mathrm{Q}_{\mathrm{Lg}}$ values for $2 \mathrm{~Hz}$ across the Peruvian Andes using the reverse twostation method Black lines across north-south in Peru represented the boundaries of the Andean regions (see Figure 4.1). Black lines represent the country borders. The black contour in southern Peru shows the location of the Titicaca Lake in the Altiplano-Puna plateau. Blue lines show the locations of the main thrust faults on the Peruvian Andes. Pisco region shows $Q$ values of around 400. 


\section{CHAPTER 5}

\section{CONCLUSIONS}

\subsection{INTRODUCTION}

In the present dissertation I provided different seismological studies in the southern Puna plateau and the Central Andes. Surface wave tomography (using the method of Forsyth and Li, 2005) helped me to map the Rayleigh wave phase velocities as a function of frequency across the Southern Puna plateau. I further inverted those phase velocities using the method of Saito (1988) and obtained a three-dimensional shear wave velocity model for the same region which allowed me to better constrain the main features and velocity-related structures down to $250 \mathrm{~km}$ depth. To study the seismic anisotropy in the southern Puna plateau I used shear wave splitting analysis (Silver and Chan, 1991). Both teleseismic and deep and intermediate local events were combined to provide a vertical constraint on mantle polarization anisotropy. Shear wave splitting tomography (Abt and Fischer, 2008) was used to study the three-dimensional anisotropic structure of the southern Puna plateau. Finally, I calculated of Lg attenuation across the Peruvian Andes using the two station method (Chun et al., 1987)

and tomographically inverted them using the LSQR algorithm to resolve lateral variations of $\mathrm{Q}_{\mathrm{Lg}}$. The main findings and conclusions to the above studies are summarized below. 


\subsection{CONCLUSIONS}

\subsubsection{CONCLUSIONS ON THE SOUTHERN PUNA PLATEAU}

- A high shear wave velocity body beneath Cerro Galan is interpreted as the delaminated body that detached from the lower crust and lithosphere. Abnormal low velocities in the crust are interpreted as widespread crustal melting that cause the eruption of the Cerro Galan ignimbrite complex and the recent uplift that the region experienced.

- The slab south of the delaminated block seems to be abnormally hot and maybe the reason why part of it is not resolved by the shear wave velocity model. The slab was heated by the convective hot asthenosphere that also caused the widespread crustal melting as the slab rolled back. A heated slab also explains the gap in intermediate seismicity.

- Shear wave splitting analysis shows a complex and possible three-dimensional anisotropic structure across the southern Puna plateau. This was confirmed by shear wave splitting tomography which shows that different mechanisms are driving the seismic anisotropy in different parts of the southern Puna plateau.

- The subslab mantle close to the trench is dominated by slab roll back and a small degree of coupling between the subducting slab and the underlying mantle. This is seen as predominantly trench parallel a-axes. The subslab beneath Cerro Galan shows indirect evidence for vertical flow, suggesting that a heat slab or slab gap is locally driving the mantle flow. Close to vertical a-axes in the mantle wedge beneath Cerro Galan and Cerro Blanco ignimbrites suggest vertical asthenospheric flow. The region above the slab in the western part of the array is 
dominated by compression of the South American plate causing trench parallel a-axes.

\subsubsection{CONCLUSIONS ON THE PERUVIAN ANDES}

- Lg attenuation in Peru shows some interesting correlations with the topography, seismic velocity, crustal thickness and heat flow. The Western Cordillera in Northern and Central Peru shows low Q values possibly associated with remnant heat flow from when this region underwent normal subduction and active faulting. North and Central Peru costal regions show moderate values of Q with exception of the city of Pisco which shows a much localized pocket with the highest values of $\mathrm{Q}$ of all the Peruvian Andes. Northern Puno and Cuzco show low Q values probably associated with scattering attenuation caused by thick crustal roots and active faulting. The Western Cordillera in southern Peru show low $\mathrm{Q}$ values associated with high heat flow and crust melts due to arc volcanism. The low to moderate $\mathrm{Q}$ values observed in the Altiplano plateau and Eastern Cordillera in southern Peru represent a transition from warm-thick crust to cold-thin crust. The high $\mathrm{Q}$ values in the Subandean region are associated with under-thrusting of the cold-high velocity Brazilian lithosphere.

- Overall, the low to moderate values of Q across the Peruvian Andes suggest that most of the regions are not likely to be significantly affected by ground motion caused by regional earthquakes. In contrast, high values of $\mathrm{Q}$ are seen beneath Pisco and are not likely representative of the crustal Q beneath Pisco. They mostly likely represent a high degree of site effect which makes this region 
highly susceptible to amplification of ground motion caused by regional earthquakes. 


\subsection{REFERENCES}

Abt, D. L., \& Fischer, K. M. (2008). Resolving three - dimensional anisotropic structure with shear wave splitting tomography. Geophysical Journal International, 173(3), 859-886.

Chun, K. Y., West, G. F., Kokoski, R. J., \& Samson, C. (1987). A novel technique for measuring $\mathrm{Lg}$ attenuation-Results from eastern Canada between 1 to $10 \mathrm{~Hz}$. Bulletin of the Seismological Society of America, 77(2), 398-419.

Forsyth, D. W., \& Li, A. (2005). Array analysis of two-dimensional variations in surface wave phase velocity and azimuthal anisotropy in the presence of multipathing interference. Geophysical Monograph Series, 157, 81-97.

Saito, M. (1988). DISPER80: A subroutine package for the calculation of seismic normal-mode solutions. Seismological algorithms, 293-319.

Silver, P. G., \& Chan, W. W. (1991). Shear wave splitting and subcontinental mantle deformation. Journal of Geophysical Research: Solid Earth (1978-2012), 96(B10), 16429-16454. 


\section{VITA}

Frank Jimmy Calixto Mory was born on January 17th, 1984, in Huanuco, Peru. He was the older of two sons. He studied his primary and secondary school in his hometown, Huanuco. In 2001, he attended the National University of Engineering, Lima, Peru, and received his B.S. degree in Physics in January, 2007. From January 2007 to June 2007, he did and internship at the Geophysics Institute of Peru. From August 2007 to August 2008, he worked at the Regional Center for Seismology for Southern America, Lima Peru. Thereafter, Frank attended a postgraduate diploma program at the International Centre for Theoretical Physics. He obtained a postgraduate diploma in Earth System Physics in August 2009.

In the fall of 2009, Frank began his Ph.D. studies in the program of Geology and Geophysics at the University of Missouri-Columbia. He has been working on his dissertation research under the guidance of Prof. Eric Sandvol. He has co-authored several publications on his research and passed his dissertation defense on April 3, 2014. Frank will continue his academic career as a Postdoctoral Fellow in the Department of Physics at the University of Alberta. 